\title{
Water Chemistry and Benthic Macroinvertebrate Ecology in Response to Acid Mine Drainage
}

Brian Carlson

Follow this and additional works at: https://researchrepository.wvu.edu/etd

\section{Recommended Citation}

Carlson, Brian, "Water Chemistry and Benthic Macroinvertebrate Ecology in Response to Acid Mine Drainage" (2013). Graduate Theses, Dissertations, and Problem Reports. 7304.

https://researchrepository.wvu.edu/etd/7304

This Thesis is protected by copyright and/or related rights. It has been brought to you by the The Research Repository @ WVU with permission from the rights-holder(s). You are free to use this Thesis in any way that is permitted by the copyright and related rights legislation that applies to your use. For other uses you must obtain permission from the rights-holder(s) directly, unless additional rights are indicated by a Creative Commons license in the record and/ or on the work itself. This Thesis has been accepted for inclusion in WVU Graduate Theses, Dissertations, and Problem Reports collection by an authorized administrator of The Research Repository @ WVU. For more information, please contact researchrepository@mail.wvu.edu. 
Water Chemistry and Benthic Macroinvertebrate Ecology in Response to Acid Mine Drainage

\title{
Brian Carlson
}

\author{
A Thesis submitted to \\ The Davis College of Agriculture, Natural Resources and Design \\ at West Virginia University \\ in partial fulfillment of the requirements \\ for the degree of \\ Master of Science \\ in \\ Wildlife and Fisheries Resources
}
George Merovich, Ph.D., Chair
J. Todd Petty, Ph.D.
Brady Gutta, M.S.

Wildlife and Fisheries Resource Program

Division of Forestry and Natural Resources

Morgantown, WV

2013

Keywords: benthic macroinvertebrates, acid mine drainage, water chemistry, restoration, diversity, disturbance, metacommunity

Copyright 2013 Brian Russell Carlson 
UMI Number: 1549733

All rights reserved

INFORMATION TO ALL USERS

The quality of this reproduction is dependent upon the quality of the copy submitted.

In the unlikely event that the author did not send a complete manuscript and there are missing pages, these will be noted. Also, if material had to be removed, a note will indicate the deletion.

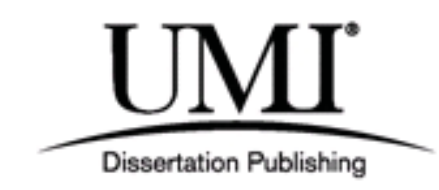

UMI 1549733

Published by ProQuest LLC (2013). Copyright in the Dissertation held by the Author.

Microform Edition (C) ProQuest LLC.

All rights reserved. This work is protected against unauthorized copying under Title 17, United States Code

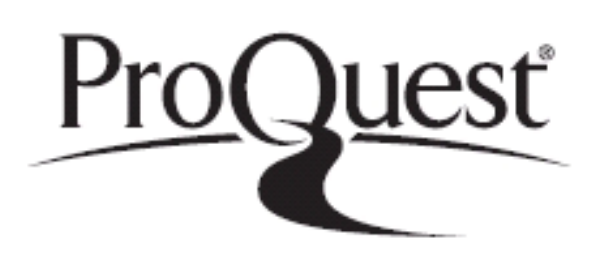

ProQuest LLC.

789 East Eisenhower Parkway

P.O. Box 1346

Ann Arbor, MI 48106 - 1346 


\begin{abstract}
Water Chemistry and Benthic Macroinvertebrate Ecology in Response to Acid Mine Drainage
\end{abstract}

Benthic macroinvertebrates, especially aquatic insects, are documented indicators of environmental quality, and often respond predictably to changes within a freshwater system. Within West Virginia, acid mine drainage (AMD) forms as a result of oxidizing sulfide rich minerals which occur alongside coal. The resulting effluent is acidic and laden with heavy metals. As a result, valued services and ecological functions provided by freshwater resources are lost. Treatment of AMD is expensive and therefore studies documenting their effect on aquatic resources are valuable. Benthic macroinvertebrate and stream water samples are often used as the deciding factors for the condition of a stream or river and its subsequent listing on a state's 303(d) list. However, little is understood about the natural variation in water chemistry and benthic macroinvertebrates over time within an AMD polluted watershed. A long term dataset consisting of water chemistry and benthic macroinvertebrates from 25 study sites was used to address the following goals (1) understand how alkaline treatment of AMD affects water chemistry and benthic macroinvertebrate assemblages along a treatment continuum, and (2) understand how variable water chemistry and benthic macroinvertebrate assemblages are temporally under different settings.

Water chemistry and benthic macroinvertebrate data were gathered at select confluences and along longitudinal continua in the Muddy Creek watershed, a subwatershed of the Cheat River basin that is severely impaired by AMD. Samples were gathered in riffle habitat annually, over 7 years during spring. Results showed that (1) water chemistry improved greatly post-AMD treatment while benthic macroinvertebrate assemblages generally did not, and (2) groups of reaches classified by water chemistry experienced significantly different temporal variation in chemical parameters and significantly different invertebrate diversities over the seven year study period. These findings support our current understanding of AMD treatment in heavily mined regions of Appalachia. Water chemistry will improve but often the fragmenting of waterways by AMD prevents biological recovery. We also present considerations for future assessments of AMD impaired watersheds. Researchers should attempt to account for temporal variation and understand its potential influence on waterways. 


\section{Acknowledgements}

I would like to thank my graduate committee, Dr. George Merovich, Dr. J. Todd Petty, and Brady Gutta, for their continuous support while I completed this research. I would especially like to thank Dr. George Merovich for investing so much of his time and effort into this project and my education. His guidance and friendship cannot be matched.

I would also like to thank everyone that helped in the field, laboratory, and classroom throughout my time at West Virginia University. Specifically, Brock Huntsman, Eric Miller, Eric Merriam, Michael Tincher, and Andrew Watson. In addition, I owe a special thank you to Donna Hartman for being an outstanding mentor. 


\section{Table of Contents}

Chapter 1: Water chemistry and benthic macroinvertebrate community response to acid mine drainage (AMD) treatment along a stream continuum.

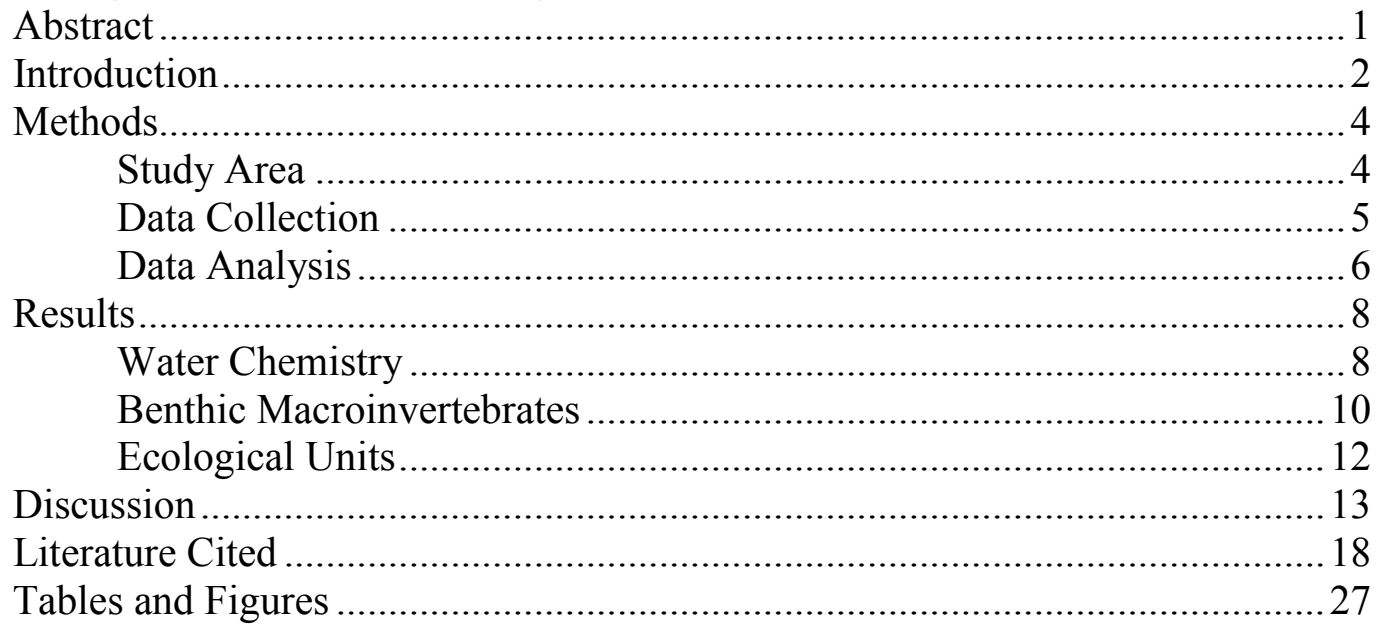

Chapter 2: Water chemistry and benthic macroinvertebrate assemblage stability within an Appalachian, AMD fragmented watershed.

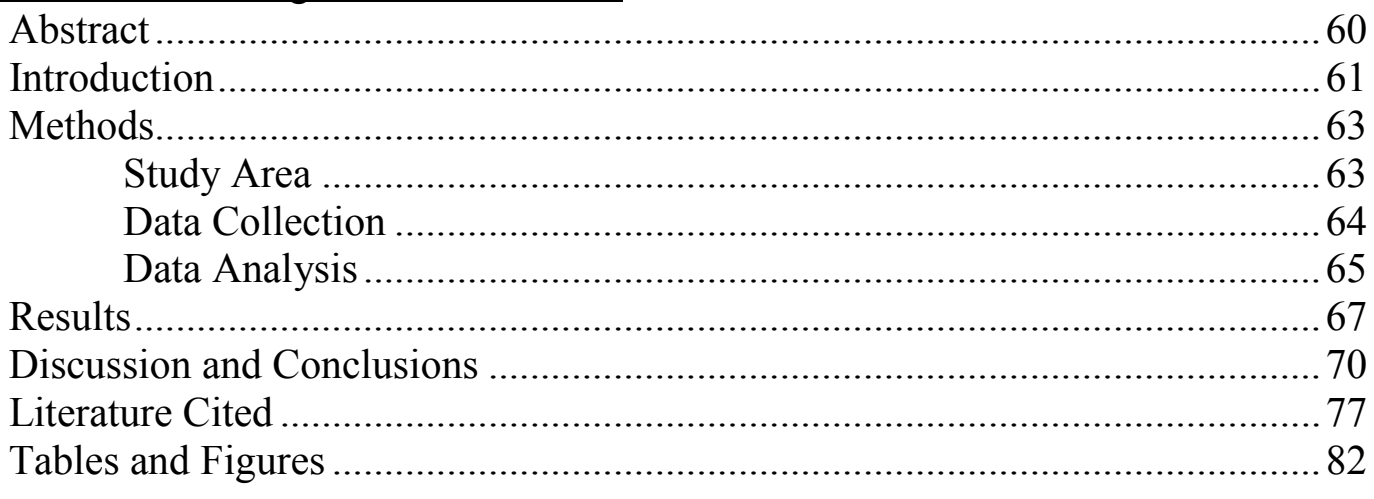




\title{
Chapter 1: Water Chemistry and benthic macroinvertebrate community response to acid mine drainage (AMD) treatment along a stream continuum.
}

\author{
Abstract \\ Acid mine drainage (AMD) negatively affects surface waters worldwide and currently \\ impairs 1,981 stream miles in the state of West Virginia. We collected water quality and \\ benthic macroinvertebrate assemblage data over 7 years within a north-central West \\ Virginia watershed fragmented by AMD. The final year of the study (2012), three major \\ sources of AMD were treated with alkaline material in an attempt to restore abiotic and \\ biotic conditions. Water chemistry data gathered before treatment revealed streams \\ within the study area to be legally impaired for $\mathrm{pH}$, aluminum, and iron concentrations. \\ Analysis of pre- and post-treatment data showed that water chemistry greatly improved at \\ study reaches downstream of treatment. However, benthic macroinvertebrate community \\ recovery was limited to minimal improvement in index of biotic integrity (IBI) scores at \\ only a select few monitoring sites, which were adjacent to relatively healthy streams. \\ With the improvement in water chemistry we expected similar results in the local benthic \\ macroinvertebrate communities; however, this did not occur. Although water chemistry \\ improved greatly, AMD sources in the region are numerous and many streams remain \\ legally impaired. We suspect this could be delaying or even preventing biotic recovery \\ post-treatment. This study provides insight into the response of water chemistry and \\ benthic macroinvertebrates to AMD remediation efforts. In addition, managers can use \\ these findings to set achievable restoration goals for AMD impaired watersheds. \\ Key words: Benthic macroinvertebrates, acid mine drainage, remediation, water \\ chemistry restoration, abandoned mine lands.
}




\section{Introduction}

The lower Cheat River watershed has a long history of unregulated coal mining. Many tributaries to the scenic river have been reduced to acidic, metal-laden waterways of acid mine drainage (AMD) often only supporting a select few highly tolerant taxa of benthic macroinvertebrates (WVDEP 1996). This pollutant forms when sulfide minerals often occurring alongside coal are exposed to oxidizing conditions (Skousen and Ziemkiewicz 1996). Within Muddy Creek, a sub-watershed of the Cheat, two notorious AMD blowouts in 1994 and 1995 resulted in an estimated acidity loading rate of 6,000 tons/year and a total iron and total aluminum loading rate of 67 tons/year (Herd et al. 2007). In addition to these large sources of AMD, there are an additional twenty-two sources of AMD within the Muddy Creek watershed from bond forfeitures or abandoned mine lands (AMLs). According to the Watershed Based Plan for the Lower Cheat River watershed, it will cost an estimated $\$ 3.2$ million to address only 6 of the Muddy Creek AML sources for which there are project cost estimates (Pavlik et al. 2005).

AMD has been shown to degrade ecological function within receiving streams through acidifying water and simplifying benthic macroinvertebrate communities (Hogsden and Harding 2012, Merovich and Petty 2010). Freund and Petty (2007) showed that benthic macroinvertebrate communities became impaired at AMD contaminant concentrations lower than West Virginia's state water quality standards. AMD treatment strategies have evolved into two approaches: passive and active treatment. Both strategies use alkaline materials to increase $\mathrm{pH}$ and provide hydroxide ions to allow dissolved metals to precipitate out of solution. One of the following alkaline materials is typically used: limestone, hydrated lime, pebble quicklime, soda ash, caustic soda, or ammonia. 
Passive treatment systems primarily consist of anoxic limestone drains or limestone based channels that transfer contaminated effluent to a constructed wetland and/or settling pond (Friends of Cheat 2013). Macrophytes within constructed wetlands are also effective at removing heavy metals associated with AMD (Mishra et al. 2008). Active treatment systems continuously incorporate alkaline materials into mine waters (Skousen et al. 2000).

Treating AMD is expensive and studies quantifying results of treatment are surprisingly few in number (Skousen et al. 1990). Treatment strategies are designed primarily to improve water quality, and the effects of treatment on inhabiting biotic communities such as benthic macroinvertebrates have had mixed results (Watanabe et al. 2000, Gunn et al. 2010, Smith et al. 2011). McClurg et al. (2007) showed that positive response to acid precipation treatment by benthic macroinvertebrate communities was dependent on distance from treatment. Other studies have shown that recovery can even be delayed after treatment anywhere from six to twenty-five years (Gunn et al. 2000, Walter et al. 2012, Watanabe et al. 2000). Still other studies have attributed loss of specific ecological services provided by benthic macroinvertebrates to AMD treatment (liming), implying treatment as an additional disturbance (McKie et al. 2006).

The use of biological communities and respective IBIs as indicators of ecological condition, contaminant toxicity, and remediation success has proven to be valuable to natural resource managers (Hedrick et al. 2010, Kimmel and Argent 2010, Merriam et al. 2011). Often using raw assemblage data or deriving a few simple metrics from a sampled community, decision makers can robustly quantify impairment, the potential causes, and thus plan remediation efforts (Pond et al. 2012). With benthic macroinvertebrates 
responding predictably to other forms of stream restoration (Selego et al. 2012), we sought to quantify ecological response to AMD treatment using benthic

macroinvertebrates. Therefore, the objectives of this study were to (1) quantify the longterm water quality conditions and benthic macroinvertebrate communities within an AMD fragmented Appalachian watershed prior to treatment, and (2) measure and evaluate response of water quality and benthic macroinvertebrates after initializing AMD treatment.

\section{Methods}

Study Area

The Muddy Creek watershed (Figure 1) is located within the Lower Cheat River basin in Preston County, West Virginia. The area is dominated by mountain hardwood forest, primarily hemlock and oak. The watershed is entirely rural and/or forested, with little residential development. The geology of the basin and surrounding area is comprised of Pennsylvanian, Mississipian, and Devonian aged sedimentary rocks. Coal is found only in the Pennsylvanian strata, of which the Allegheny formation has been primarily mined. This formation has little capability to neutralize acidity produced from surrounding sulfur geology (Merovich et al. 2007). Water chemistry conditions in Muddy Creek vary longitudinally and laterally across the watershed (Figure 2). Along the Muddy Creek mainstem and across its headwaters, water chemistry varies from near pristine to severe AMD impairment. Previous studies have shown that within the larger Cheat River basin, AMD from abandoned mine lands is the limiting factor to water quality and healthy biological communities (Petty and Thorne 2005, Merovich et al. 2007). 


\section{Data Collection}

We sampled water chemistry and benthic macroinvertebrate assemblages at fifteen sites within the Muddy Creek watershed (Table 1) and at one untreated-impaired control within a nearby watershed. Sites were chosen to capture the response of AMD treatment on tributaries to Martin Creek (Figure 3), Martin Creek, and along Muddy Creek below its confluence with Martin Creek. Sites were also selected based on best available riffle habitat.

Benthic macroinvertebrate samples were collected during the months of April or May from 2006 to 2012 by following the United States Environmental Protection Agency's rapid bioassessment protocols for wadeable streams and rivers (Barbour et al. 1999). At every study site, four kick samples (net dimensions 355 x $508 \mathrm{~mm}$ with 500 $\mu \mathrm{m}$ mesh) were gathered from widely separated riffle habitat (1 $\mathrm{m} \times 1 \mathrm{~m})$ and were combined into a single composite sample. Samples were preserved in $95 \%$ ethanol. In the lab, each composite sample was initially filtered through a 2-mm sieve mounted on a $0.25-\mathrm{mm}$ sieve. All organisms retained by the $2-\mathrm{mm}$ sieve were identified. All organisms retained by the $0.25-\mathrm{mm}$ sieve were suspended in water and were sub-sampled with a Folsom plankton splitter (Model Number 1831-F10, Wildco Supply Company, Buffalo, NY), and individuals from 1/8th of the total water volume were identified. We used Peckarsky et al. (1990) and Merritt and Cummins (2008) to identify individuals to the lowest possible taxonomic resolution, usually Genus level, except for chironomid midges (Chironomidae). The West Virginia Stream Condition Index (WVSCI) and the Genus-Level Index of Most Probable Stream Status (GLIMPPS), both mulitmetric 
indices of biotic integrigy (IBI) that summarize macroinvertebrate community composition, were calculated and used as the response variables to track changes related to AMD treatment (Gerritsen et al. 2000, Pond et al. 2008). Several component metrics of WVSCI (e.g., EPT) were also used in analyses.

Watershed-scale water quality monitoring took place at the same time as benthic macroinvertebrate sampling. Stream water was measured in the field for $\mathrm{pH}$ (SU), temperature $\left({ }^{\circ} \mathrm{C}\right)$, dissolved oxygen $(\mathrm{ppm})$, specific conductance $(\mu \mathrm{S} / \mathrm{cm})$, and total dissolved solids ( $\mathrm{g} / \mathrm{L}$ ) during each visit using a YSI 650 unit with a $600 \mathrm{XL}$ sonde or a YSI 556 multi-parameter probe (Yellow Springs Instruments, Yellow Springs, OH, USA). Stream discharge was measured using the area-velocity technique with a MarshMcBirney Flo-Mate 2000 flow meter (Marsh-McBirney, Frederick, MD). Additionally, water samples were collected at each site and stored on ice until analysis at the National Research Center for Coal and Energy at West Virginia University. Raw water was analyzed at the labs for general water chemistry including hot acidity, alkalinity, $\mathrm{pH}$, conductivity, and sulfate. Water samples were filtered with a 0.45 micrometer and acidified to $\mathrm{pH}$ of $<2$ with concentrated nitric acid. They were then analyzed for dissolved $\mathrm{Al}, \mathrm{Ba}, \mathrm{Cd}, \mathrm{Ca}$, chloride ion, $\mathrm{Cr}, \mathrm{Co}, \mathrm{Cu}, \mathrm{Fe}, \mathrm{Mg}, \mathrm{Mn}, \mathrm{Ni}, \mathrm{Na}$, and $\mathrm{Zn}$ concentrations $(\mathrm{mg} / \mathrm{L})$.

\section{Data Analysis}

In order to quantify the long-term abiotic and biotic conditions within the watershed, we summarized water chemistry and Family and Genus level biological data prior to AMD treatment (2006 - 2011) by obtaining mean values and $95 \%$ confidence 
intervals about the mean. We also utilized principal component analysis (PCA) to simplify the water chemistry dataset and discover what parameters were responsible for differences between study sites. Water chemistry variables were either log or log+1 transformed in order to meet the assumption that parameters are normally distributed in order to perform PCA. When a water chemistry variable had a loading factor $>|0.4|$ it was considered an important variable for contributing to a principal component. The number of principal components was chosen based on the cumulative percent of variation in the water chemistry dataset captured by the axes. These statistics were used to evaluate conditions within sample reaches before treatment was administered. This allowed us to gain perspective of the intensity and severity of AMD impairment at sample locations.

To further evaluate change in abiotic conditions within the watershed due to treatment we compared post-treatment (2012) water chemistry and benthic macroinvertebrate IBI data to pre-treatment means and respective $95 \%$ confidence intervals. We considered treatment effective when post treatment water chemistry parameters and benthic macroinvertebrate WVSCI or GLIMPSS biometrics for a specific reach were improved at levels outside pre-treatment means and respective $95 \%$ confidence intervals. In addition, we compared water chemistry improvements in Muddy Creek to data gathered at a known AMD impaired, untreated stream outside of the watershed. This was done in order to better attribute observed chemical improvements to treatment. We also utilized repeated measures analysis of variance (ANOVA) to statistically define improvements as a result of AMD treatment in regard to water chemistry, WVSCI biometrics, as well as the finer scale GLIMPSS biometrics. Time was 
treated as a predictor within the model with water chemistry variables (Al, Fe, Mn, etc.) and family and genus level benthic macroinvertebrate bio-metrics (EPT Richness, \% EPT, etc.) being the response variables. Changes from pre- to post-treatment were considered statistically significant, and therefore treatment was considered effective at improving the respective variable at a p-value less than 0.05 . We used the R Environment for statistical computing for our analyses (R Development Core Team 2013).

We also calculated a metric we called ecological units (EU), which is a stream length weighted measure of biological integrity. First, we standardized WVSCI scores to the highest regional score attained pre and post treatment across study sites. We then weighted the standardized WVSCI scores by reach-scale stream lengths for pre and post treatment data. These EU scores were then linearly interpolated across reach-scale stream segments without monitoring data, which then served as a currency in order to assign value to stream segments. They were also cumulated to interpret EU change at the watershed scale from pre to post treatment. Comparing pre and post treatment EUs we were able to better evaluate any change in biological condition. This approach of utilizing standardized units of biological integrity was adapted from Merovich and Petty (2007).

\section{Results}

Water Chemistry

We observed highly variable water chemistry across the Muddy Creek watershed before treatment. Water chemistry at reaches within the Martin Creek sub-watershed and along the Muddy Creek mainstem below its confluence with Martin Creek, were typical of AMD impairment. Pre-treatment water chemistry displayed high metal concentrations 
(Table 2), low $\mathrm{pH}$, and high acidity values (Table 3), as well as elevated specific conductance, total dissolved solids, and total suspended solids (Table 4). Across all study sites, $\mathrm{pH}$ ranged from $2.42 \mathrm{SU}$ to $8.31 \mathrm{SU}$, specific conductance ranged from $58 \mu \mathrm{S} / \mathrm{cm}$ to $2,248 \mu \mathrm{S} / \mathrm{cm}$, and iron concentrations ranged from $0.007 \mathrm{mg} / \mathrm{L}$ to $107.13 \mathrm{mg} / \mathrm{L}$. AMD constituents were especially elevated within the Martin Creek watershed (Figure 4). However, on Muddy Creek, just upstream of its confluence with Martin Creek, water chemistry parameters did not violate state water quality standards and were representative of an unimpaired system.

PCA revealed 3 important dimensions (axes) (eigenvalues $>1$ ), however the first two represented over $67 \%$ of the variation observed in water chemistry (Table 5). PC1 represented an AMD impairment gradient with over $59 \%$ of the variation in the dataset explained. Increasing PC1 values had higher factor loadings for acidity and heavy metal concentrations, therefore representing an AMD gradient. PC 2 is best interpreted as a hardness gradient with increased barium $(\mathrm{Ba})$, calcium $(\mathrm{Ca})$, and magnesium $(\mathrm{Mg})$ at the upper end of the axis. This axis captured an additional $9 \%$ of the variation observed. Not only does Figure 2 show variation in water chemistry pre-treatment across the watershed, but it also shows how treated sites (labeled 'Y'") responded to treatment. In general, our treated observations are very similar to each other in comparison to pre-treatment observations especially with regard to PC 2 . They are also beginning to move towards our reference condition sites (labeled " $\mathrm{R}$ ") and are slightly outside our grouped untreated observations.

Repeated measures ANOVA revealed that all but eight measured variables significantly improve due to treatment. We observed statistically significant 
improvements in $\mathrm{pH}$, alkalinity, acidity, specific conductance, total dissolved solids, $\mathrm{Al}$, $\mathrm{Mg}, \mathrm{Mn}, \mathrm{Ni}, \mathrm{Zn}$, and $\mathrm{SO}_{4}{ }^{2}$ (Table 6). Each AMD treatment system installed in 2012 within Martin Creek was correlated with significant reductions in contaminant pollutants (Figure 5). In addition, Figure 6 shows how $\mathrm{pH}$, alkalinity (as $\mathrm{mg} / \mathrm{L} \mathrm{CaCO}_{3}$ ), acidity (as $\mathrm{mg} / \mathrm{L} \mathrm{CaCO}_{3}$ ), and specific conductance change along Muddy Creek before and after treatment. $\mathrm{pH}$, alkalinity $\left(\right.$ as $\left.\mathrm{CaCO}_{3}\right)$, acidity $\left(\right.$ as $\left.\mathrm{CaCO}_{3}\right)$, and specific conductance downstream of AMD all improved after treatment. Figure 7 demonstrates the same pattern with aluminum, iron, and manganese concentrations, and sulfates. While all water chemistry variables experienced improvements, water chemistry remained legally impaired. State water quality standards are now being meet for manganese, aluminum, iron, and $\mathrm{pH}$ on Muddy Creek because of AMD treatment. However, these standards are not being met in all stream segments on Muddy Creek and are still not being met immediately downstream of treatment in the Martin Creek watershed. Further, Figure 8 shows that our impaired untreated control study site did not have improved water chemistry in 2012 when compared to pre-treatment data. All 2012 observations were within the inter-quartile range of our box plot of pre-treatment data for that location.

\section{Benthic Macroinvertebrates}

Overall, benthic macroinvertebrate assemblages varied greatly across the Muddy Creek watershed prior to treatment. \% EPT ranged from $0 \%$ to $100 \%$, EPT Family Richness ranged from 0 to 22 (Table 7), total family richness ranged from 1 to 38 , and WVSCI scores ranged from 6.32 to 95.82 (Table 8). In addition, benthic macroinvertebrate assemblages displayed a relatively high $\%$ of generally tolerant taxa, 
$\%$ of assemblage comprised of acid tolerant taxa (those taxa that can tolerate acidic conditions), and $\%$ of assemblage comprised of top two dominant taxa. Genus data also reflected these conditions with low overall genera richness, Ephemperoptera, Plecoptera, clinger, and shredder genera richness (Table 9). In addition, assemblages were rather simple and GLIMPSS scores were very low (Table 10).

When we examined pre and post treatment IBI data, we saw little improvement in benthic macroinvertebrate assemblages with treatment. In some cases it seemed that IBIs became degraded after treatment. We selected four of the most commonly used benthic macroinvertebrate metrics of biological integrity including the WVSCI, \% Ephemeroptera, EPT family richness, and total family richness, and then examined them over time. We choose four reaches to compare including our "impaired-control" at South Fork Greens Run, our "unimpaired-reference" at Million Dollar Bridge, and two treated reaches on Muddy Creek with similar physical habitat characteristics. We found that benthic macroinvertebrate indices were highly variable at the AMD-impaired reaches in Muddy Creek pre-treatment and in most cases became more similar to the "impairedcontrol" reach, South Fork Greens Run, post-treatment (Figure 9). Our "impairedcontrol" and "unimpaired-reference" were relatively stable from year-to-year when compared to the two impaired-treated reaches on Muddy Creek.

Repeated measures ANOVA revealed that not one of the regionally developed family or genus level bio-indices, improved or degraded statistically due to AMD treatment (Table 11). Pollutant intolerant genus richness (TV4) and clinger genus richness were the only indices that made noteworthy changes $(p \leq 0.10)$ from pre to post- 
treatment along the treatment continuum. However, these metrics declined rather than improved post-treatment.

Study sites that had improvements in bioassessment metrics post treatment outside their pre-treatment 95\% confidence interval include the metrics: GLIMPSS, percent of assemblage comprised of top five dominant taxa, percent of assemblage comprised of Chironomidae and Annelidae, percent of assemblage comprised of EPT taxa excluding Cheumatopsyche, genus richness, WVSCI, \% Ephemeroptera, \% EPT, family richness, and percent of assemblage comprised of generally tolerant taxa at MCM; percent of assemblage comprised of Chironomidae and Annelidae, genus richness, WVSCI, and family richness at UUG, genus richness, percent of assemblage comprised of Chironomidae, and family richness at MCO, and finally \% Ephemeroptera at MUM (Figure 10).

\section{Ecological Units}

Ecological Units (EU)s, a stream length weighted measurement of stream condition, within the Muddy Creek watershed had mixed responses across study sites to AMD treatment. A majority responded positively to treatment with eight reaches gaining ecological units over six reaches decreasing in ecological units (Table 12). In general, the change in ecological units from pre to post-treatment in reaches treated with AMD did not take on any distinguishable pattern. All "unimpaired-reference" reaches were stable or had slight increases in EUs. Increases in EUs post-treatment at treated reaches were much larger than any increases at "unimpaired-reference" reaches. Higher order reaches, such as those on Muddy Creek, downstream of Martin Creek, experienced 
decreases in EUs from pre to post treatment. Most reaches immediately downstream of AMD treatment (FRM, UUG, GRM, MGR, MCM) with the exception of two saw increases in EUs post treatment (Figure 11). However, despite differences observed at the stream segment scale, an overall cumulative ecological unit increase from pre to post treatment on a watershed scale can be observed in Figure 12. After treatment was initiated there was an obvious increase in total ecological units for the entire Muddy Creek watershed.

\section{Discussion and Conclusions}

Despite statistically significant improvements in water chemistry at all study sites due to AMD treatment, we saw little to no improvement in benthic macroinvertebrate assemblages post-treatment. Heavy metals and acidity, known to be toxic to most aquatic biota (Liu et al. 2003), were still legally impairing waterways in the Muddy Creek watershed post-treatment. Post-treatment monitoring revealed that state standards were still not being met one year later, and streams within the Muddy Creek watershed remain legally impaired by West Virginia's water quality standards despite treatment (Table 13) (WVDEP 2000). All treated streams were still violating state standards for iron post treatment, however other parameters that were also violating state standards pretreatment, were being met $(\mathrm{pH}, \mathrm{Al}$, and $\mathrm{Mn})$ at the furthest downstream study sites. Known sources of AMD within the Muddy Creek watershed total twenty-three, and this study only cataloged benefits from addressing three of those (Pavlik et al. 2005). AMD sources may also still be too numerous to allow any benthic macroinvertebrate recovery in studied reaches. State standards may also still be violated due to release of heavy metal 
precipitates directly into the stream channel. One active treatment system, which was part of this study, directly discharged alkaline material mixed with mine water into the stream channel. The deposition of heavy metal precipitates and subsequent sediment contamination could delay recovery indefinitely unless physically removed. Unruh et al. (2009) propose that even when water chemistry is improved, contaminated sediment already within the stream can have ill effects on aquatic biota.

Using various metrics, researchers have previously found liming to have an array of effects on benthic macroinvertebrate assemblages. From further filtering and simplifying benthic macroinvertebrate communities (Chadwick and Canton 1983, McKie et al. 2006), to improving benthic macroinvertebrate communities even if recovery may depend on distance from treatment or time after initiation of treatment. The fact that we monitored once, six months post-treatment, may explain the lack of significant recovery observed. Had we monitored long-term post-treatment we may have captured statistically significant recovery and/or a delay in benthic macroinvertebrate recovery. Walter et al. (2012) found that improvements in benthic macroinvertebrate IBIs lagged 6 years behind chemical improvements due to AMD treatment. Gunn et al. (2010) found benthic macroinvertebrate recovery to be delayed 8 years following the diversion of a chronic AMD source. In addition, Smith and Distler (1981) found that benthic macroinvertebrate community recovery lagged a minimum of 7 months after only a pulse chemical disturbance. Our one post-treatment observance seems to be too soon to detect biological improvement, especially when the disturbance was chronic and severe. Smith et al. (2011) recommends that benthic macroinvertebrate monitoring continue longer than 4 
years post-remediation in order to fully detect changes due to treatment at highly impacted locations.

Using repeated measures testing, WVSCI or GLIMPSS metrics were found not to have statistically improved pre to post-treatment. However, some bio-indices were found to have increased (i.e. WVSCI, \% E, \% EPT, Family Richness) or decreased (\% GenTol) outside their pre-treatment mean and respective $95 \%$ confidence intervals. These were therefore considered significantly improved from pre to post-treatment. These improvements were only observed at impaired reaches that were $<200$ meters from an unimpaired reach and therefore potential source of colonizers. This may provide insight into the mechanics that drive the first step of benthic macroinvertebrate community recovery. Numerous sources of AMD and regionally degraded benthic macroinvertebrate communities may be preventing the expected recovery of benthic macroinvertebrates within the study area. In using our ecological units, we see that reaches responded positively and negatively to treatment. We saw increases and decreases in EUs at treated reaches from pre to post-treatment. All decreases in EUs were observed at treated reaches on the mainstem of Muddy Creek. These are higher order reaches, further downstream from treatment. The lower Muddy Creek mainstem and many of its contributing tributaries are degraded by AMD. This reduces the likelihood of benthic macroinvertebrate community recovery because accessible regional species pools are most likely simple; and potential sources for recovery are out of reach as dispersal is limited (Brown et al. 2011, Heino 2011).

Reaches experiencing increases in EUs from pre to post treatment were those immediately downstream from treatment or "unimpaired-reference" reaches elsewhere in 
the watershed. All reaches just downstream from treatment had noticeably larger increases in EUs compared to all increases at "unimpaired-reference" reaches. These reaches are part of lower order, headwater streams that are closer to "unimpairedreference" reaches relative to those previously discussed on the mainstem of Muddy Creek. The observed increases in EUs at these treated reaches could be a result of high beta diversity across "unimpaired" reaches just upstream of AMD discharges. This lateral arrangement of benthic macroinvertebrate diversity across a watershed's headwaters could be influencing post-treatment recovery due to taxa specific dispersal patterns such as drift behavior (Bohonak and Jenkins 2003). Finn et al. (2011) found that headwater streams contribute greatly to biodiversity at the watershed scale. In addition, Clarke et al. (2010) found headwater streams to have high alpha diversity indicating that they could potentially be significant species pools for connected habitats. Immigration from upstream habitats may have been prevented prior to treatment due to species sorting from AMD discharges. As previously mentioned, these reaches were also higher up in the watershed and therefore more closely connected to potential species pools relative to the sites with degraded EUs on the Muddy Creek mainstem. Despite the variability in findings in EU response to treatment at the stream segment scale, we found that EUs improved from pre to post-treatment at the watershed scale. This was especially evident when we examined the cumulative EUs sourced from the Martin Creek sub-watershed pre to post-treatment. This demonstrates that at the watershed scale, the application of alkaline material, whether passive or active, had a net benefit to biological communities within the Muddy Creek watershed even if it was not detected at the stream segment scale. 
Spatial processes, such as mass effects via aerial migration or diel drift, may be the initial driver for community recovery in high gradient Appalachian watersheds impacted by AMD. In fact, when examining the assemblage data for study sites with significant improvement in bio-indices, we found that the taxa responsible for improvements were those that primarily utilize aerial migration (i.e. Baetis sp., Leuctra sp., Alloperla sp., and Amphinemura sp.) However, at two locations Gammarus sp. was also responsible for increases in richness and tolerance value scores at two of our treated study sites. This taxon is generally intolerant of low $\mathrm{pH}$ and heavy metal concentrations. Gammarus is strictly aquatic for the entirety of its life and is mostly active at night utilizing diel drift behavior for distribution (Voshell 2002). With that, it seems that most of our biological improvements were a result of aerial migration by more pollutant tolerant, high dispersal genera (Baetis and Leuctra) of generally pollutant sensitive orders (Ephemeroptera and Plecoptera). Position of a treated reach within a watershed network may have a significant influence on the success and speed of community recovery (Trekels et al. 2011). Sundermann et al. (2011) found that taxonomic recovery only occurred when species pools were in close vicinity to restored areas. In fact, new research is emerging with restoration approaches that consider metacommunity dynamics. Considering metacommunity theory, Merovich et al. (2013) suggests that restoration priorities should be focused on impaired watersheds physically adjacent to high quality watersheds to allow large-scale community recovery. Our results suggest metacommunity paradigms such as species sorting and mass effects are heavily influencing benthic macroinvertebrate community recovery post-treatment or restoration. 


\section{Literature Cited}

Barbour, M.T., J. Gerritsen, B. Snyder, and J. Stribling. 1999. Rapid Bioassessment Protocols for Use in Streams and Wadeable Rivers: Periphyton, Benthic Macroinvertebrates and Fish, Second Edition. EPA 841-B-99-002. U.S. Environmental Protection Agency; Office of Water; Washington, D.C.

Baron, J.S., N. Poff, P. Angermeier, C. Dahm, P. Gleick, N.Hairston, Jr., R. Jackson, C. Johnston, B. Richter, and A. Steinman. 2003. Sustaining healthy freshwater ecosystems. Issues in Ecology. No. 10, Winter 2003

Bohonak, A.J., and D. Jenkins. 2003. Ecological and evolutionary significance of dispersal by freshwater invertebrates. Ecology Letters 6:783:8796

Brown, B.L., C. Swan, D. Auerbach, E. Grant, N. Hitt, K. Maloney, and C. Patrick. 2011. Metacommunity theory as a multispecies, multiscale framework for studying the influence of river network structure on riverine communities and ecosystems. J. N. Am. Bethol. Soc. 30:310-327

Chadwick, J.W. and S.Canton. 1983. Coal mine drainage effects on a lotic system in Northwest Colorado, U.S.A. Hydrobiologia 107:25-33 
Clarke, A., R. Mac Nally, N. Bond, and P. Lake. 2010. Conserving macroinvertebrate diversity in headwater streams: the importance of knowing the relative contributions of $\alpha$ and $\beta$ diversity. Diversity and Distrubtions, (Diversity Distrib.) $16: 725-736$

Freund, J.G. and J.T. Petty. 2007. Response of fish and macroinvertebrate bioassessment indices to water chemistry in a mined Appalachian watershed. Environ Manage $39: 707-720$

Friends of Cheat. June 5, 2013. AMD Remediation. URL: http://www.cheat.org/ourwork/watershed-restoration/amd-remediation/. 119 S. Price St. Suite \# 206 Kingwood, West Virginia 26537-1478

Gerritsen, J., J. Burton, M.T. Barbour. 2000. A stream condition index for West Virginia wadeable streams. Tetra Tech, Inc. Owings Mills, MD. March 28, 2000 (Revised July 21, 2000).

Gunn, J., C. Sarrazin-Delay, B. Wesolek, A. Stasko, and E. Szkookan-Emilson. 2010. Delayed recovery of benthic macroinvertebrate communities in Junction Creek, Sudbury, Ontario, after the diversion of Acid Mine Drainage. Human and Ecological Risk Assessment 16:901-912 
Hedrick, L.B., S. Welsh, J. Anderson, L. Lin, Y. Chen, X. Wei. 2010. Response of benthic macroinvertebrate communities to highway construction in an Appalachian watershed. 641:115-131

Heino, J. 2011. A macroecological perspective of diversity patterns in the freshwater realm. Freshwater Biology 56:1703-1722

Herd, R., J. Fulton, P. Ziemkiewicz. 2007a Muddy Creek Targeted Watershed Initiative: Strategic AMD Restoration. West Virginia Water Research Institute. WV Mine Drainage Task Force Symposium, April 10, 2007.

Hogsden, K.L., and J. Harding. 2012. Consequences of acid mine drainage for the structure and function of benthic macroinvertebrate communities: a review. Freshwater Science 31:108-120

Finn, D.S., N. Bonada, C. Múrria, and J. Hughes. 2011. Small but mighty: headwaters are vital to stream network biodiversity at two levels of organization. J. N. Am. Benthol. Soc. 30:963-980

Kimmel, W.G. and D. Argent. 2010. Stream fish community response to a gradient of specific conductance. Water Air Soil Pollut 206:49-56 
Liu, W.X., R. Coveney, J. Chen. 2002. Environmental quality assessment on a river system polluted by mining activities. Applied Geochemistry 18:749-764

McClurg, S.E., J.T. Petty, P. Mazik, and J. Clayton. 2007. Stream ecosystem response to limestone treatment in acid impacted watersheds of the Allegheny plateau. Ecological Applications 17:1087:1104

McIlmoil, R., E. Hansen, T. Boettner, P. Miller. 2010. Coal and Renewables in Central Appalachia: The Impact of Coal on the West Virginia State Budget. Downstream Strategies. June 22, 2010.

McKie, B.G., Z. Petrin, and B. Malmqvist. 2006. Mitigation or disturbance? Effects of liming on macroinvertebrate assemblage structure and leaf-litter decomposition in the humic streams of northern Sweden. Journal of Applied Ecology. 43:780-791

Merovich, Jr. G.T. and J.T. Petty, 2007. Interactive effects of multiple stressors and restoration priorities in a mined Appalachian watershed. Hydrobiologia 575:13-31

Merovich, Jr. G.T., J. Stiles, J.T. Petty, P. Ziemkiewicz, J. Fulton. 2007. Water chemistry—based classification of streams and implications for restoring mined Appalachian watersheds. Environmental Toxicology and Chemistry 26:13611369 
Merovich, Jr., G.T. and J.T. Petty, 2010. Continuous response of benthic macroinvertebrate assemblages to a discrete disturbance gradient: consequences for diagnosing stressors. J. N. Am. Benthol. Soc. 29:1241-1257

Merovich, Jr., G.T., J.T. Petty, M. Strager, and J. Fulton. 2013. Hierarchical classification of stream condition: a house-neighborhood framework for establishing conservation priorities in complex riverscapes. Freshwater Science 32:874-891

Merriam, E., J.T. Petty, G.T. Merovich, Jr., J. Fulton, and M. Strager. 2011. Additive effects of mining and development in a central Appalachian watershed. J. N. Am. Benthol. Soc. 30:399-418

Merritt, R.W., K.W. Cummins. 2008. An Introduction to the Aquatic Insects of North America. Kendall/Hunt Publishing Co., $4^{\text {th }}$ Edition. Dubuque, IA.

Mishra, V.K., A. Upadhyaya, S. Pandley, and B. Tripathi. 2008. Heavy metal pollution induced due to coal mining effluent on surrounding aquatic ecosystem and its management through naturally occurring aquatic macrophytes. Bioresource Technology 99:930-936

Nutter, Jr., R., J. Weese, R. Eades. 2002. West Virginia Streams Impaired by Acid Mine Drainage. Ohio Valley Environmental Coalition. 
Pavlik, M. E. Hansen, M. Christ. 2005. Watershed Based Plan for the Lower Cheat River Watershed: From River Mile 43 at Rowlesburg, WV to the West Virginia/Pennsylvania Border, including all tributaries. Submitted to WVDEP and USEPA Region 3 on January $26^{\text {th }}, 2005$.

Peckarsky, B.L., P.R. Fraissinet, M.A. Penton, D.J. Conklin, Jr. 1990. Freshwater Macroinvertebrates of Northeastern North America. Cornell Paperback Publishing 1990.

Petty, J.T. and D. Thorne. 2005. An ecologically based approach to identifying restoration priorities in an acid-impacted watershed. Restoration Ecology 13:348357

Pond, G. J., Bailey, J. E., Lowman, B. 2008. West Virginia GLIMPSS (Genus-Level Index of Most Probable Stream Status): A Benthic Macroinvertebrate Index of Biotic Integrity for West Virginia's Wadeable Streams. West Virginia Department of Environmental Protection, Division of Water and Waste Management, Watershed Branch, Charleston, WV, USA.

R Development Core Team (2013). R: A language and environment for statistical computing, reference index version 2.2.1. R Foundation for Statistical Computing, Vienna, Austria. ISBN 3-900051-07-0, URL http://www.R-project.org. 
Selago, S.M., C. Rose, G. Merovich, Jr., S. Welsh, and J. Anderson. 2012. Communitylevel response of fishes and aquatic macroinvertebrates to stream restoration in a third-order tributary of the Potomac River, USA. International Journal of Ecology. Article ID 753634.

Smith, J.G., C. Brandt, and S. Christensen. 2011. Long-term benthic macroinvertebrate community monitoring to assess pollution abatement effectiveness. Environmental Management 47:1077-1095

Smith, D.L. and D.A. Distler. 1981. Recovery of a benthic macroinvertebrate community following a toxic chemical discharge in a Sandy Plains stream. The Southwestern Naturalist. 25:547-551.

Skousen, J., K. Politan, T. Hilton, and A Meek. 1990. Acid mine drainage treatment systems: chemicals and costs. Geen Lands 20:31-37.

Skousen, J., T. Hilton, and B. Faulkner. 1996. Overview of acid mine drainage treatment with chemicals. Green Lands 26:40:49

Skousen, J., A. Sextone, and P. Ziemkiewicz. 2000. Acid mine drainage control and treatment. Reclamation of Drastically Disturbed Lands. American Society of Agronomy and American Society for Surface Mining and Reclamation. Agronomy No. 41. Chapeter 6. 
Sundermann, R., S. Stoll, P. Haase. 2011. River restoration success depends on the species pool of the immediate surroundings. Ecological Applications 21:19621971

Trekels, H., F. Van de Meutter, and R. Stocks. 2011. Habitat isolation shapes the recovery of aquatic insect communities from a pesticide pulse. Journal of Applied Ecology 48:1480-1489

Unruh, D.M., S. Church, D. Nimick, and D. Fey. 2009. Metal contamination and postremediation recovery in the Boulder River watershed, Jefferson County, Montana. Geochemistry: Exploration, Environment Analysis 9:179-199

Walter, C.A., D. Nelson, and J. Earle. 2012. Assessment of stream restoration: sources of variation in macroinvertebrate recovery throughout an 11-year study of coal mine drainage treatment. Restoration Ecology 20:431-440

Watanabe, N. C., S. Harada, and Y. Komai. 2000. Long-term recovery from mine drainage disturbance of a macroinvertebrate community in the Ichi-kawa River, Japan. Hydrobiologia 428:171-180

West Virginia Department of Environmental Protection (WVDEP). 1996. An ecological assessment of the Cheat River Watershed. Report No. 0502004 - 1996. 
Watershed Assessment Program, Office of Water Resources. 1201 Greenbrier Street, Charleston, West Virginia 25311

West Virginia Department of Environmental Protection (WVDEP). 2010. Title 47:

Legislative Rule Department of Environmental Protection Water Resources Series 2 Requirements Governing Water Quality Standards. 47CSR2, Appendix E.

Voshell, Jr., J.R. 2002. A Guide to Common Freshwater Invertebrates of North America. The McDonald \& Woodward Publishing Company. Blacksburg, VA. 
Table 1. Site names, descriptions, GPS coordinates of sampling locations, and abbreviations used throughout document. Coordinates are in Decimal Degrees.

\begin{tabular}{lccc}
\hline Site Name & Site ID & Latitude & Longitude \\
\hline \hline Upper Muddy Creek & UMC & 39.57237 & -79.53014 \\
Muddy Creek above Jump Rock & MJR & 39.58951 & -79.54680 \\
Muddy Creek in Cuzzart & CZZ & 39.58509 & -79.56506 \\
Muddy at Tack Shop & MTS & 39.57969 & -79.60688 \\
Muddy at Million Dollar Bridge & MDB & 39.56149 & -79.62199 \\
Muddy Creek above Martin Creek & MAM & 39.5619 & -79.62193 \\
Muddy Creek above Crab Orchard Run & MCO & 39.54025 & -79.63189 \\
Muddy Creek above Sypolt Run & MSR & 39.52493 & -79.63548 \\
Muddy Creek Mouth & MUM & 39.51217 & -79.64681 \\
Fickey Run Mouth & FRM & 39.55135 & -79.63743 \\
Martin Creek Mouth & MCM & 39.54979 & -79.63243
\end{tabular}


Upper Glade Run

Upper UNT of Glade Run

Glade Run Mouth

Martin above Fickey Run

$\begin{array}{lll}\text { UGR } & 39.57401 & -79.64492 \\ \text { UUG } & 39.57100 & -79.65300 \\ \text { GRM } & 39.55299 & -79.64838 \\ & & \\ \text { MFR } & 39.55103 & -79.63763\end{array}$


Table 2. Pre-treatment dissolved aluminum (Al), iron (Fe), and manganese $(\mathrm{Mn})$ concentrations with $\pm 95 \%$ confidence intervals about the mean are given by study site on the left side of the table. Post treatment Al, Fe, and Mn concentrations are given to the right of the vertical line with observed differences from pre to post treatment in parentheses.

\begin{tabular}{cccc|ccc}
\hline \hline Site & $\mathrm{Al}(\mathrm{mg} / \mathrm{L})$ & $\mathrm{Fe}(\mathrm{mg} / \mathrm{L})$ & $\mathrm{Mn}(\mathrm{mg} / \mathrm{L})$ & $\mathrm{Al}(\mathrm{mg} / \mathrm{L})$ & $\mathrm{Fe}(\mathrm{mg} / \mathrm{L})$ & $\mathrm{Mn}(\mathrm{mg} / \mathrm{L})$ \\
\hline \hline UMC & $0.2 \pm 0.2$ & $0.2 \pm 0.1$ & $0.04 \pm 0.02$ & $0.05(0.1)$ & $0.05(-0.1)$ & $0.05(0.01)$ \\
MJR & $0.2 \pm 0.1$ & $0.1 \pm 0.02$ & $0.05 \pm 0.03$ & $0.11(-0.04)$ & $0.05(-0.01)$ & $0.05(0.00)$ \\
CZZ & $0.3 \pm 0.3$ & $0.2 \pm 0.3$ & $0.2 \pm 0.3$ & $0.05(-0.1)$ & $0.05(-0.2)$ & $0.05(-0.1)$ \\
MTS & $0.1 \pm 0.04$ & $0.1 \pm 0.1$ & $0.2 \pm 0.04$ & $0.05(-0.03)$ & $0.05(-0.07)$ & $0.05(-0.1)$ \\
MDB & $0.1 \pm 0.1$ & $0.1 \pm 0.2$ & $0.2 \pm 0.1$ & $0.05(-0.06)$ & $0.05(-0.07)$ & $0.05(-0.1)$ \\
MAM & $0.4 \pm 0.4$ & $0.5 \pm 0.4$ & $0.2 \pm 0.1$ & $0.05(-0.4)$ & $0.05(-0.4)$ & $0.2(-0.05)$ \\
MCO & $6.4 \pm 2.9$ & $5.1 \pm 2.7$ & $1.4 \pm 0.5$ & $0.9(-5.5)$ & $2.4(-2.7)$ & $0.6(-0.8)$ \\
MSR & $5.0 \pm 1.9$ & $3.6 \pm 1.1$ & $1.3 \pm 0.3$ & $0.05(-4.9)$ & $2.0(-1.6)$ & $0.6(-0.7)$ \\
MUM & $5.0 \pm 2.5$ & $3.3 \pm 1.2$ & $1.3 \pm 0.4$ & $0.05(-4.9)$ & $1.7(-1.6)$ & $0.5(-0.7)$ \\
FRM & $23.6 \pm 10.1$ & $158.6 \pm 175.0$ & $5.3 \pm 1.9$ & $0.9(22.6)$ & $9.1(149.5)$ & $15.1(-9.7)$ \\
MCM & $13.6 \pm 4.3$ & $15.8 \pm 6.3$ & $4.5 \pm 1.2$ & $0.7(12.9)$ & $5.2(10.6)$ & $24.5(-19.9)$ \\
& & & & &
\end{tabular}




\begin{tabular}{cccc|ccc} 
UGR & $15.3 \pm 4.3$ & $7.7 \pm 7.5$ & $2.9 \pm 0.7$ & $1.4(13.9)$ & $0.5(7.2)$ & $2.0(0.9)$ \\
UUG & $12.6 \pm 4.7$ & $1.8 \pm 0.8$ & $8.3 \pm 3.0$ & $1.6(11.0)$ & $0.9(0.8)$ & $0.8(7.5)$ \\
GRM & $13.1 \pm 4.2$ & $1.9 \pm 0.6$ & $5.0 \pm 1.4$ & $4.6(8.5)$ & $0.4(1.6)$ & $1.8(3.0)$ \\
MFR & $7.8 \pm 2.1$ & $0.9 \pm 0.2$ & $3.8 \pm 0.8$ & $3.7(-4.1)$ & $0.3(-0.6)$ & $1.6(-2.2)$ \\
\hline
\end{tabular}


Table 3. Pre-treatment $\mathrm{pH}$, alkalinity (as $\mathrm{mg} / \mathrm{L} \mathrm{CaCO}_{3}$ ), and acidity (as $\mathrm{mg} / \mathrm{L} \mathrm{CaCO}_{3}$ ) mean values with $\pm 95 \%$ confidence intervals about the mean are given by study site on the left side of the table. Post-treatment $\mathrm{pH}$, alkalinity, and acidity values are given to the right of the vertical line with observed differences from pre to post treatment in parentheses.

\begin{tabular}{cccc|ccc}
\hline \hline Site & $\mathrm{pH}$ & Alk $(\mathrm{mg} / \mathrm{L})$ & Acid $(\mathrm{mg} / \mathrm{L})$ & $\mathrm{pH}$ & Alk $(\mathrm{mg} / \mathrm{L})$ & Acid $(\mathrm{mg} / \mathrm{L})$ \\
\hline \hline UMC & $7.4 \pm 0.4$ & $32.5 \pm 10.1$ & $2.0 \pm 2.6$ & $7.2(-0.3)$ & $33.5(0.9)$ & $0.5(-1.5)$ \\
MJR & $7.1 \pm 0.4$ & $25.9 \pm 6.8$ & $36.4 \pm 36.5$ & $6.9(-0.1)$ & $26.4(0.5)$ & $6.9(-29.6)$ \\
CZZ & $7.2 \pm 0.3$ & $21.0 \pm 4.9$ & $19.7 \pm 18.8$ & $6.9(-0.2)$ & $22.0(0.9)$ & $4.9(-14.8)$ \\
MTS & $7.2 \pm 0.3$ & $24.5 \pm 7.7$ & $22.7 \pm 17.8$ & $7.1(-0.1)$ & $20.9(-3.6)$ & $8.7(-13.9)$ \\
MDB & $7.3 \pm 0.3$ & $30.8 \pm 5.2$ & $23.7 \pm 20.8$ & $7.0(-0.3)$ & $30.7(-0.1)$ & $10.9(-12.8)$ \\
MAM & $6.5 \pm 0.5$ & $13.1 \pm 5.0$ & $38.4 \pm 30.9$ & $5.9(-0.6)$ & $12.9(-1.1)$ & $18.3(-20.1)$ \\
MCO & $4.1 \pm 0.3$ & $0.6 \pm 0.7$ & $101.7 \pm 29.9$ & $4.9(0.9)$ & $4.8(4.2)$ & $45.2(-56.5)$ \\
MSR & $4.8 \pm 0.4$ & $1.7 \pm 2.0$ & $96.4 \pm 31.5$ & $6.4(1.7)$ & $4.4(2.7)$ & $28.5(-67.9)$ \\
MUM & $4.9 \pm 0.5$ & $1.0 \pm 0.9$ & $97.3 \pm 24.8$ & $6.5(1.6)$ & $7.7(6.7)$ & $29.9(-67.5)$ \\
FRM & $3.3 \pm 0.4$ & $0.1 \pm 0.1$ & $553.5 \pm 171.7$ & $3.4(0.01)$ & $0.5(0.4)$ & $257.7(-257.8)$ \\
MCM & $3.5 \pm 0.3$ & $0.1 \pm 0.1$ & $246.5 \pm 53.7$ & $3.8(0.3)$ & $0.5(0.4)$ & $119.6(-126.9)$ \\
& & & & &
\end{tabular}




\begin{tabular}{cccc|ccc} 
UGR & $3.9 \pm 0.4$ & $0.1 \pm 0.1$ & $212.5 \pm 52.7$ & $4.8(0.9)$ & $0.5(0.4)$ & $43.8(-168.7)$ \\
UUG & $4.1 \pm 0.4$ & $0.3 \pm 0.4$ & $205.4 \pm 54.5$ & $4.7(0.6)$ & $0.4(0.1)$ & $45.6(-159.8)$ \\
GRM & $3.8 \pm 0.4$ & $0.4 \pm 0.6$ & $182.1 \pm 41.1$ & $3.9(0.06)$ & $0.5(0.2)$ & $107.4(-74.7)$ \\
MFR & $3.95 \pm 0.24$ & $0.1 \pm 0.1$ & $162.7 \pm 26.3$ & $4.21(0.26)$ & $0.5(0.4)$ & $81.3(-81.3)$ \\
\hline
\end{tabular}


Table 4. Pre-treatment specific conductance (SpC), total dissolved solids (TDS), and total suspended solids (TSS) mean values with \pm $95 \%$ confidence intervals about the mean are given by study site on the left side of the table. Post-treatment SpC, TDS, and TSS values are given to the right of the vertical line with observed differences in pre to post treatment in parentheses.

\begin{tabular}{cccc|ccc}
\hline \hline Site & SpC $(\mu \mathrm{S} / \mathrm{cm})$ & TDS $(\mathrm{mg} / \mathrm{L})$ & TSS $(\mathrm{mg} / \mathrm{L})$ & SpC $(\mu \mathrm{S} / \mathrm{cm})$ & TDS $(\mathrm{mg} / \mathrm{L})$ & TSS $(\mathrm{mg} / \mathrm{L})$ \\
\hline \hline UMC & $106.5 \pm 17.7$ & $70 \pm 10$ & $8.2 \pm 7.1$ & $99(-7.5)$ & $65(-5)$ & $1.2(-6.9)$ \\
MJR & $82.1 \pm 10.0$ & $100 \pm 90$ & $16.1 \pm 11.0$ & $76(-6.1)$ & $94(-6)$ & $1.2(-14.9)$ \\
CZZ & $76.2 \pm 9.4$ & $50 \pm 10$ & $3.9 \pm 2.7$ & $71(-5.2)$ & $46(-4)$ & $1.2(-2.7)$ \\
MTS & $200.7 \pm 43.7$ & $130 \pm 30$ & $11.4 \pm 11.5$ & $142(-58.7)$ & $92(-38)$ & $4(-7.4)$ \\
MDB & $239.2 \pm 41.3$ & $160 \pm 30$ & $8.7 \pm 8.6$ & $183(-56.2)$ & $119(-41)$ & $1.2(-7.5)$ \\
MAM & $221.4 \pm 33.1$ & $210 \pm 100$ & $16.3 \pm 16.0$ & $211(-10.4)$ & $137(-73)$ & $12(-4.3)$ \\
MCO & $649.8 \pm 103.5$ & $450 \pm 100$ & $18.7 \pm 6.4$ & $467(-182.8)$ & $303(-147)$ & $30(11.3)$ \\
MSR & $621.5 \pm 77.9$ & $430 \pm 90$ & $22.8 \pm 10.9$ & $463(-158.5)$ & $301(-129)$ & $20(-2.8)$ \\
MUM & $635.3 \pm 84.8$ & $440 \pm 100$ & $127.5 \pm 194.4$ & $443(-192.3)$ & $288(-152)$ & $40(-87.5)$ \\
FRM & $1844 \pm 245.9$ & $1270 \pm 220$ & $40.8 \pm 37.7$ & $4.21(0.4)$ & $500(-420)$ & $120(79.2)$
\end{tabular}




\begin{tabular}{cccc|ccc} 
MCM & $1271.3 \pm 165.5$ & $870 \pm 130$ & $21.4 \pm 16.5$ & $3.83(0.3)$ & $500(-370)$ & $12(-9.4)$ \\
UGR & $884.3 \pm 166.2$ & $610 \pm 120$ & $15.1 \pm 14.6$ & $479(-405.3)$ & $310(-300)$ & $4(-11.1)$ \\
UUG & $1014.5 \pm 190.3$ & $680 \pm 170$ & $7.4 \pm 4.9$ & $405(-609.5)$ & $263(-417)$ & $16(8.8)$ \\
GRM & $1149.2 \pm 144.7$ & $780 \pm 110$ & $17.9 \pm 22.9$ & $1001(-148.2)$ & $650(-130)$ & $1.2(-16.7)$ \\
MFR & $1060.8 \pm 61.1$ & $690 \pm 40$ & $10.8 \pm 7.07$ & $988(-72)$ & $642(-48)$ & $4.0(-6.8)$ \\
\hline
\end{tabular}


Table 5. Eigenvalues, standard deviations (Std dev.), percent of variance captured by respective principal component, and percent of variance captured by respective and subsequent principal components (Cumulative \%). In addition, the factor loadings for each water chemistry variables are presented. Variables with a factor loading $(>|0.4|)$ were considered important contributors to principal components.

\begin{tabular}{lccc}
\hline & PC1 & PC2 & PC3 \\
\hline Eigenvalues & 10.63 & 1.65 & 1.16 \\
Std dev. & 3.26 & 1.28 & 1.08 \\
\% of Var & 59.09 & 9.19 & 6.43 \\
Cumulative \% & 59.09 & 68.28 & 74.71 \\
pH & 0.88 & 0.32 & -0.10 \\
Alkalinity & 0.87 & 0.17 & -0.11 \\
Acidity & -0.83 & -0.30 & -0.12 \\
SpCond & -0.93 & -0.25 & 0.00 \\
Al & -0.66 & 0.21 & -0.11
\end{tabular}




\begin{tabular}{llll}
$\mathrm{Ba}$ & 0.29 & 0.64 & -0.25 \\
$\mathrm{Ca}$ & -0.77 & 0.49 & -0.11 \\
$\mathrm{Cl}$ & -0.77 & -0.12 & -0.28 \\
$\mathrm{Co}$ & -0.53 & 0.14 & 0.47 \\
$\mathrm{Fe}$ & -0.88 & 0.21 & -0.20 \\
$\mathrm{Mg}$ & -0.72 & 0.53 & -0.03 \\
$\mathrm{Mn}$ & -0.90 & 0.32 & 0.10 \\
$\mathrm{Na}$ & -0.60 & -0.12 & -0.09 \\
$\mathrm{Ni}$ & -0.90 & 0.16 & 0.17 \\
$\mathrm{Zn}$ & -0.89 & 0.15 & 0.18 \\
$\mathrm{SO} 42$ & -0.90 & -0.31 & 0.06 \\
$\mathrm{TSS}$ & -0.13 & -0.12 & -0.79 \\
$\mathrm{TDS}$ & -0.83 & -0.20 & -0.10 \\
\hline
\end{tabular}


Table 6. Repeated Measures ANOVA p-values for pre- and post- treatment water chemistry parameters within treated reaches.

Significant changes in water chemistry variables from pre-treatment observations to the post-treatment observation are shown in bold (P-Value $<0.05)$. R Code: aov(variable $\sim$ Treated $(Y / N) *$ Year +Error $($ Site $))$

\begin{tabular}{ccc}
\hline Variable & $\mathrm{F}_{1,52}$ & P-Value \\
\hline \hline $\mathrm{pH}$ & 5.75 & $\mathbf{0 . 0 2}$ \\
$\mathrm{Alk}$ & 6.91 & $\mathbf{0 . 0 1}$ \\
$\mathrm{Acid}$ & 10.59 & $\mathbf{0 . 0 0 2}$ \\
$\mathrm{SpC}$ & 6.55 & $\mathbf{0 . 0 1}$ \\
$\mathrm{Al}$ & 8.39 & $\mathbf{0 . 0 0 5}$ \\
$\mathrm{Ba}$ & 0.93 & 0.34 \\
$\mathrm{Ca}$ & 1.57 & 0.21 \\
$\mathrm{Cd}$ & 0.17 & 0.68 \\
$\mathrm{Cl}$ & 3.06 & 0.08 \\
$\mathrm{Co}$ & 3.20 & 0.07
\end{tabular}




\begin{tabular}{ccc}
$\mathrm{Fe}$ & 1.21 & 0.27 \\
$\mathrm{Mg}$ & 5.59 & $\mathbf{0 . 0 2}$ \\
$\mathrm{Mn}$ & 11.56 & $\mathbf{0 . 0 0 3}$ \\
$\mathrm{Na}$ & 0.62 & 0.43 \\
$\mathrm{Ni}$ & 13.60 & $\mathbf{0 . 0 0 0 5}$ \\
$\mathrm{Zn}$ & 5.45 & $\mathbf{0 . 0 2}$ \\
$\mathrm{SO}_{4}{ }^{2}$ & 10.49 & $\mathbf{0 . 0 0 2}$ \\
$\mathrm{TSS}$ & 2.47 & 0.12 \\
$\mathrm{TDS}$ & 6.59 & $\mathbf{0 . 0 1}$ \\
\hline
\end{tabular}


Table 7. Pre-treatment mean values for percent of assemblage comprised of EPT taxa (\% EPT), EPT family richness (EPT Rich), and percent of assemblage comprised of Ephemeroptera (\% Ephem), with $\pm 95 \%$ confidence intervals about the mean are given by study site on the left side of the table. Post-treatment \% EPT, EPT Rich, and \% Ephem, values are given to the right of the vertical line with observed differences in pre to post treatment in parentheses.

\begin{tabular}{cccc|ccc}
\hline \hline Site & \% EPT & EPT Rich & \% Ephem & \% EPT & EPT Rich & \% Ephem \\
\hline \hline UGR & $10.4 \pm 0.7$ & $0.5 \pm 0.6$ & $0.3 \pm 0.6$ & $1.6(-8.7)$ & $1(0.5)$ & $0(-0.3)$ \\
UUG & $1.1 \pm 1.7$ & $0.5 \pm 0.4$ & $0.1 \pm 0.2$ & $3.1(2.1)$ & $1(0.5)$ & $0(0.1)$ \\
GRM & $2.8 \pm 2.4$ & $2.8 \pm 2.5$ & $0.3 \pm 0.6$ & $1.2(-1.5)$ & $1(-1.8)$ & $1.2(0.9)$ \\
MFR & $4.0 \pm 3.5$ & $2.0 \pm 1.1$ & $0.5 \pm 1.1$ & $0.0(-4.0)$ & $0(-2)$ & $0(-0.5)$ \\
MCM & $14.9 \pm 14.7$ & $1.5 \pm 1.5$ & $6.8 \pm 13.3$ & $40(25.1)$ & $3(1.5)$ & $26.7(19.8)$ \\
MCO & $29.6 \pm 29.3$ & $2.3 \pm 1.6$ & $3.8 \pm 4.3$ & $4.4(-25.1)$ & $2(-0.3)$ & $0(-3.8)$ \\
MSR & $40.1 \pm 20.4$ & $4.6 \pm 2.3$ & $10.5 \pm 7.0$ & $12.3(-27.7)$ & $3(-1.7)$ & $10.1(-0.4)$ \\
MUM & $27.1 \pm 21.4$ & $5.1 \pm 4.3$ & $7.8 \pm 9.3$ & $33.3(6.2)$ & $2(-3.1)$ & $31.4(23.6)$ \\
FRM & $0.0 \pm 0.0$ & $0.0 \pm 0.0$ & $0.0 \pm 0.0$ & $0.0(0.0)$ & $0(0.0)$ & $0(0.0)$ \\
\hline
\end{tabular}


Table 8. Pre-treatment family richness (Taxa Rich), percent of assemblage comprised of only two families (\%2Dom), West Virginia Stream Condition Index (WVSCI) score mean values with $\pm 95 \%$ confidence intervals about the mean are given by study site on the left side of the table. Post-treatment Taxa Rich, \%2Dom, and WVSCI values are given to the right of the vertical line with observed differences in pre to post treatment in parentheses.

\begin{tabular}{cccc|ccc}
\hline \hline Site & Taxa Rich & \%2Dom & WVSCI & Taxa Rich & \%2Dom & WVSCI \\
\hline \hline UGR & $7.0 \pm 1.6$ & $87.2 \pm 4.4$ & $25.7 \pm 3.2$ & $5(-2)$ & $97.8(10.7)$ & $13.8(-11.8)$ \\
UUG & $4.7 \pm 1.2$ & $97.5 \pm 1.8$ & $12.8 \pm 3.0$ & $8(3.3)$ & $71.0(-26.4)$ & $26.2(13.4)$ \\
GRM & $7.7 \pm 3.9$ & $95.9 \pm 2.9$ & $19.9 \pm 8.8$ & $9(1.3)$ & $96.2(0.3)$ & $17.2(-2.7)$ \\
MFR & $6.7 \pm 2.8$ & $95.3 \pm 2.9$ & $18.6 \pm 5.1$ & $5(-1.7)$ & $96.6(1.3)$ & $11.7(-6.8)$ \\
MCM & $4.0 \pm 2.2$ & $85.8 \pm 10.0$ & $23.9 \pm 14.8$ & $8(4)$ & $53.3(-32.4)$ & $49.1(25.2)$ \\
MCO & $4.0 \pm 2.2$ & $70.2 \pm 29.6$ & $33.2 \pm 18.1$ & $8(4)$ & $80.2(10.0)$ & $32.8(-0.4)$ \\
MSR & $8.3 \pm 4.0$ & $71.3 \pm 15.9$ & $51.6 \pm 13.5$ & $9(0.7)$ & $65.1(-6.1)$ & $36.4(-15.1)$ \\
MUM & $9.8 \pm 7.7$ & $72.4 \pm 18.0$ & $47.2 \pm 19.6$ & $7(-2.8)$ & $77.8(5.3)$ & $39.2(-7.9)$ \\
FRM & $1.7 \pm 0.7$ & $99.0 \pm 1.9$ & $13.6 \pm 11.5$ & $3(1.3)$ & $96.7(-2.3)$ & $15.8(2.3)$ \\
\hline
\end{tabular}


Table 9. Pre-treatment mean values for various genera richness measurements with $\pm 95 \%$ confidence intervals about the mean are given by study site on the left side of the table. Post-treatment genera richness observations are given to the right of the vertical line with observed differences in pre to post treatment in parentheses.

\begin{tabular}{|c|c|c|c|c|c|c|c|c|c|c|}
\hline Site & Total & Ephemeroptera & Plecoptera & Clinger & Shredder & Total & Ephemeroptera & Plecoptera & Clinger & Shredder \\
\hline UGR & $7.2 \pm 1.8$ & $0.2 \pm 0.3$ & $0 \pm 0$ & $0.5 \pm 0.6$ & $0.3 \pm 0.4$ & $5.0(-2.2)$ & $0.0(-0.2)$ & $1.0(1.0)$ & $1.0(0.5)$ & $1.0(0.7)$ \\
\hline UUG & $4.5 \pm 1.1$ & $0.2 \pm 0.3$ & $0.2 \pm 0.3$ & $0.3 \pm 0.4$ & $0.3 \pm 0.4$ & $8.0(7.8)$ & $0.0(-0.2)$ & $0.0(-0.3)$ & $0.0(-0.3)$ & $1.0(0.7)$ \\
\hline GRM & $6.2 \pm 3.4$ & $0.2 \pm 0.3$ & $1.3 \pm 0.7$ & $1.7 \pm 0.8$ & $1.0 \pm 0.5$ & $9.0(2.8)$ & $1.0(-0.3)$ & $0.0(-1.7)$ & $1.0(0.0)$ & $1.0(0.0)$ \\
\hline MFR & $7.7 \pm 2.1$ & $0.7 \pm 0.9$ & $1.0 \pm 0.9$ & $2.3 \pm 0.7$ & $1.0 \pm 0.5$ & $6.0(-1.7)$ & $0.0(-0.7)$ & $0.0(-1.0)$ & $1.0(-2.3)$ & $0.0(-1.0)$ \\
\hline $\mathrm{MCM}$ & $4.2 \pm 2.3$ & $0.7 \pm 1.3$ & $0.5 \pm 0.7$ & $1.7 \pm 1.8$ & $0.7 \pm 0.7$ & $8.0(3.8)$ & $1.0(0.3)$ & $2.0(0.7)$ & $2.0(0.3)$ & $1.0(0.3)$ \\
\hline $\mathrm{MCO}$ & $4.2 \pm 2.3$ & $1.0 \pm 0.7$ & $0.7 \pm 0.4$ & $1.7 \pm 1.4$ & $0.8 \pm 0.8$ & $8.0(3.8)$ & $0.0(-1.0)$ & $1.0(0.3)$ & $1.0(-0.7)$ & $1.0(0.2)$ \\
\hline MSR & $8.2 \pm 3.9$ & $1.8 \pm 1.2$ & $1.5 \pm 1.2$ & $3.0 \pm 1.6$ & $1.2 \pm 0.8$ & $9.0(0.8)$ & $1.0(-1.2)$ & $1.0(-1.5)$ & $1.0(-2.0)$ & $1.0(-0.2)$ \\
\hline MUM & $11.7 \pm 11.0$ & $2.2 \pm 1.9$ & $2.8 \pm 3.0$ & $4.7 \pm 5.4$ & $2.8 \pm 2.7$ & $6.0(-5.7)$ & $1.0(-1.2)$ & $1.0(-1.8)$ & $0.0(-4.7)$ & $1.0(-1.8)$ \\
\hline FRM & $1.7 \pm 0.6$ & $0.0 \pm 0.0$ & $0.0 \pm 0.1$ & $0.0 \pm 0.2$ & $0.2 \pm 0.3$ & $3.0(1.3)$ & $0.0(0.0)$ & $0.0(0.0)$ & $0.0(0.0)$ & $0.0(-0.2)$ \\
\hline
\end{tabular}


Table 10. Pre-treatment mean values for genus richness with tolerance value less than 4 (TV4), \% of assemblage comprised of EPT taxa excluding Cheumatopsyche (\%EPT_nCheut), \% of assemblage comprised of Chironomidae and Annelidae (\%Chir_Ann), \% of assemblage comprised of top five dominant taxa (\%5DomTax), and the Genus Level Index of Most Probable Stream Statue

(GLIMPSS) with $\pm 95 \%$ confidence intervals about the mean are given by study site on the left side of the table. Post-treatment TV3, \%EPT_nCheut, \%Chir_Ann, \%5Domtax, and GLIMPSS values are given to the right of the vertical line with observed differences in pre to post treatment in parentheses.

\begin{tabular}{|c|c|c|c|c|c|c|c|c|c|c|}
\hline Site & TV4 & \%EPT_nCheut & $\%$ Chir_Ann & $\% 5$ DomTax & GLIMPSS & TV4 & \%EPT_nCheut & $\%$ Chir_Ann & $\% 5$ DomTax & GLIMPSS \\
\hline$\overline{\mathrm{UGR}}$ & $0.8 \pm 0.9$ & $0.4 \pm 0.7$ & $42.1 \pm 8.5$ & $98.9 \pm 1.3$ & $\overline{~ 5.6 \pm 2.3}$ & $1.0(0.2)$ & $=1.7(1.3)$ & 91.8(49.7) & $100(1.1)$ & $4.6(-1.0)$ \\
\hline UUG & $0.5 \pm 0.7$ & $1.1 \pm 1.7$ & $95.5 \pm 2.7$ & $99.9 \pm 0.1$ & $1.7 \pm 1.8$ & $1.0(0.5)$ & $3.1(2.0)$ & $71.1(-24.4)$ & $96.1(-3.8)$ & $4.8(3.1)$ \\
\hline GRM & $2.0 \pm 1.4$ & $4.0 \pm 4.2$ & $91.0 \pm 7.1$ & $97.4 \pm 3.6$ & $7.7 \pm 4.5$ & $0.0(-2.0)$ & $1.3(-2.7)$ & $94.5(3.5)$ & $98.7(1.3)$ & $1.6(-6.1)$ \\
\hline MFR & $2.7 \pm 1.5$ & $4.6 \pm 3.4$ & $87.6 \pm 4.5$ & $97.1 \pm 3.2$ & $7.9 \pm 4.4$ & $0.0(-2.7)$ & $0.0(-4.6)$ & $94.0(6.4)$ & $99.1(2.0)$ & $0.0(-7.9)$ \\
\hline $\mathrm{MCM}$ & $1.7 \pm 1.9$ & $14.9 \pm 14.8$ & $75.3 \pm 20.8$ & $92.6 \pm 12.4$ & $11.6 \pm 12.9$ & $3.0(1.3)$ & $42.9(28.0)$ & $35.7(-39.6)$ & $78.6(-14)$ & $26.5(14.9)$ \\
\hline $\mathrm{MCO}$ & $1.8 \pm 1.4$ & $29.4 \pm 29.4$ & $60.8 \pm 31.9$ & $96.6 \pm 5.7$ & $14.7 \pm 10.6$ & $1.0(-0.8)$ & $4.5(-24.9)$ & $44.6(-16.2)$ & $91.4(-5.2)$ & $11.5(-3.2)$ \\
\hline MSR & $3.5 \pm 2.9$ & $39.7 \pm 20.6$ & $35.8 \pm 19.5$ & $86.9 \pm 10.6$ & $26.9 \pm 14.1$ & $1.0(-2.5)$ & $12.4(-25.3)$ & $65.2(-29.4)$ & $95.5(8.6)$ & $7.4(-19.5)$ \\
\hline MUM & $5.7 \pm 5.9$ & $27.3 \pm 21.4$ & $42.3 \pm 30.3$ & $89.3 \pm 8.9$ & $31.8 \pm 20.8$ & $6.0(0.3)$ & $33.9(6.6)$ & $47.2(4.9)$ & $96.2(6.9)$ & $14.0(-17.8)$ \\
\hline
\end{tabular}




\begin{tabular}{|c|c|c|c|c|c|c|c|c|c|}
\hline FRM & $0.2 \pm 0.3$ & $0.0 \pm 0.3$ & $80.6 \pm 31.8$ & $98.4 \pm 3.2$ & $4.4 \pm 6.6$ & $0.0(-0.2)$ & $0.0(0.0)$ & $70.0(-10.6)$ & $100(1.6)$ \\
\hline
\end{tabular}


Table 11. Repeated Measures ANOVA p-values for pre- and post- AMD treatment for benthic macroinvertebrate bio-indices of stream health within treated reaches. TV4 $=$ Number of genera with an tolerance value greater than four, E_Genus_Rich = Ephemeroptera genus richness, P_Genus_Rich = Plecoptera genus richness, Clinger_Genus_Rich $=$ Clinger genus richness, $\%$ EPT w/o Ch. $=\%$ of assemblage comprised of EPT genera not including Cheumatopsyche, $\%$ Chir \& Ann = Percent of assesmblage compised of Chironomidae or Annelids, GLIMPSS = Genus-Level Index of Most Probably Stream Status, \%EPT $=$ Percent of assemblage comprised of EPT families, GenTol Rich $=$ Number of generally tolerant families, $\% \mathrm{E}=$ Percent of assemblage comprised of Ephemeroptera, $\%$ Dom $=$ Percent of assemblage comprised of only one family, Family_Richness $=$ Number of families represented, $\%$ Acid Tol $=$ Percent of assemblage comprised of acidity $($ low $\mathrm{pH})$ tolerant taxa, and $\% \mathrm{Al}$ Tol $=$ Percent of assemblage comprised of aluminum tolerant taxa. Degrees of freedom $=1$ for each.

\begin{tabular}{ccc}
\hline Variable & $\mathrm{F}_{1,52}$ & P-Value \\
\hline \hline TV4 & 0.17 & 0.67 \\
E_Genus_Rich & 0.55 & 0.46 \\
P_Genus_Rich & 0.05 & 0.83 \\
Clinger_Genus_Rich & 1.21 & 0.27 \\
\% EPT w/o Ch. & 0.14 & 0.71 \\
\% Chir \& Ann & 0.001 & 0.97 \\
\% 5 Dom Taxa & 0.003 & 0.95 \\
Shredder_Genus_Rich & 0.33 & 0.57 \\
GLIMPSS & 0.97 & 0.32 \\
\% EPT & 0.19 & 0.67
\end{tabular}




\begin{tabular}{ccc} 
EPT_Rich & 0.65 & 0.43 \\
GenTol_Rich & 0.30 & 0.58 \\
\% E & 2.37 & 0.13 \\
\% Dom & 3.32 & 0.07 \\
Family_Richness & 0.55 & 0.46 \\
\% Acid Tol & 0.58 & 0.45 \\
\% Al Tol & 0.39 & 0.54 \\
\% 2 Dom & 1.74 & 0.19 \\
N & 0.00 & 0.98 \\
WVSCI & 0.005 & 0.94 \\
\hline
\end{tabular}


Table 12. West Virginia Stream Condition Index (WVSCI) scores and assigned ecological units (EUs) for each study site pre and post treatment. The prefix " $t$ " denotes "treated" or "post-treatment value". The Ecological Change column displays observed changes from pre to post treatment in WVSCI and EUs.

\begin{tabular}{|c|c|c|c|c|c|c|c|}
\hline \multirow[b]{2}{*}{ Site Name } & \multirow[b]{2}{*}{ Reach Length (m) } & \multicolumn{2}{|c|}{ Pre-Treatment } & \multicolumn{2}{|c|}{ Post-Treatment } & \multicolumn{2}{|c|}{ Ecological Change } \\
\hline & & WVSCI & EU & tWVSCI & $\mathrm{tEU}$ & $\Delta \mathrm{WVSCI}$ & $\Delta \mathrm{EU}$ \\
\hline MUM & 381 & 44.62 & 3.62 & 39.26 & 3.24 & -5.36 & -0.38 \\
\hline MSR & 683 & 53.53 & 7.8 & 36.46 & 5.39 & -17.07 & -2.41 \\
\hline $\mathrm{MCO}$ & 2007 & 34.66 & 14.83 & 32.81 & 14.24 & -1.85 & -0.59 \\
\hline UUM & 2206 & 84.43 & 39.71 & 86.32 & 41.19 & 1.89 & 1.48 \\
\hline UMC & 2621 & 91.64 & 51.21 & 90.33 & 51.21 & -1.31 & 0 \\
\hline MDB & 3588 & 76.09 & 58.21 & 89.58 & 69.52 & 13.49 & 1.31 \\
\hline $\mathrm{MCM}$ & 713 & 23.58 & 3.58 & 49.12 & 7.58 & 25.54 & 4 \\
\hline FRM & 5118 & 7.05 & 7.69 & 15.87 & 17.57 & 8.82 & 9.88 \\
\hline MFR & 934 & 23.58 & 4.7 & 11.78 & 2.38 & -11.8 & -2.32 \\
\hline GRM & 1685 & 16.44 & 5.91 & 17.23 & 6.28 & 0.79 & 0.37 \\
\hline LUG & 1312 & 18.29 & 5.12 & 16.15 & 4.58 & -2.14 & -0.54 \\
\hline UUG & 1057 & 10.53 & 2.37 & 26.19 & 5.99 & 15.66 & 3.62 \\
\hline UGR & 3166 & 25.57 & 17.26 & 13.87 & 9.5 & -11.7 & -7.76 \\
\hline MGR & 3651 & 22.91 & 17.83 & 44.39 & 35.06 & 21.48 & 17.23 \\
\hline
\end{tabular}


Table 13. West Virginia State Water Quality Standards as of September 16, 2013 for parameters analyzed to determine effectiveness of $\mathrm{AMD}$ treatment. $\mathrm{Al}=$ Aluminum concentration, $\mathrm{Fe}=$ Iron concentration, $\mathrm{Mn}=$ Manganese concentration $($ WVDEP 2010).

\begin{tabular}{cl}
\hline Parameter & \multicolumn{1}{c}{ State Standard } \\
\hline \hline $\mathrm{pH}$ & $<6$ nor $>9$ \\
$\mathrm{Al}$ & Concentration $>0.75 \mathrm{mg} / \mathrm{L}^{*}$ \\
$\mathrm{Fe}$ & Concentration $>1.0 \mathrm{mg} / \mathrm{L}^{* *}$ \\
$\mathrm{Mn}$ & Concentration $>1.0 \mathrm{mg} / \mathrm{L}^{* * *}$
\end{tabular}

*Acute state standard. Al chronic standard is $0.087 \mathrm{mg} / \mathrm{L}$.

** Fe standard is $1.0 \mathrm{mg} / \mathrm{L}$ for trout waters, and $1.5 \mathrm{mg} / \mathrm{L}$ for warm water habitats. ***State Standard for the protection of human health. 

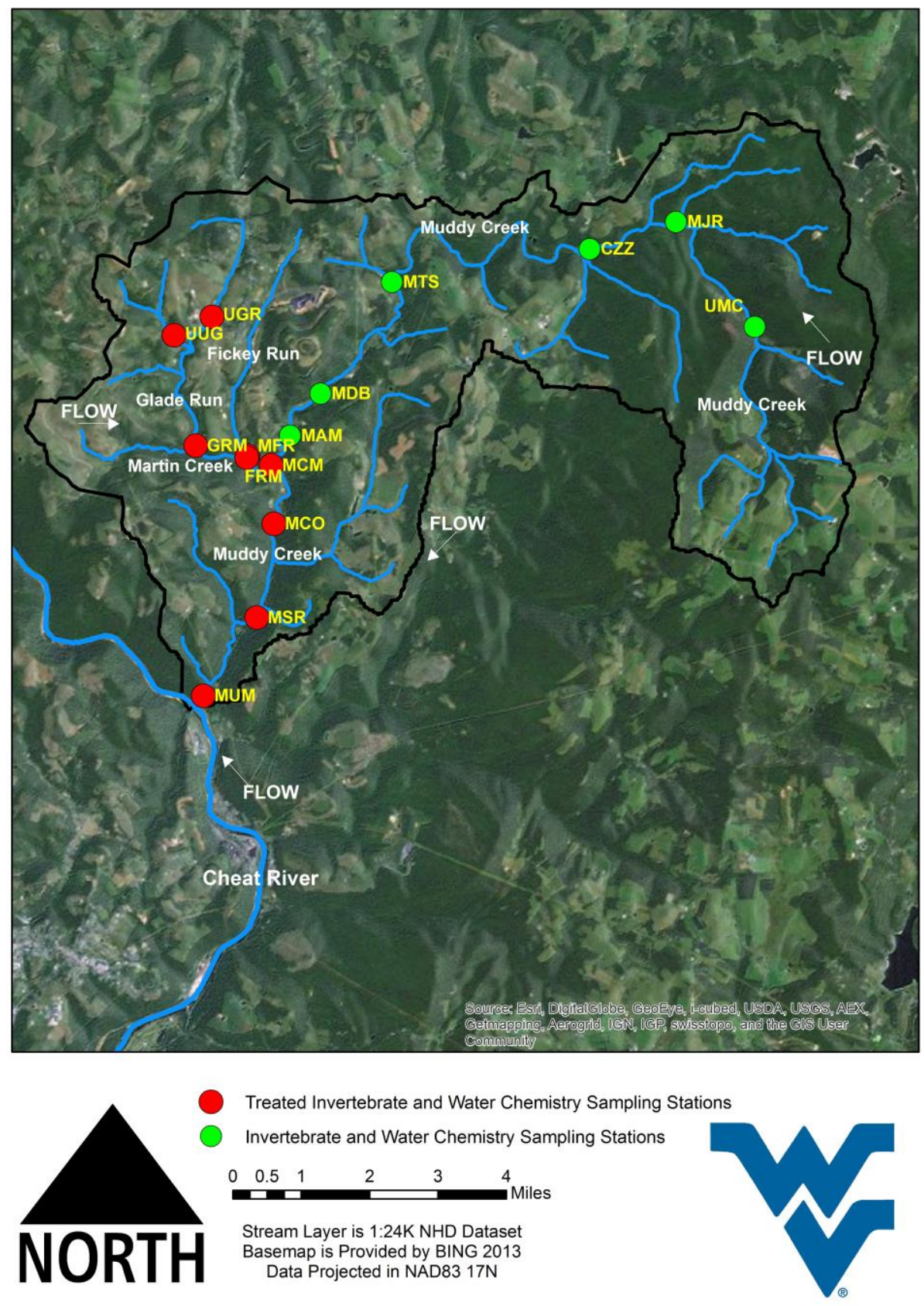

Figure 1. The Muddy Creek watershed with study locations and their assigned site names shown. The Cheat River is shown. See Table 1 for site abbreviations. 


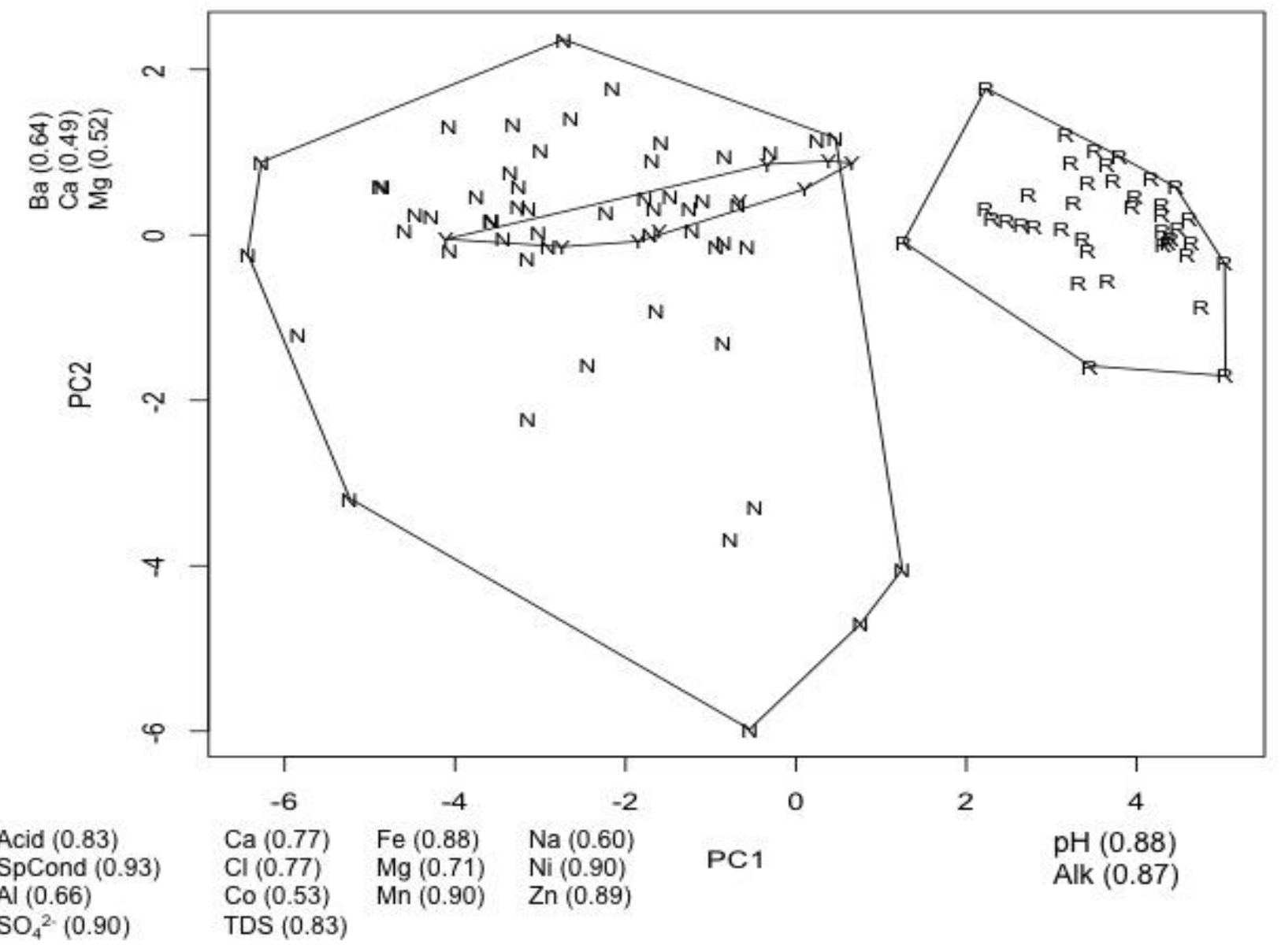

Figure 2. Principal component analysis plot of PC1 and PC2. Variables labeled on the axes are lab tested water chemistry variables with factor loadings $>|0.4| . \mathrm{N}=$ Not treated AMD impaired, $\mathrm{Y}=$ Treated AMD impaired, and $\mathrm{R}=$ Untreated reference condition. 

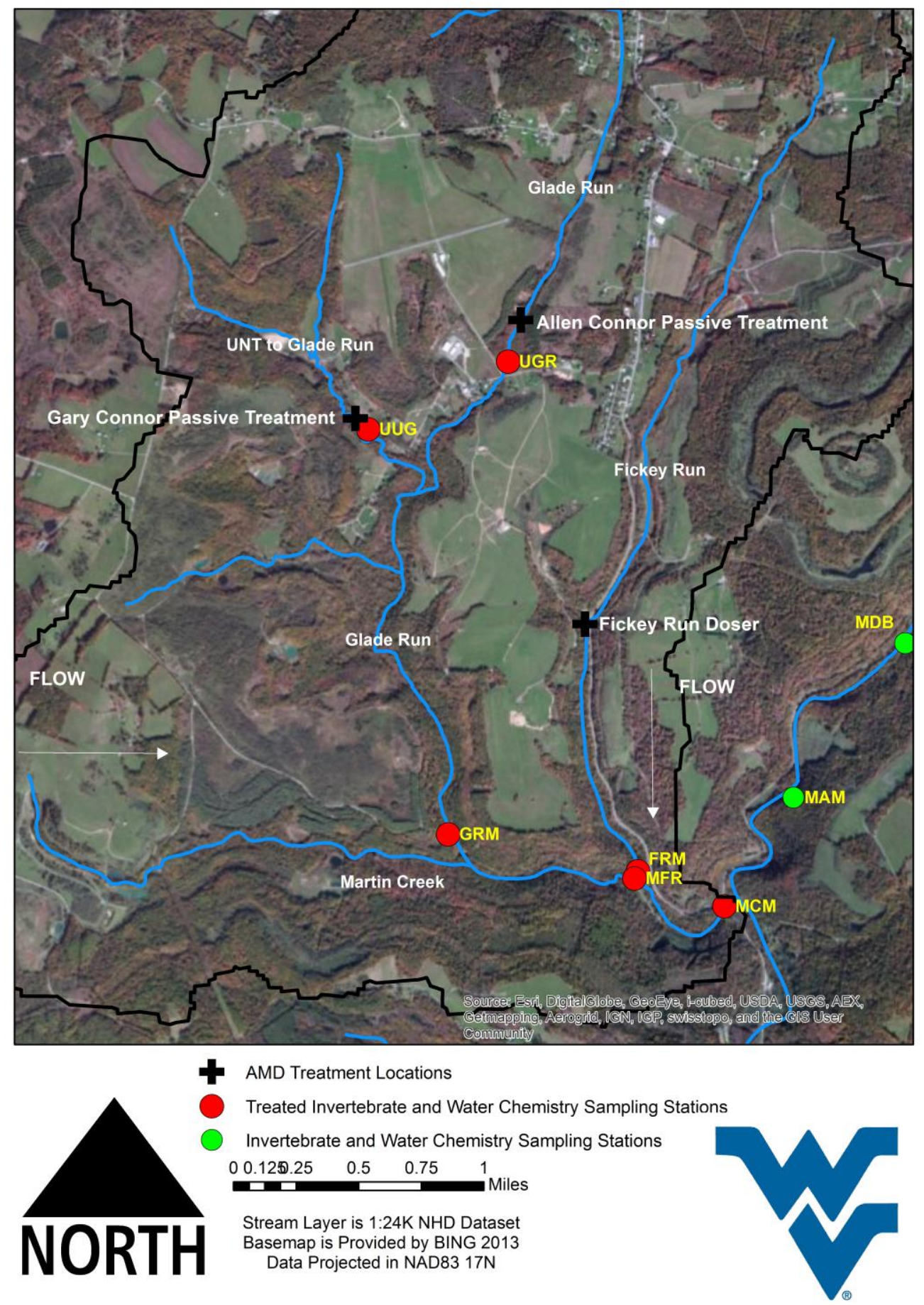

Figure 3. AMD treatment locations are shown within the Martin Creek watershed. 

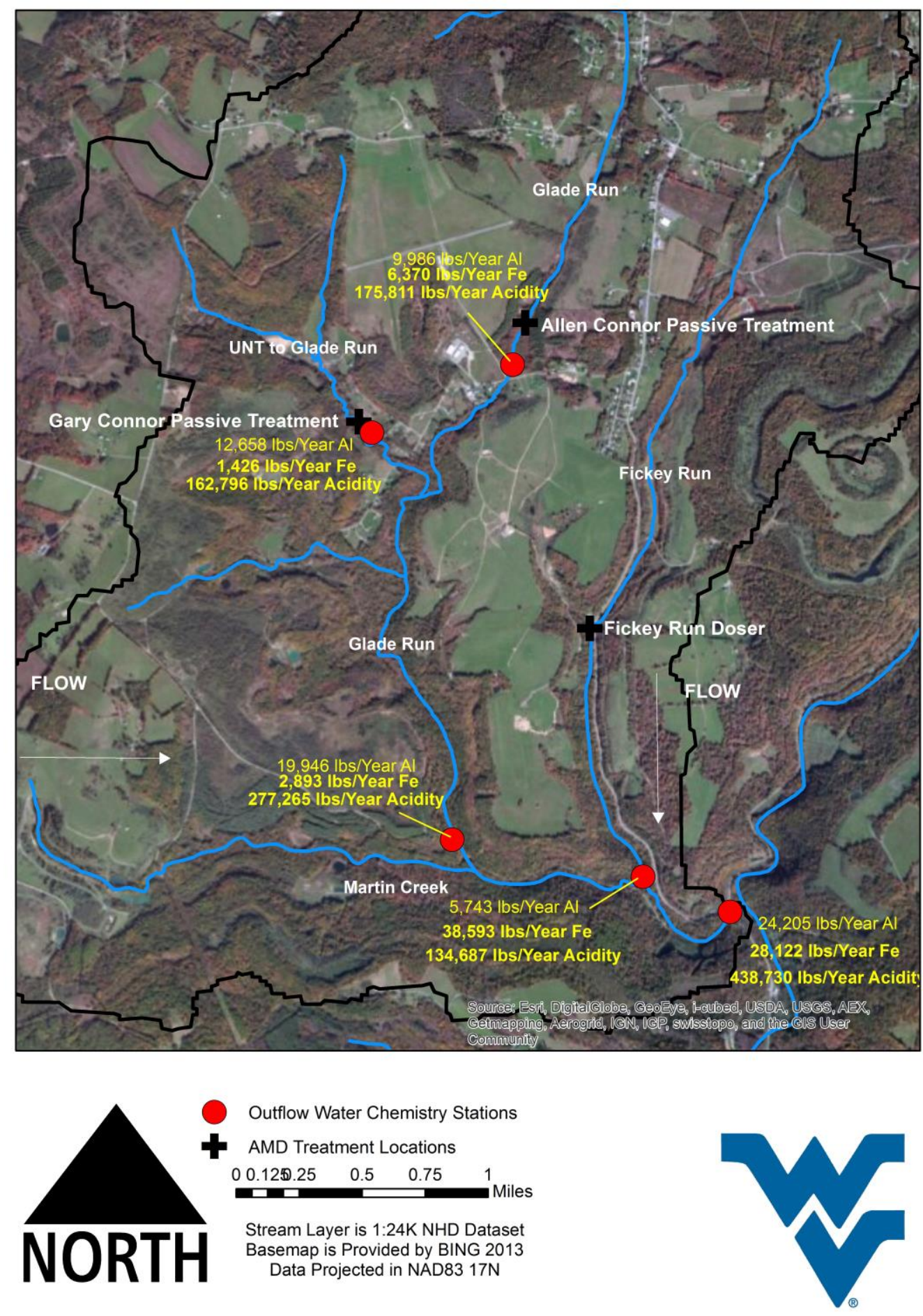

Figure 4. Pre-treatment annual polluntants (in pounds) of aluminium (Al), iron (Fe), and acidity are given at study locations immediately downstream of AMD sources 

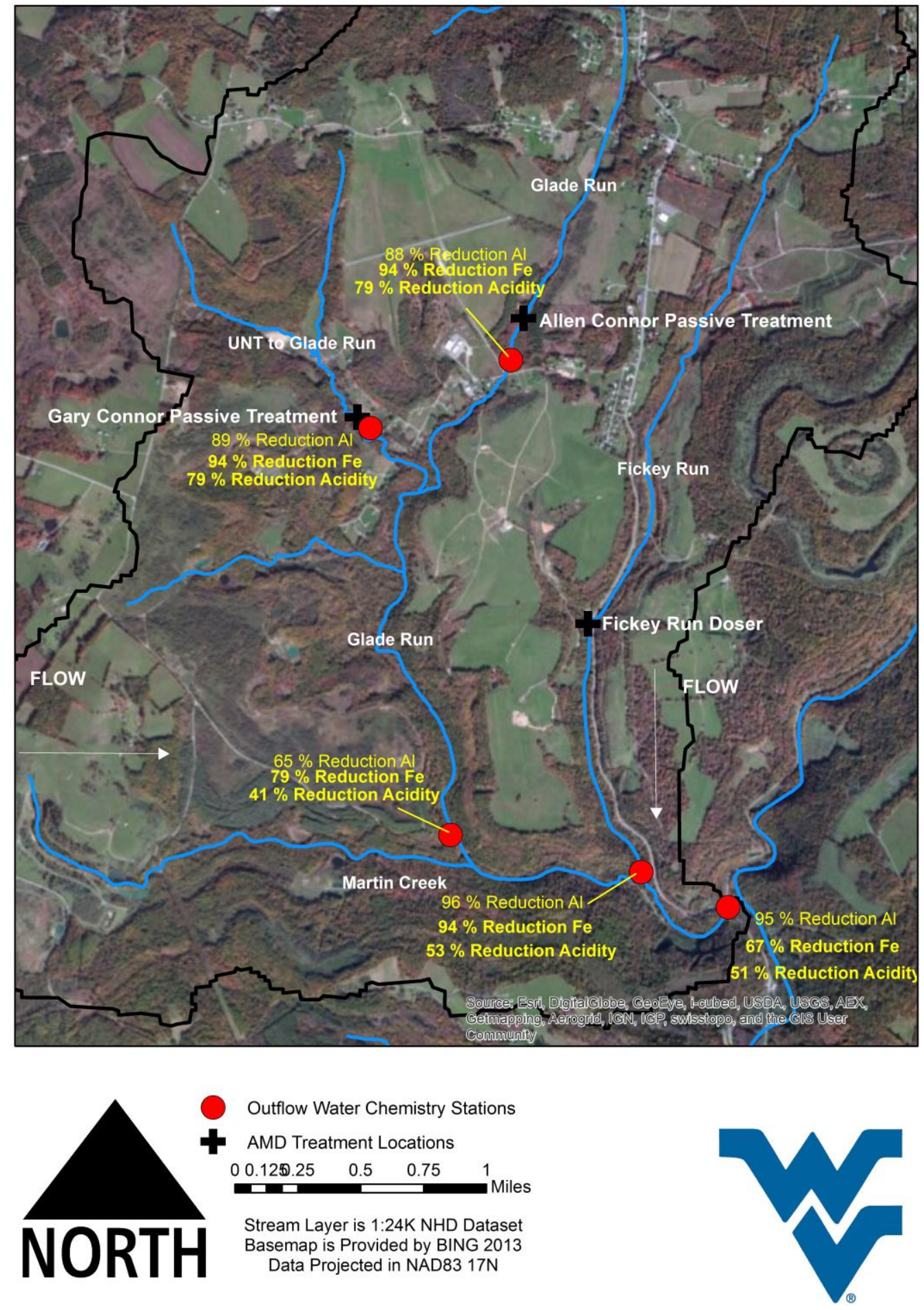

Figure 5. Load reductions for aluminum, iron, and acidity at study locations immediately downstream from AMD treatment within the Martin Creek watershed. 
a.

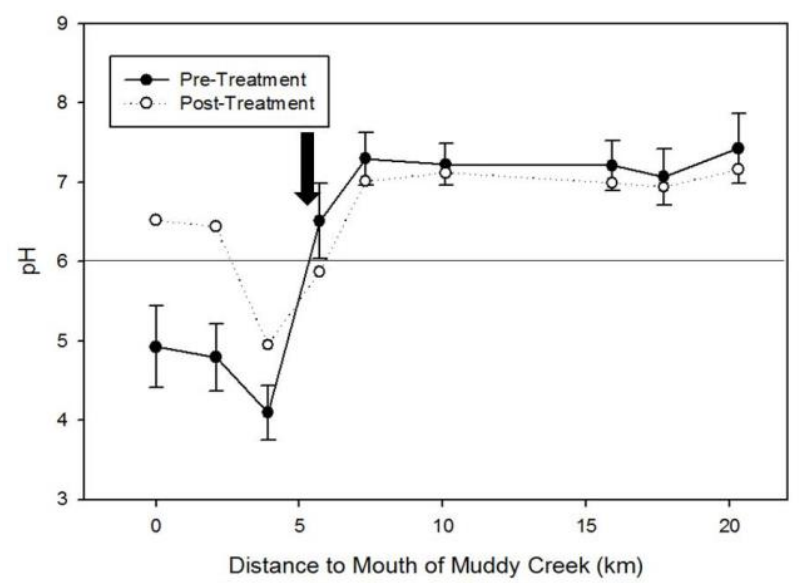

c.

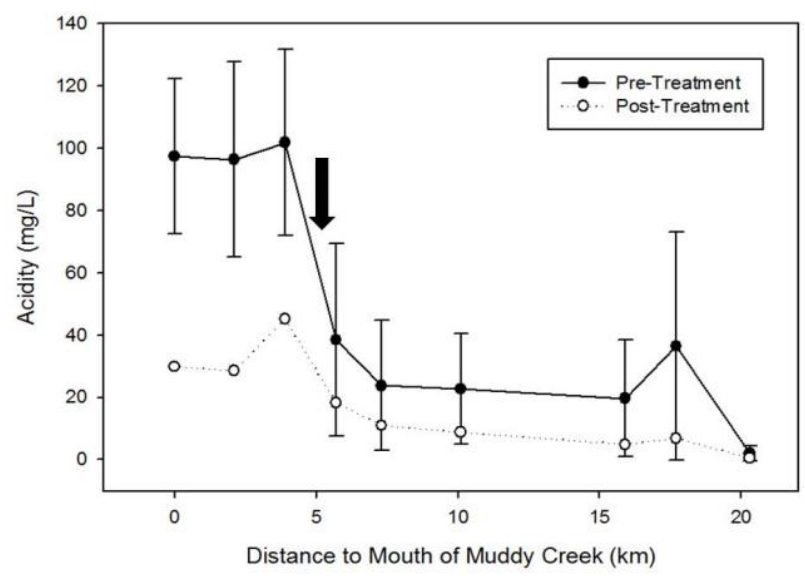

b.

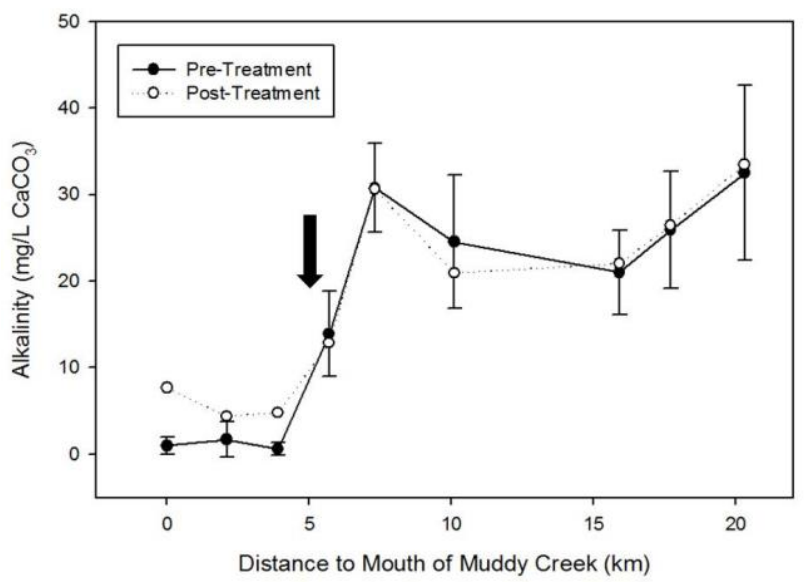

d.

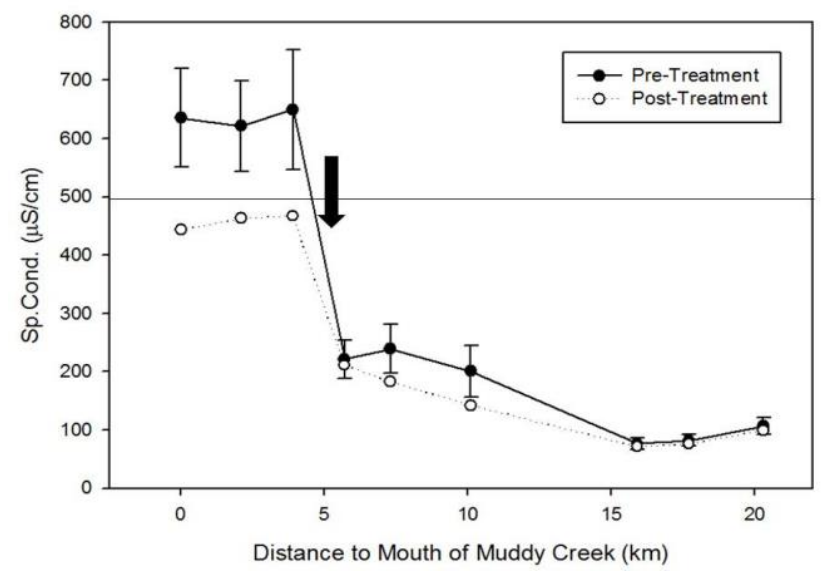

Figure 6. pH (a), alkalinity (b), acidity (c), and specific conductivity (d) along the Muddy Creek stream continuum pre-and-post AMD treatment. Error bars on pre-treatment line represent $95 \%$ confidence intervals about the mean for 2006-2011 data. Vertical arrows in each figure represent the confluence of Martin Creek and Muddy Creek. The horizontal line in panel a represents West Virginia state water quality standards for the lower limit of $\mathrm{pH}$. The upper limit for $\mathrm{pH}$ corresponds to the upper limit of the $\mathrm{y}-$ axis. The horizontal line in panel $\mathrm{d}$ represents the EPA guidance level for specific conductivity. 
a.

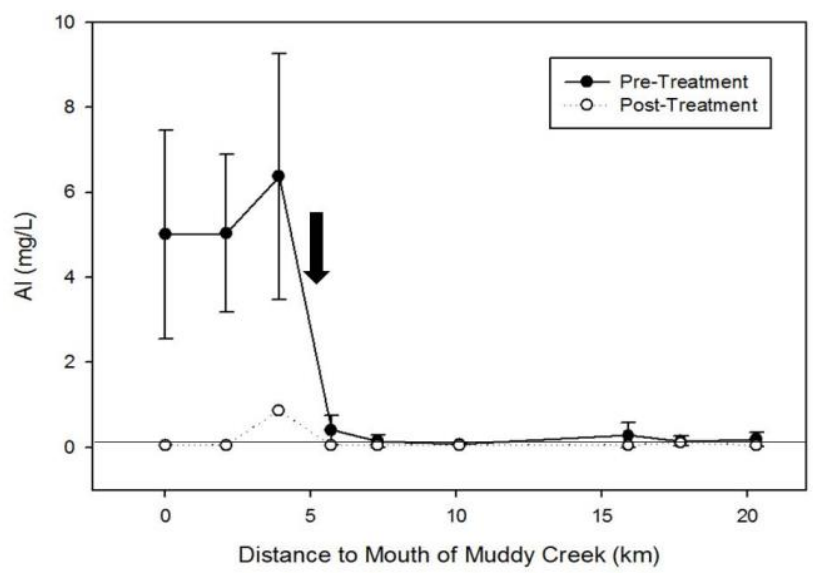

c.

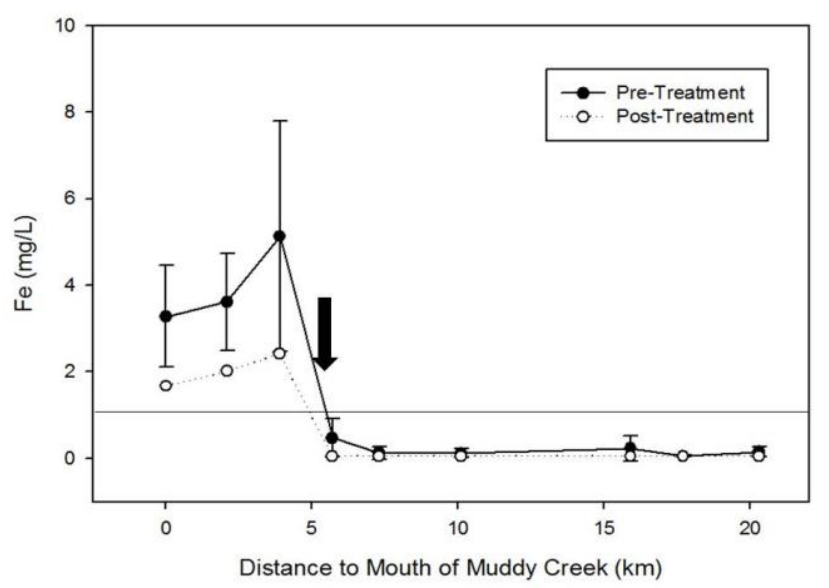

b.

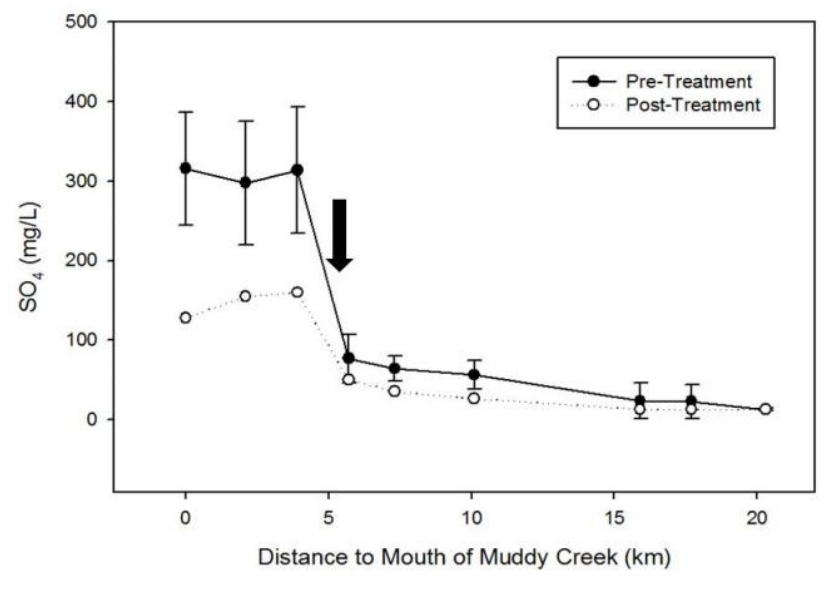

d.

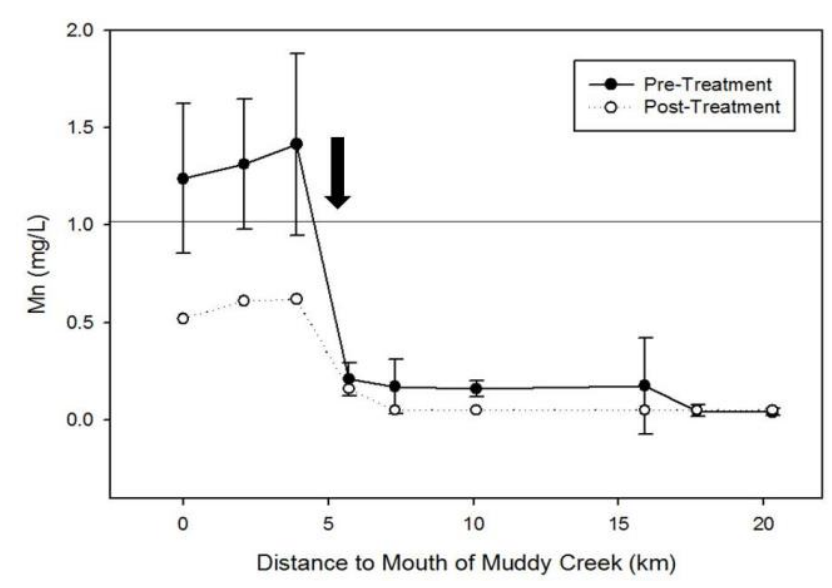

Figure 7. Concentration of aluminum (mg/L) (a), sulfates $(\mathrm{mg} / \mathrm{L})(\mathrm{b})$, iron $(\mathrm{mg} / \mathrm{L})(\mathrm{c})$, and manganese $(\mathrm{mg} / \mathrm{L})(\mathrm{d})$ for all study sites along the Muddy Creek stream continuum. Error bars represent $95 \%$ confidence intervals about the mean for pre-treatment data from 2006-2011. The horizontal bars in each figure represent West Virginia state water quality standards for that parameter. The vertical arrows in each figure represent the confluence of Martin Creek with Muddy Creek (5.6 km from the mouth of Muddy Creek). 

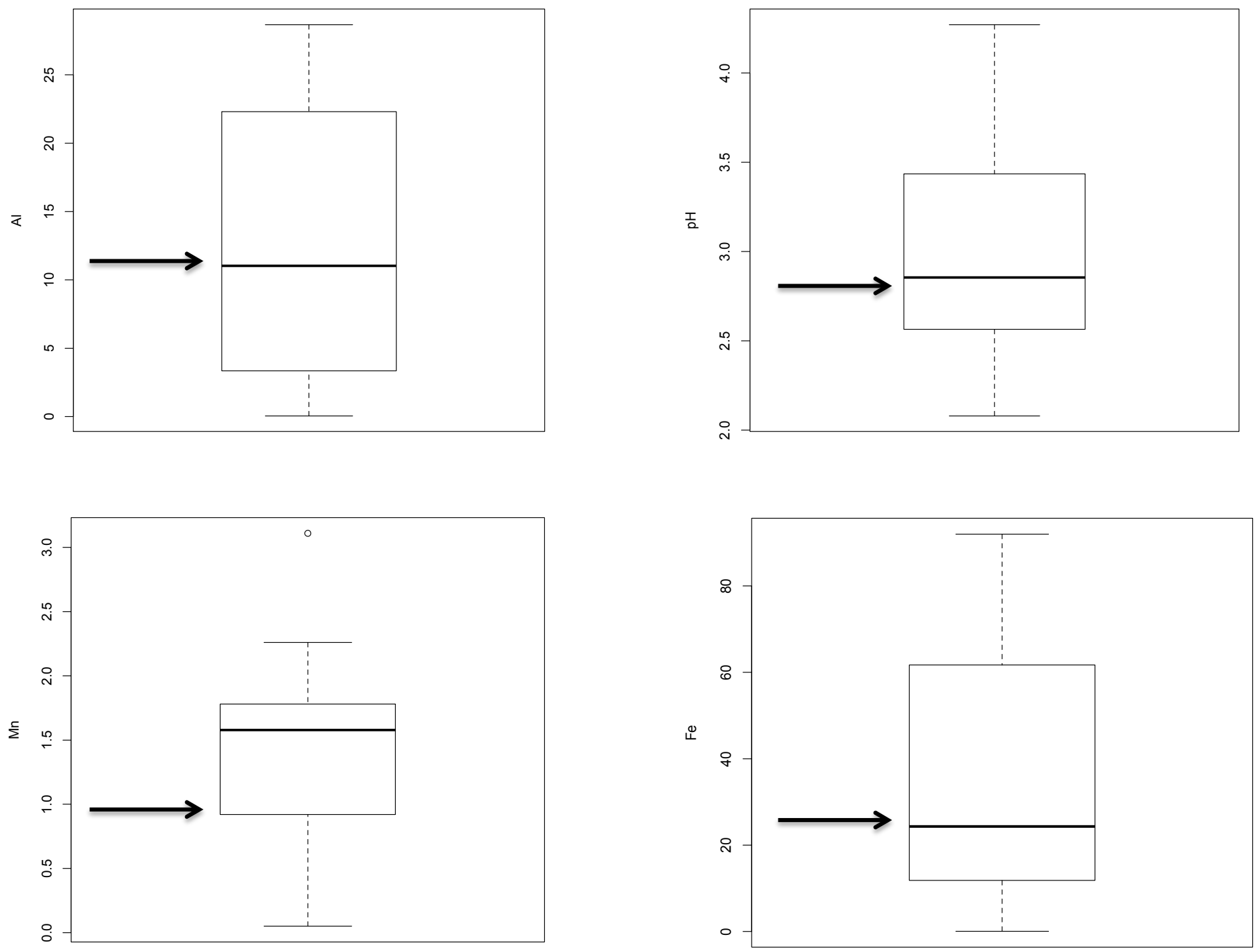

South Fork Green Run - Impaired Control

South Fork Green Run - Impaired Control

Figure 8. Boxplots of aluminum (Al), $\mathrm{pH}$, manganese $(\mathrm{Mn})$, and iron (Fe) observations at South Fork Greens Run, our impaired control. Concentrations of $\mathrm{Al}, \mathrm{Mn}$, and Fe are displayed in $\mathrm{mg} / \mathrm{L}$. $\mathrm{pH}$ is displayed in standard units. The vertical black arrows point to values observed in 2012, post-treatment for Muddy Creek. 
a.

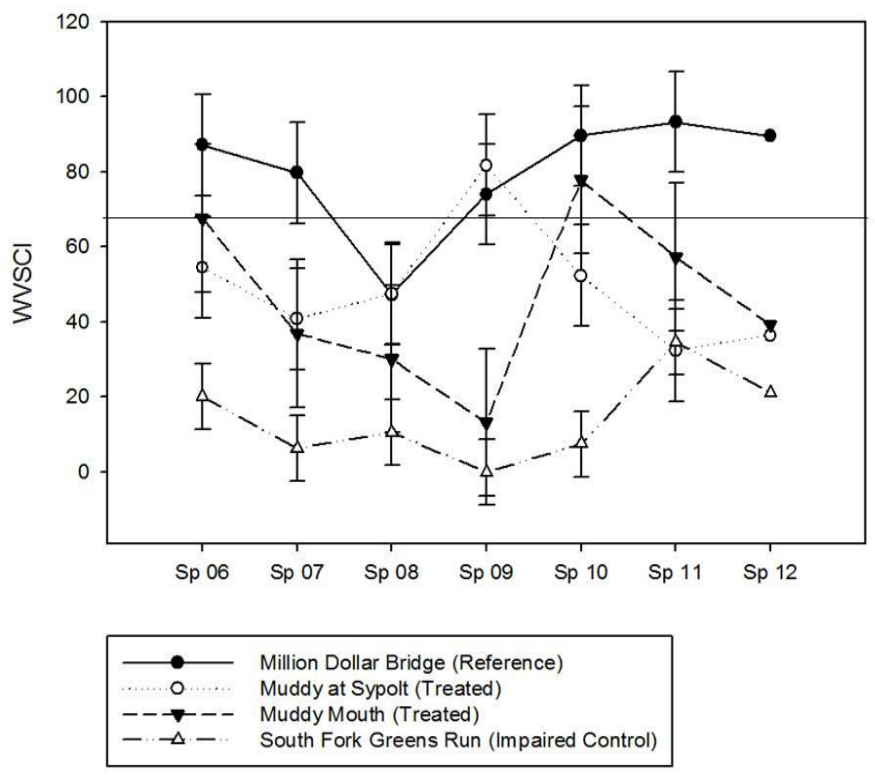

c.
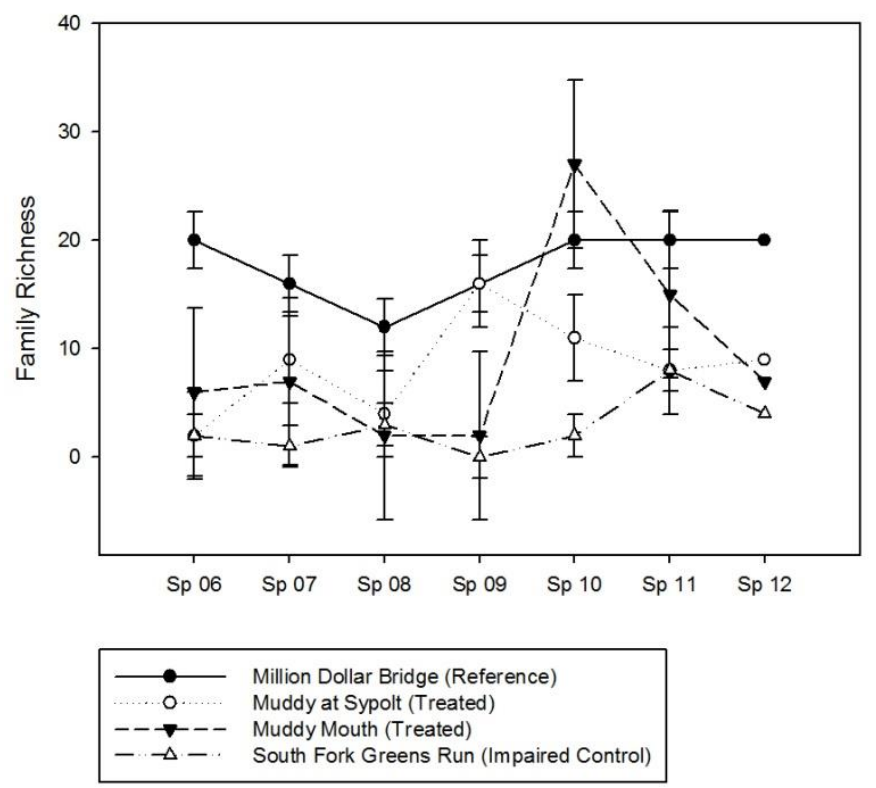

b.

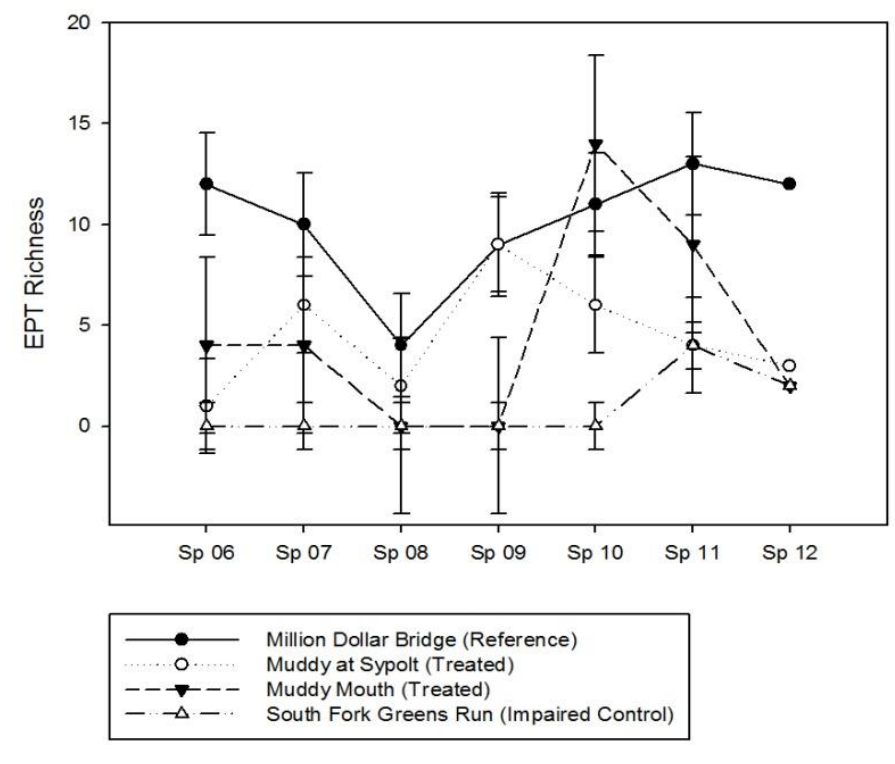

d.

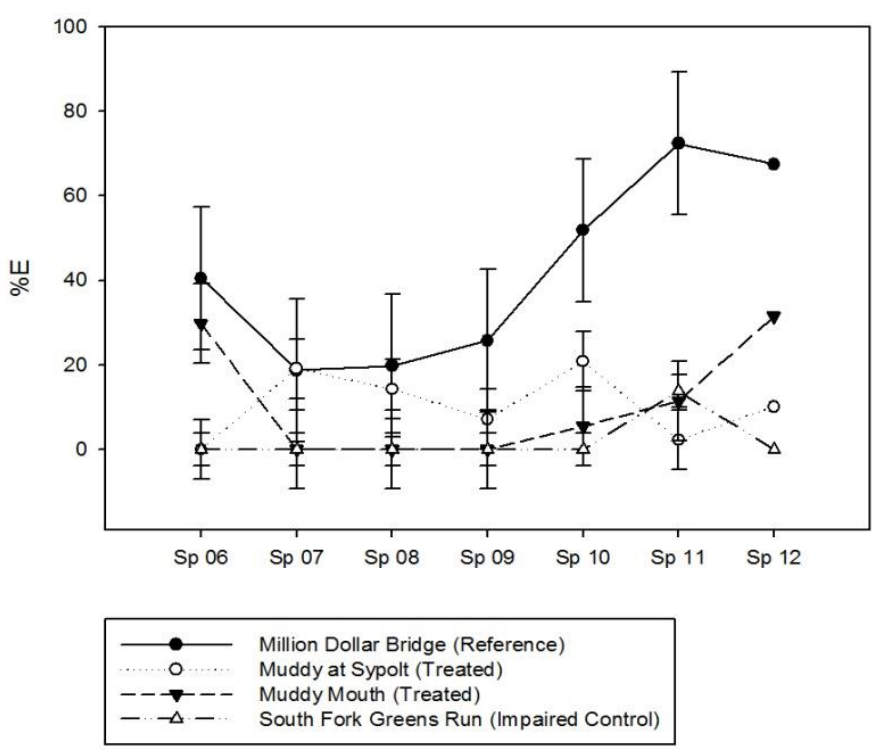

Figure 9. West Virginia Stream Condition Index (WVSCI) scores (a), the number of families within the orders Ephemeroptera, Plecoptera, and Trichoptera (b), the total number of families within each assemblage (c), and percent of the assemblage comprised of Ephemeroptera (d) for a reference site, two treated sites, and an impaired, untreated control site. Error bars represent pretreatment $95 \%$ confidence intervals about the mean for each parameter. The horizontal line in (a) represents the impairment threshold for WVSCI (68.0) (Gerritsen et al. 2000). 


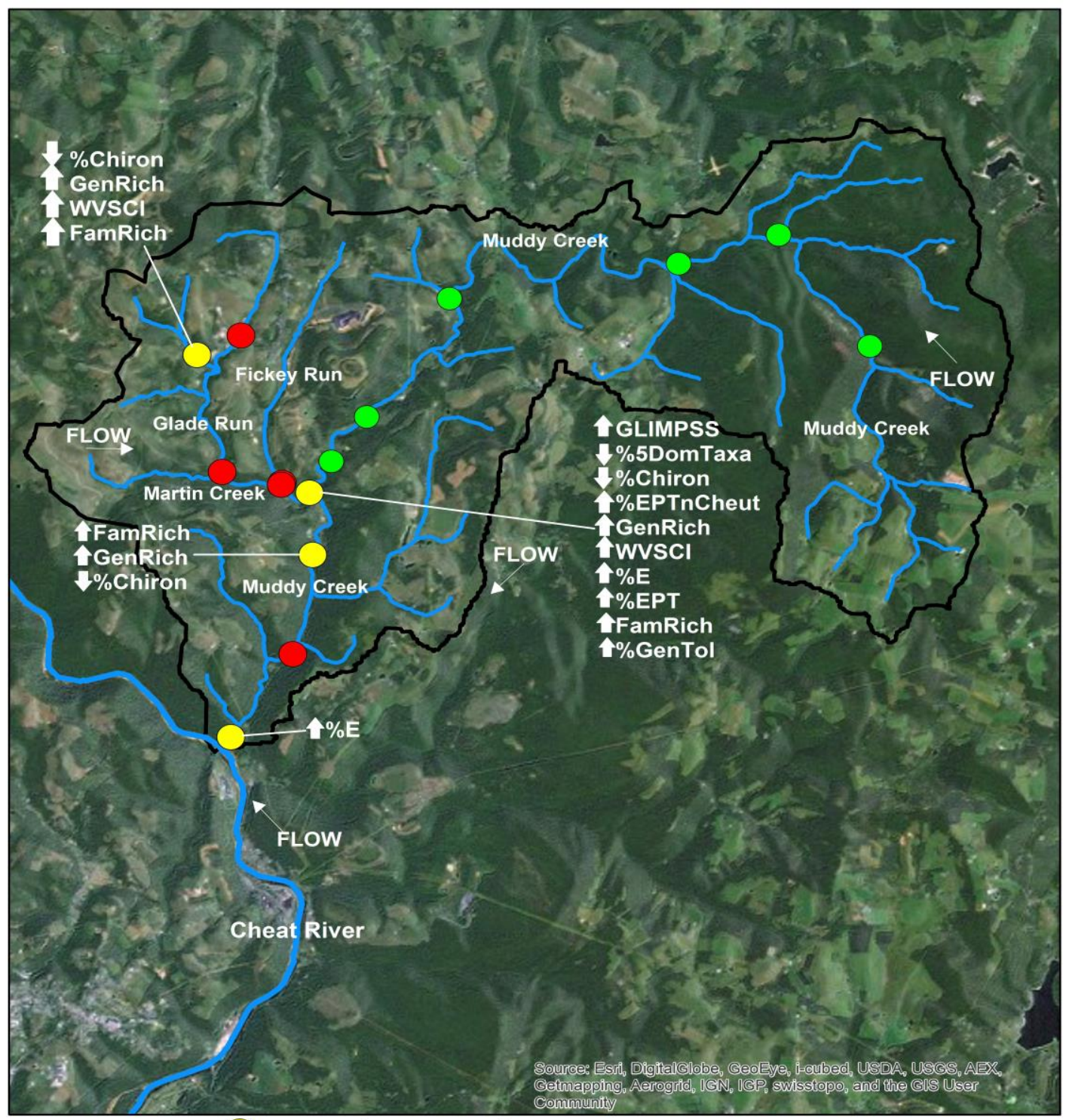

Treated Sites with IBI Lift

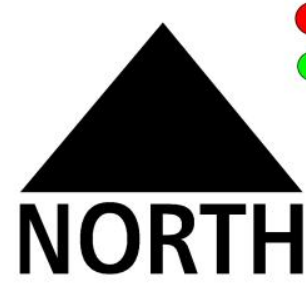

Treated Invertebrate and Water Chemistry Sampling Stations

Invertebrate and Water Chemistry Sampling Stations

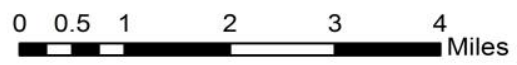

Stream Layer is 1:24K NHD Dataset Basemap is Provided by BING 2013 Data Projected in NAD83 17N

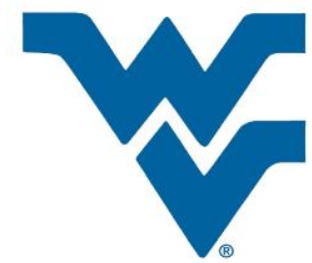

Figure 10. Improvements in GLIMPSS and WVSCI bio-indices from pre-to post- treatment labeled by study location. 

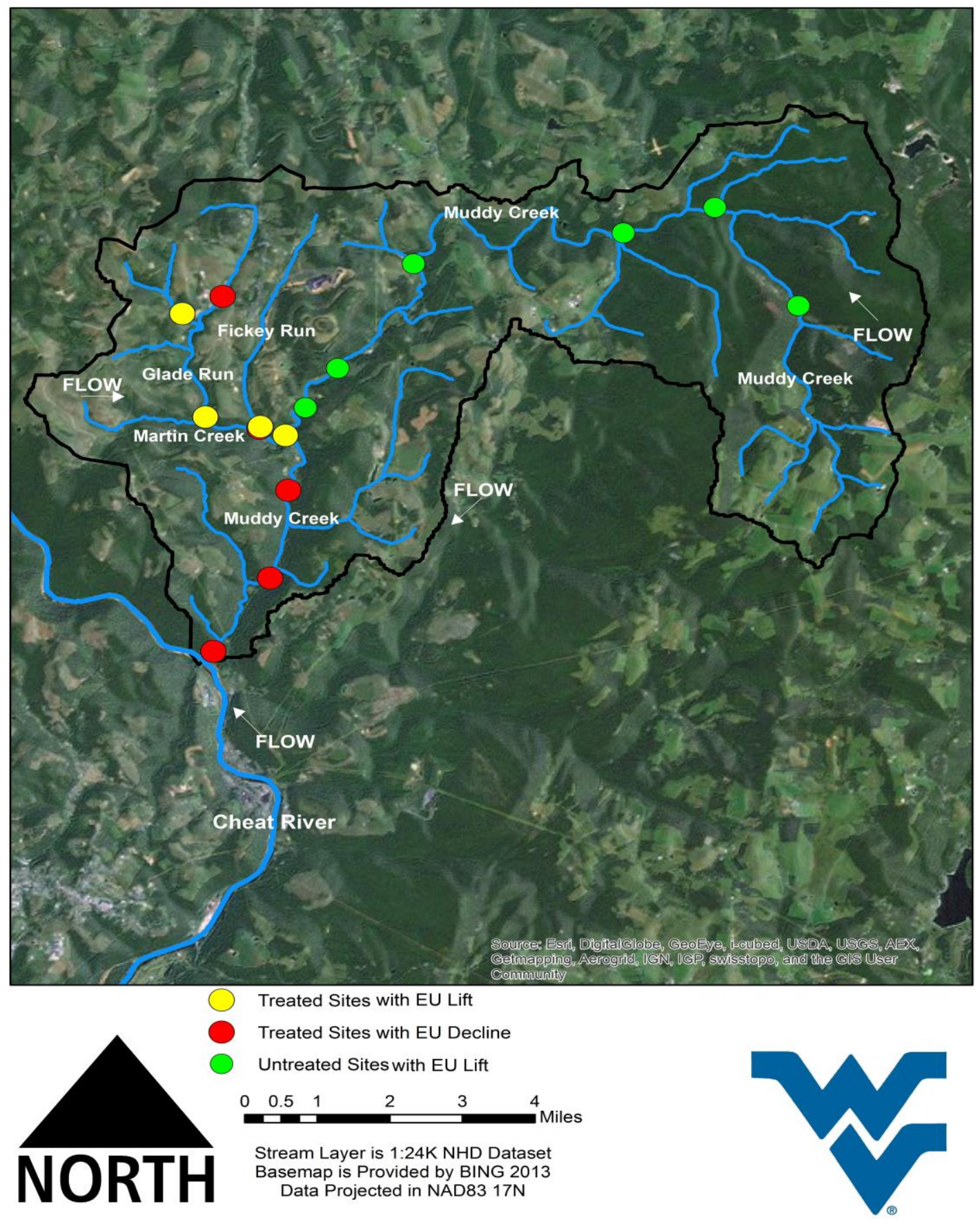

Figure 11. Map of study locations within the Muddy Creek watershed and their corresponding ecological unit response from pre- to post- treatment. 


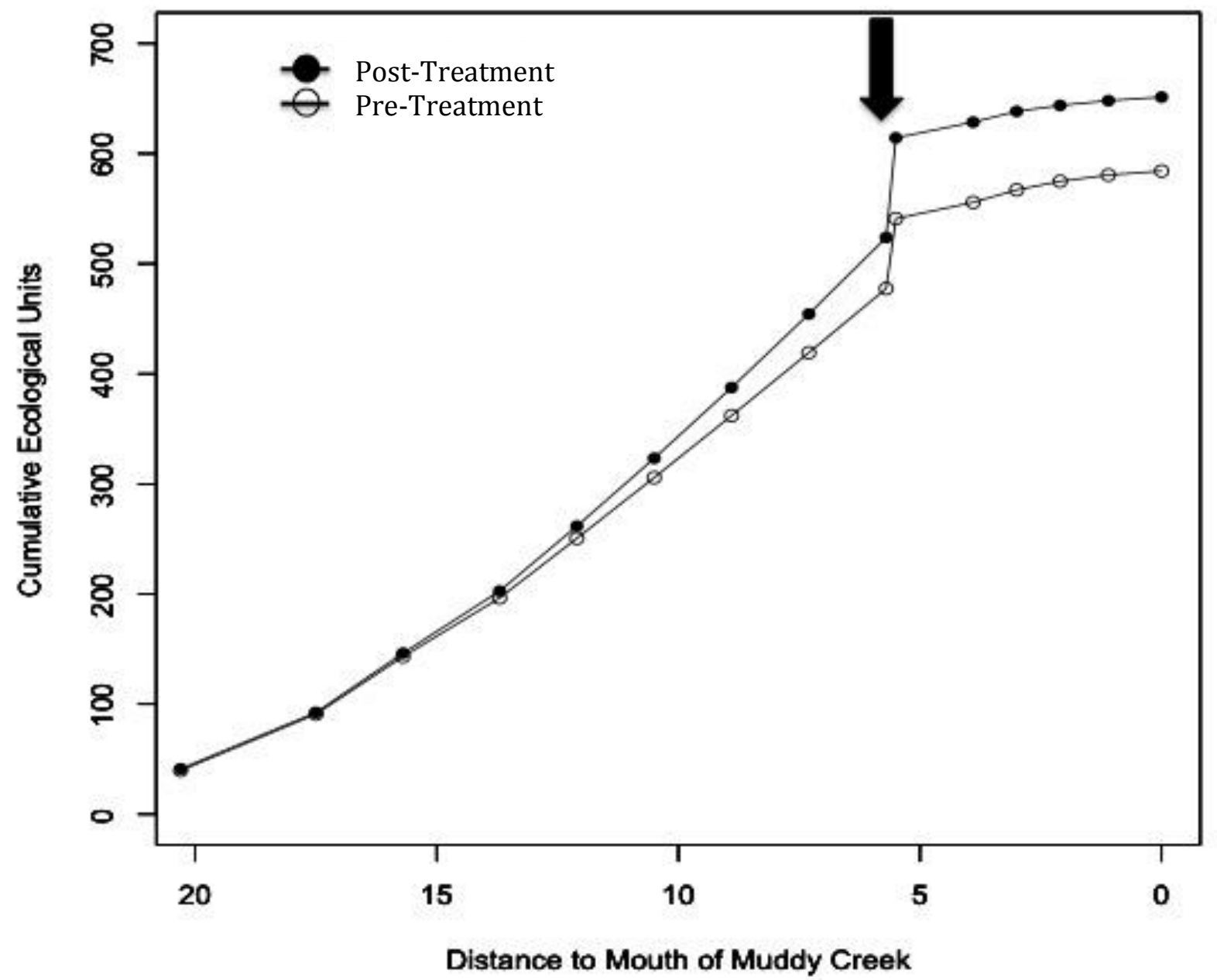

Figure 12. Ecological units are accumulated across the entire Muddy Creek watershed from headwaters to mouth and displayed how they accumulate along the Muddy Creek mainstem from pre to post-treatment. Distance is given in kilometers $(\mathrm{km})$. The vertical black arrow indicates the point at which Martin Creek enters Muddy Creek. 


\title{
Chapter 2: Water chemistry and benthic macroinvertebrate assemblage stability within an Appalachian, AMD fragmented watershed
}

\begin{abstract}
Acid mine drainage (AMD) currently impairs nearly 2,000 stream miles in West Virginia, United States (Nutter et al 2002). The acidic, heavy metal ridden water in this region of the United States can devastate freshwater organisms and habitats. Our study area was mostly comprised of a HUC-12, AMD fragmented, sub-watershed of the Lower Cheat Basin in Northeastern West Virginia. First, we sought to quantify and describe the water chemistry conditions that existed across the watershed over our 7-year study, and then relate the observed temporal trends and stability in environmental condition to benthic macroinvertebrate community stability. We found three distinct AMD water quality types within our study area, and utilized measures of dissimilarity to evaluate abiotic and biotic stability over seven years within the three types. Analysis revealed that moderate AMD impaired reaches exhibited moderately consistent water chemistry conditions while also exhibiting the most temporally dissimilar benthic macroinvertebrate assemblages. Reaches that were unimpaired by AMD exhibited highly stable water chemistry conditions while also exhibiting moderately stable benthic macroinvertebrate assemblages. Finally, reaches with severe AMD impairment had unstable water chemistry conditions while exhibiting the most stable benthic macroinvertebrate assemblages. These results seem to follow findings associated with the intermediate disturbance hypothesis. However, multiple metacommunity processes are also likely contributing to the patterns of community stability observed across water quality types. We suggest that within a drainage network, patterns of biodiversity pointing to the intermediate disturbance hypothesis may actually be result of metacommunity processes and arrangement.
\end{abstract}




\section{Keywords: Benthic macroinvertebrates, water chemistry, stability, acid mine drainage, diversity, disturbance, metacommunity.}

\section{Introduction}

Diversity has long been used as a descriptor of how complex an ecological community is. It is primarily comprised of the richness (number of species) and evenness (relative abundance) of species that comprise a community (Hayek and Buzas 2010). The diversity of species within a system is a strong indicator of environmental quality, and many studies show that high diversity is an indicator of environmental health (Walter et al. 2012). For example, McCormick et al. (2001) developed an index of biotic integrity (IBI) utilizing fish community data to evaluate the health and condition of freshwater streams in the Mid-Atlantic Highlands region. In addition, Gerritsen et al. (1999) developed an IBI around benthic macroinvertebrate assemblages in West Virginia to assess freshwater stream condition. In both of these IBIs, high species diversity is valued in describing healthy environments. Frequently, these metrics are also used to evaluate biological response to a disturbance or land use (Freund and Petty 2007, Merriam et al. 2011). Recent research suggests that the relationship between diversity and disturbance is highly dependent, not only on the type of disturbance, but also the intensity and frequency of the disturbance (Hall et al. 2012). Often results support a negative correlation between the two such that increased disturbance results in decreased diversity (Limberger and Wickham 2012). Other studies have supported a unimodal diversity-disturbance curve in which moderate or intermediate levels of disturbance result in the greatest diversity (Connell 1978, Lake 2000). 
Three measures of diversity at various spatial scales are commonly used to evaluate diversity of a community. These are alpha $(\alpha)$ : the number of species in a specific habitat, beta $(\beta)$ : the variation in species between spatially separate habitat types, and gamma $(\gamma)$ diversity: the total number of species in a region of multiple habitats (Heino 2011).

Community stability is another attribute of communities that has intrigued ecologists for a long time. Grimm and Wissel (1997) present over 163 definitions of stability from 70 different stability concepts. The most regularly used are constancy, resilience, persistence, resistance, and elasticity. Constancy, resilience, and resistance of species richness and evenness, are regularly used to describe ecological or community stability over time (Grimm and Wissel 1997, Yang et al. 2012). How similar or dissimilar biological communities are over time (constancy and resilience) can be used to provide insight into how a disturbance impacts diversity and ecological stability (resistance) (Maloney et al. 2011). Thébault and Loreau (2005) describe diversity as an insurance policy for ecosystem processes in the event of a disturbance. In addition, other researchers present that a disturbance can have compounding negative effects on diversity at multiple trophic levels along a river continuum (Vannote et al 1980, Woodward and Hildrew 2012). Further, other research has shown that increased diversity corresponds with increased ecological and community stability (Tilman 1996, Tilman 1999, Hector et al 2010, Cadotte et al 2012). Researchers often utilize dissimilarity measurements regularly to quantify a community's response to perturbations over time (Limberger and Wickham 2012).

In this study, we examined stability patterns in stream benthic macroinvertebrates communities. To our knowledge there has been no previous research examining these patterns relative to water quality impairment associated with the effects of acid mine drainage from coal mining. Therefore, we sought to classify the water quality disturbance gradient by intensity and 
then relate this impairment to community stability. Furthermore, we measured community stability in a novel way by using beta diversity on a long-term dataset of sites across varying levels of AMD impairment. Traditionally, beta diversity is evaluated as change in taxonomic composition from one habitat to the next across space. We chose to analyze change at single locations across time. Therefore, this temporal approach to beta diversity was used to describe community stability at multiple locations with various abiotic conditions. We also used it as a response variable to water quality variability. Using a long-term dataset comprising survey data on water chemistry and benthic macroinvertebrates assemblages in a severely impacted AMD watershed our objectives were to: (1) classify water chemistry conditions, and (2) quantify and relate stability in water chemistry to benthic macroinvertebrate community stability.

\section{Methods}

Study Area

Our study area consisted of the Muddy Creek, Roaring Creek, and Daugherty Run watersheds located within the Lower Cheat River basin in Preston County, West Virginia. This area is dominated by mountain hardwood forest, primarily hemlock and oak. These watersheds are entirely rural and/or forested, with little residential development. The geology of the basins and surrounding area is comprised of Pennsylvanian, Mississipian, and Devonian aged sedimentary rocks. Coal is found only in the Pennsylvanian strata, of which the Allegheny formation has been primarily mined. This formation has little capability to neutralize acidity produced from surrounding sulfur geology (Merovich et al. 2007). Water chemistry conditions in Muddy Creek vary longitudinally and laterally across the watershed. Along the Muddy Creek mainstem and across its headwaters, water chemistry varies from near pristine to severe AMD 
impairment. Previous studies have shown that within the larger Cheat River basin, AMD from abandoned mine lands is the limiting factor to water quality and healthy biological communities (Petty and Thorne 2005, Merovich et al. 2007). On the other hand, the Roaring Creek and Daugherty Run watersheds are unaffected by AMD and support healthy trout fisheries and diverse benthic macroinvertebrate communities.

\section{Data Collection}

We sampled water chemistry, physical habitat, and benthic macroinvertebrate assemblages at 25 stream locations from 2006 to 2011. Benthic macroinvertebrate samples were collected during the months of April or May by following the Environmental Protection Agency's rapid bioassessment protocols for wadeable streams and rivers (Barbour et al. 1999). At every study site, four kick samples (net dimensions 355 x $508 \mathrm{~mm}$ with $500 \mu \mathrm{m}$ mesh) were gathered from widely separated riffle habitat $(1 \mathrm{~m} \mathrm{x} 1 \mathrm{~m})$ and were combined into a single composite sample. Samples were preserved in $95 \%$ ethanol. In the lab, each composite sample was initially filtered through a $2-\mathrm{mm}$ sieve mounted on a $0.25-\mathrm{mm}$ sieve. All organisms retained by the $2-\mathrm{mm}$ sieve were identified. All organisms retained by the 0.25 -mm sieve were suspended in water and were sub-sampled with a Folsom plankton splitter (Model Number 1831F10, Wildco Supply Company, Buffalo, NY), and individuals from 1/8th of the total water volume were identified. We used Peckarsky et al. (1990) and Merritt and Cummins (2008) to identify individuals to the lowest possible taxonomic resolution, usually Genus level, with the exception the family Chironomidae, and sub-class Oligochaeta. 
Watershed-scale water quality monitoring took place at the same time as benthic macroinvertebrate sampling. Stream water was measured in the field for $\mathrm{pH}(\mathrm{SU})$, temperature $\left({ }^{\circ} \mathrm{C}\right)$, dissolved oxygen $(\mathrm{ppm})$, specific conductance $(\mu \mathrm{S} / \mathrm{cm})$, and total dissolved solids $(\mathrm{g} / \mathrm{L})$ during each visit using a YSI 650 unit with a 600XL sonde or a YSI 556 multi-parameter probe (Yellow Springs Instruments, Yellow Springs, OH, USA). Stream discharge was measured using the area-velocity technique with a Marsh-McBirney Flo-Mate 2000 flow meter (MarshMcBirney, Frederick, MD). Additionally, grab water samples were collected at each site and stored on ice until analysis at the National Research Center for Coal and Energy at West Virginia University. Raw water was analyzed at the labs for general water chemistry including hot acidity, alkalinity, $\mathrm{pH}$, conductivity, and sulfate. Grab samples filter with a 0.45 micrometer and acidified to $\mathrm{pH}$ of $<2$ with concentrated nitric acid were analyzed for dissolved $\mathrm{Al}, \mathrm{Ba}, \mathrm{Cd}, \mathrm{Ca}$, chloride, $\mathrm{Cr}, \mathrm{Co}, \mathrm{Cu}, \mathrm{Fe}, \mathrm{Mg}, \mathrm{Mn}, \mathrm{Ni}, \mathrm{Na}$, and $\mathrm{Zn}$ concentrations (mg/L). Total metal concentrations were used over the dissolved counterpart were applicable in all data analyses. Water and benthic macroinvertebrates were sampled over a range of conditions. Multiple sites were sampled over time to accurately capture and represent regional abiotic and biotic conditions without impairment, under severe impairment, and under moderate impairment scenarios.

\section{Data Analysis}

In order to classify water chemistry conditions, we summarized water chemistry data across our study locations first by performing principal component analysis (PCA). Water chemistry variables were either $\log$ or $\log +1$ transformed in order to meet the assumption that parameters are normally distributed in order to perform PCA. PCA was used to find the water chemistry variables most responsible for variation across sites. Those variables with factor 
loadings on principal component 1 (PC 1) and/or principal component 2 (PC 2) $\geq|0.4|$ were then used to differentiate and classify three levels of AMD impairment. The number of principal components was chosen based on the cumulative percent of variation in the water chemistry dataset captured by the axes. Mean observation values for each water chemistry variable with a factor loading $\geq|0.4|$ were then gathered for each study location. We then used cluster analysis (CA) to cluster study locations based on those water chemistry variables, or degree of AMD impairment. Euclidean distance values between each pairwise comparison of sites using Ward's Linkage Method was used to cluster sites by water chemistry. Study locations grouped together based on similar water chemistry and were assigned a degree of AMD impairment based on a priori knowledge of grouped sites. One of the following three groups was assigned to each study location: "R" for reference condition, "I" for intermediate or moderate impairment, and " $\mathrm{A}$ " for severe AMD impairment.

In order to quantify and relate stability in water chemistry to benthic macroinvertebrate community stability, we calculated measures of distance to estimate the stability of benthic macroinvertebrate assemblages and water chemistry collected in the spring for each site over seven years. For the biotic data we utilized the Bray-Curtis metric of distance and for the abiotic data we utilized the Euclidean distance measurement. Distance measurements were calculated for each site, comparing data across years. The biotic (Bray-Curtis) and abiotic (Euclidean Distance) measurements were then averaged for each study location across time. These mean values were used as measures of community and water chemistry stability at each study location. We also employed non-metric multidimensional scaling (NMDS) to visualize assemblage differences between clustered groups and study sites in distance ordination space. PCA was used in this same manner with the water chemistry dataset. 
To relate assemblage stability to water chemistry stability we extracted PC 1 from our PCA and plotted it with our mean Bray-Curtis and Euclidean distance values for each study location. These plots were able to demonstrate how community stability changed with degree of AMD impairment. It also allowed us to visualize how water chemistry stability changed with degree of AMD impairment. We also utilized classification and regression tree analysis (CART) to find which water chemistry parameters were responsible for classifying degrees of AMD impairment, and therefore patterns in biotic and abiotic stability. Finally, we used non-parametric multivariate analysis of variance to further analyze our dataset report on the significance of differences in community and water chemistry data between degrees of AMD impairment (Cluster Groups : A, I, and R). We used 999 randomized permutations in order to confirm differences among our water quality types. Multiple pairwise posthoc ADONIS tests were then conducted to find specific differences in water chemistry and benthic macroinvertebrate assemblages between each combination of cluster groups. We used the R Environment for all data analyses (R Development Core Team 2013).

\section{Results}

We found water chemistry across our study sites to be highly variable. Dissolved metals, sulfate, and acidity were extremely elevated at AMD impaired sites, while $\mathrm{pH}$ was circumneutral and dissolved metals were un-detectable at reference sites (Table 1 and Table 2). PCA found four significant dimensions of variation in the water chemistry data, however the first two (PC 1 and PC 2) accounted for $65 \%$ of the variation in the water chemistry dataset. PC 1 is defined by increasing $\mathrm{pH}$ and alkalinity to the right and increasing acidity, specific conductance, 
aluminum, calcium, chloride, cobalt, iron, magnesium, nickel, zinc, sulfates $\left(\mathrm{SO}_{4}{ }^{2-}\right)$, and total dissolved solids (TDS) to the left.

Cluster analysis revealed three distinct degrees of AMD impairment that separated along this AMD impairment gradient (PC 1). We classified these degrees of AMD impairment as reference "R", intermediate AMD impairment "I", and AMD impaired "A". Out of the 25 study locations, twelve were classified as R-type sites, six were classified as I-type sites, and seven were classified as A-type sites.

The plot of PC1 scores with stability of water chemistry (Figure 2) shows that as AMD impairment increases (left side of PC 1), water chemistry stability decreases. In the positive direction along PC 1, average Euclidean distance values decrease indicating less temporal variation and increased stability as water quality improves. Further, as AMD impairment increases (move from right to left along PC 1) benthic macroinvertebrate assemblage stability takes a unimodal pattern (Figure 3). Benthic macroinvertebrate assemblages are least stable with I-type sites, and most stable with A-type and R-type sites.

In regard to water chemistry, R-type sites are the most stable year-to-year with a Euclidean mean distance value of 117.79. A-type sites are the least stable year-to-year, with a Euclidean mean distance value of 504.85, and I-type sites fall between the other two cluster groups as being moderately stable with a Euclidean mean distance value of 329.98 (Table 4). Euclidean distance values closer to 0 indicate a more stable environment, while higher values indicate an unstable, highly variable environment.

While A-type sites exhibited the most unstable water chemistry over the 7-year study, they generally exhibited the most stable year-to-year benthic macroinvertebrate assemblages with a mean Bray-Curtis distance value of 0.66. While I-type sites had relatively stable water 
chemistry over the 7-year study, they had the most unstable benthic macroinvertebrate assemblages with a group mean Bray-Curtis distance value of 0.80. In addition, R-type sites had the most stable water chemistry year-to-year and their respective benthic macroinvertebrate assemblages ranged evenly from relatively stable to relatively unstable year-to-year with a mean group Bray-Curtis distance value of 0.76 (Table 5). In addition, Table 6, Figure 4, and Figure 5 display mean Euclidean distance values for water chemistry and mean Bray-Curtis values for benthic macroinvertebrate assemblages associated with each classified degree of AMD impairment, as well as within group, between group, and overall dissimilarity values. A-type sites exhibited the most stable benthic macroinvertebrate assemblages but the most unstable water chemistry.

Differences in water chemistry variables and benthic macroinvertebrate assemblages were found to be statistically significant between clustered degrees of AMD impairment (Table 7). Multiple posthoc analyses were performed to examine pairwise differences in chemical and assemblage data between water chemistry cluster groups. We see statistically significant differences in all pairwise comparisons of cluster groups in regard to water chemistry (Table 8) and benthic macroinvertebrate assemblages (Table 9). All water chemistry clustered groupings are significantly different with regard to individual water chemistry parameters and benthic macroinvertebrate community assemblages. The PCA plot and the distinct separating of clustered groups in NMDS ordination help visualize the significant differences observed with varying degree of AMD impairment (Figure 6). Benthic macroinvertebrates were especially diverse in R-type reaches and R-type and A-type were distinctly different from each other. As expected I-type sites were the only site type to overlap with R-type and A-type sites in both PCA 
and NMDS space. This essentially means that I-type sites are occasionally similar in water chemistry and benthic macroinvertebrate assemblage structure to A-type and R-type sites.

With benthic macroinvertebrate community stability described for each water chemistry clustered group, we were then interested in what AMD constituents were driving benthic macroinvertebrate assemblage stability and associated with water chemistry stability. All R-type reaches in our study area separate out with a specific conductance $<338.5 \mu \mathrm{S} / \mathrm{cm}$ (Figure 7 ). Once conductivity increases above $338.5 \mu \mathrm{S} / \mathrm{cm}$ then water chemistry became less stable. Figure 6 shows most of our I-type reaches (38 of 42 I-type reach observations) being those with specific conductance $>338.5 \mu \mathrm{S} / \mathrm{cm}$, cobalt $(\mathrm{Co})<0.1495 \mathrm{mg} / \mathrm{L}$, calcium $(\mathrm{Ca})<79.27 \mathrm{mg} / \mathrm{L}$, and chloride $(\mathrm{Cl})<11.86 \mathrm{mg} / \mathrm{L}$. These were also found to be important factors in defining variation between sites with PCA. A-type reaches are scattered across our terminal leaves in CART analysis with most (38 of 48 A-type reach observations) being those with specific conductance $>$ $338.5 \mu \mathrm{S} / \mathrm{cm}$, TDS $>0.6105 \mathrm{~g} / \mathrm{L}$, manganese $(\mathrm{Mn})<8.6 \mathrm{mg} / \mathrm{L}$, and barium $(\mathrm{Ba})>0.01 \mathrm{mg} / \mathrm{L}$. Atype sites were found to be associated with increases in specific conductance, TDS, and Mn, while increases in Ba where found to separate I-type from A-type sites.

\section{Discussion and Conclusions}

In this study we were able to use long term benthic macroinvertebrate and water chemistry data to show that abiotic and biotic stability varied by degree of AMD impairment. Generally, water chemistry was most stable when AMD was not present. When AMD was present and impairment became more severe, water chemistry became increasingly unstable. However, benthic macroinvertebrate communities were most unstable within I-type study sites, and were relatively stable at A-type and R-type sites. Therefore, we identified a unimodal 
distribution of community stability along a gradient of AMD impairment. We measured stability in a novel way by using distance measures to define temporal diversity over a 6 -year period. We interpreted PC 1 as a gradient of AMD impairment. When we overlay the degree of AMD impairment assigned during CA we see that A-type, I-type, and R-type sites separate relatively cleanly along this AMD gradient, confirming CA was successful in defining groups based on water chemistry and parameters that defined groups were those strongly influenced by the presence/absence of AMD.

At R-type sites, water chemistry represented the best of the region. These sites were brook trout fisheries that met all water quality standards and had very rich benthic macroinvertebrate assemblages. A-type sites fluctuated in regard to water chemistry stability more so than R-type reaches but remained in an area of the impairment gradient that was unable to support most aquatic life. Finally, I-type sites were essentially a mix of R-type and A-type water. Despite these patterns in environmental conditions, we found that the temporal diversity of invertebrate communities was greatest at I-type sites. Several mechanisms can be invoked in order to possibly explain the unimodal diversity pattern observed across our disturbance gradient.

Some possible reasons for the temporal patterns found in our study include limited dispersal, taxa specific dispersal patterns/histories (i.e. drift behavior and aerial migration), watershed structure, and low interspecific competition. For example, Capers et al. (2010) found that aquatic plant communities were dissimilar even when environmental conditions were similar, indicating that species-specific dispersal abilities may have a larger influence on community structure than environmental conditions. Further, Matthiessen et al. (2010) presented that limited dispersal between metacommunities exposed to an environmental gradient can 
actually increase diversity by reducing influence of regionally superior taxa. In addition, Brown et al. (2011) showed that the physical structure of the watershed, the interconnectedness of habitats, and their connectivity to regional species' pools strongly influence observed patterns in diversity and aquatic assemblages. Finally, Johnson and Arunachalam, (2012) found that feeding specializations strongly influenced assemblage structure in regionally diverse fish communities. Our findings could have also been the result of temporal patchiness in the metacommunity. In fact, when studying the relationship between diversity and stability over time, Mykra et al. (2011) found that variation in abiotic conditions could result in a temporal checkerboard, i.e., low stability over time (high Bray-Curtis dissimilarity at a location over time). Our results could support I-type reaches creating temporally checkered communities rather than temporally diverse communities, as in Mykra et al. (2011). We did find I-type sites to have moderately unstable, or variable, water chemistry relative to R-type sites indicating that the diversity of the invertebrate community could be limited simply due to their sensitivity to environmental perturbation. In addition, Leibold et al. (2004) suggests source-sink dynamics as a cause for higher diversity in areas of impaired or poor habitats. In this example, I-type sites could be acting as a sink and "mixer" of A-type and R-type assemblages in which generalists and specialists co-exist. Previous research has also shown that local disturbances can temporarily increase the traditional definition (i.e., spatial reference) of beta diversity in that separate habitats become more dissimilar due to a disturbances effect on a local community (Limberger and Wickham 2012). If this is true, disturbances such as an AMD source could increase diversity temporally (i.e., our temporal approach to beta diversity), especially if the disturbance was highly variable in intensity over time, which we have shown could be true. 
The overall pattern we saw in benthic macroinvertebrate community stability over 6 years is similar to predictions of the intermediate disturbance hypothesis. This hypothesis maintains that the highest levels of bio-diversity are found in environments with intermediate levels of disturbance (Connell 1978). This is primarily due to the fact that competitive and opportunistic species can co-exist, which would not occur under undisturbed conditions where interspecific competition controls assemblage structure, or in highly disturbed environments where all species are impacted negatively. The fact that most I-type sites were downstream of R-type and A-type sites, essentially a true result of A-type and R-type mixing, leads us to believe the intermediate disturbance hypothesis can explain our observed patterns in temporal diversity along our impairment gradient. Spatial processes such as mass effects are most likely allowing I-type sites to act as a sink for specialists colonizing from source R-type sites upstream, as well as providing adequate habitat for generalists colonizing from upstream A-type sites. In addition, we also see a distinct separation in community stability between R-type and A-type sites. We see that benthic macroinvertebrate communities within R-type sites are more temporally unstable than benthic macroinvertebrates in A-type sites. This finding seems to support the theory that the most fragile communities, or those expected to experience greatest temporal instability, are those that exist within predictable environments (stable water chemistry) (Fjeldsá and Lovett 1997). This is primarily due to communities being dependent on the stability of their environment. If any change in abiotic stability occurred, the community within would be altered and in some cases be unable to rebound. In another sense our findings also support the ecological theory that the more complex or diverse a community is, the more unstable it is (May 1978). Recent research however, has refuted this and actually suggests that increases in species diversity and species' interactions results in a more stable biological community (Mougi and Kondoh 2012). The fact 
that our impaired sites were so void of life and assemblages collected were so simple is most likely the reason we found A-type sites to have the greatest stability/ lowest temporal diversity. The relationship between diversity and stability has long been studied and ecological community stability can be interpreted and studied in various ways. Donohue et al. (2013) presented separate components that define ecological stability (variability, resistance, resilience, persistence, and robustness) and they are interrelated. Studies that examine a perturbation on an ecological community, and focus on only one or two of these measures should be able to confidently discuss the disturbances' effect on ecological stability. In this study we considered taxonomic variability over a 6-year time frame as a surrogate and accurate representation of ecological stability. This assumes that with loss in taxa completeness comes loss in ecological processes and function.

However, if we were to consider membership into benthic macroinvertebrate functional feeding groups or guilds rather than taxonomy, we may find the insurance hypothesis to hold true rather than the intermediate disturbance hypothesis. This insurance hypothesis maintains that the richest communities (R-type) are the most ecologically stable due to the increased likelihood of functional redundancy (Pillar et al. 2013). These communities may experience a high degree of taxonomic change due to a number of reasons previously explored: inherent life histories, metacommunity dynamics, or seasonal/annual fluctuation in water chemistry. However, despite taxonomic variability, the communities will remain highly functional and ecologically stable. Examining community stability over multiple years could be used to evaluate the progress or success of AMD remediation efforts aimed to restore biotic communities and ecological processes usually lost with degraded water quality (Palmer et al. 1997). However, we still found impaired sites to exhibit the greatest temporal diversity over time. Therefore, examining for high 
beta diversity may not accurately represent ideal ecological condition. We speculate in our I-type sites that the intermediate disturbance hypothesis accurately explains the high dissimilarity observed. Year-to-year variability is most likely a result of mass effects, or a source-sink relationship between R-type and I-type sites, as well as colonization of I-type sites by generalists that are successful in A-type sites. Our variability in water chemistry at A-type sites is most likely determining any variability at I-type sites and further increasing temporal dissimilarity at these downstream, intermediate AMD sites.

\section{Literature Cited}

Barbour, M.T., J. Gerritsen, B.D. Snyder, and J.B. Stribling. 1999. Rapid Bioassessment Protocols for Use in Streams and Wadeable Rivers: Periphyton, Benthic Macroinvertebrates and Fish, Second Edition. EPA 841-B-99-002. U.S. Environmental Protection Agency; Office of Water; Washington, D.C.

Brown, B.L., C.M. Swan, D.A. Auerbach, E.H. Campbell Grant, N.P. Hitt, K.O. Maloney, C.Patrick. 2011. Metacommunity theory as a multispecies, multiscale framework for studying the influence of river network structure on riverine communities and ecosystems. J.N. Am. Bentol. Soc. 30: 319 -327.

Cadotte, M.C., R. Dinnage, and D. Tilman. 2012. Phylogenetic diversity promotes ecosystem stability. Ecology. 93: S223 - S233. 
Capers, R. S., Selsky, R., Bugbee, G. J. 2010. The relative importance of local conditions and regional processes in structuring aquatic plant communities. Freshwater Biology 55, 952966

Connell, J.H. 1978. Diversity in tropical rain forests and coral reefs. Science. 199: $1302-1310$.

Donohue, I., O.L. Petchey, J.M. Montoya, A.L. Jackson, L. McNally, M. Viana, K. Healy, M. Lurgi, N.E. O'Connor, and M.C. Emmerson. 2013. On the dimensionality of ecological stability. Ecology Letters 16: $421-429$.

Fjeldsá, J. and J.C. Lovett. 1997. Biodiversity and environmental stability. Biodiversity and Conservation. 6: $315-323$.

Freund, J.G. and J.T. Petty. 2007. Response of fish and macroinvertebrate bioassessment indices to water chemistry in a mined Appalachian watershed. Environ Manage 39:707-720

Gerritsen, J., J. Burton, M.T. Barbour. 2000. A stream condition index for West Virginia wadeable streams. Tetra Tech, Inc. Owings Mills, MD. March 28, 2000 (Revised July 21, 2000).

Grimm, V. and C. Wissel. 1997. Babel, or the ecological stability discussions: an inventory and analysis of terminology and a guide for avoiding confusion. Oecologia. 109: $323-334$. 
Hall, A.R., A.D. Miller, H.C. Leggett, S.H. Roxburgh, A. Buckling, and K. Shea. 2012. Diversity -disturbance relationships: frequency and intensity interact. Biology Letters. 8: 768 771.

Hayek, L-A.C., and M.A. Buzas. 2010. Surveying Natural Populations: Quantitative Tools for Assessing Biodiversity. 2nd Edition. Columbia University Press. Copyright 2010 The Smithsonian Institution.

Hector, A., Y. Hautier, P. Saner, L. Wacker, R. Bagchi, J. Joshi, M. Scherer-Lorenzen, E.M. Spehn, E. Bazeley-White, M. Weilenmann, M.C. Caldeira, P.G. Dimitrakopoulos, J.A. Finn, K. Huss-Danell, A. Jumpponen, C.P.H. Mulder, C. Palmborg, J.S. Pereira, A.S.D. Siamantziouras, A.C. Terry, A.Y. Troumbis, B. Schmid, and M. Loreau. 2010. General stabilizing effects of plant diversity on grassland productivitythrough population asynchrony and overyielding. Ecology. 91: $2213-2220$.

Heino, J. 2011. A macroecological perspective of diversity patterns in the freshwater realm. Freshwater Biology. 56:1703-1722.

Johnson, J.A., M. Arunachalam. 2012. Feeding habitat and food partitioning in a stream fish community of Western Ghat, India. Environ Biol Fish. 93:51-60

Lake, P.S. 2000. Disturbance, patchiness, and diversity in streams. Journal of the North American Benthological Society. 19: 573 - 592. 
Leibold, M.A., M. Holyoak, N. Mouquet, P. Amarasekare, J.M. Chase, M.F. Hoopes, R.D. Holt, J.B. Shurin, R. Law, D. Tilman, M. Loreau, and A. Gonzalez. 2004. The metacommunity concept: a framework for multi-scale community ecology. Ecology Letters. 7: 601 - 613 .

Limberger, R. and S.A. Wickham. 2012. Disturbance and diversity at two spatial scales. Oecologia 168: 785-795.

Maloney, K.O., Munguia, P., Mitchell, R.M. 2011. Anthropogenic disturbance and landscape patterns affect diversity patterns of aquatic benthic macroinvertebrates. Journal of the North American Benthological Society. 30:284 - 295.

Matthiessen, B., Mielke, E., Sommer, U. 2010. Dispersal decreases diversity in heterozygous metacommunities by enhancing regional competition. Ecology. 91(7)2022-2033

May, R.M. 1972. Will a large complex system be stable? Nature. 238: 413-414.

Merriam, E., J.T. Petty, G.T. Merovich, Jr., J. Fulton, and M. Strager. 2011. Additive effects of mining and development in a central Appalachian watershed. J. N. Am. Benthol. Soc. 30:399-418

Merritt, R.W., K.W. Cummins, and M.B. Berg. 2008. An Introduction to the Aquatic Insects of North America. Kendall/Hunt Publishing Co., Dubuque, IA. 
Mougi, A. and M. Kondoh. 2012. Diversity of interaction types and ecological community stability. Science. 337: $349-351$.

Mykra, H., J. Heino, J. Oksanen, T. Muotka. 2011. The stability-diversity relationship in stream macroinvertebrates: influences of sampling effects and habitat complexity. Freshwater Biology 56:1122-1132.

Nutter, Jr., R., J. Weese, R. Eades. 2002. West Virginia Streams Impaired by Acid Mine Drainage. Ohio Valley Environmental Coalition.

Palmer, M.A., R.F. Ambrose, N.L. Poff. 1997. Ecological theory and community restoration ecology. Society for Ecological Restoration. 5: $291-300$.

Peckarsky, B.L., P.R. Fraissinet, M.A. Penton, D.J. Conklin, Jr. 1990. Freshwater Macroinvertebrates of Northeastern North America. Cornell Paperback Publishing 1990.

Petty, J.T. and J. Barker. 2004. Water quality variability in tributaries of the Cheat River, a mined Appalachian watershed. Paper presented at the 2004 National Meeting of the American Society of Mining and Reclamation and the $25^{\text {th }}$ West Virginia Surface Mine Drainage Task Force, April 18-24, 2004. Published by ASMR, 3134 Montavesta Rd., Lexington, KY 40502. 
Pillar, V.D., C.C. Blanco, S.C. Müller, E.E. Sosinski, F. Joner, and L.D.S. Duarte. 2013. Functional redundancy and stability in plant communities. Journal of Vegetation Science. 24: $963-974$.

R Development Core Team (2013). R: A language and environment for statistical computing, reference index version 2.2.1. R Foundation for Statistical Computing, Vienna, Austria. ISBN 3-900051-07-0, URL http://www.R-project.org.

Thébault, E. and M. Loreau. 2005. Trophic interactions and the relationship between species diversity and ecosystem stability. The American Naturalist. 166: E95 - E114.

Tilman, D. 1999. The ecological consequences of changes in biodiversity: A search for general principles. Ecology. 80: 1455 - 1474 .

Tilman, D. 1996. Population versus ecosystem stability. Ecology. 77: 350 - 363.

Vannote, R. R., G. W. Minshall, K. W. Cummins, J. R. Sedell, and C. E. Cushing. 1980. The river continuum concept. Canadian Journal of Fisheries and Aquatic Sciences 37: 130-137.

Walter, C.A., Nelson, D., Earle, J.I. 2012. Assessment of stream restoration: sources of variation in macroinvertebrate recovery throughout an 11-year study of coal mine drainage treatment. Restoration Ecology. 20(4):431-440. 
Woodward, G., A.G. Hildrew. 2002. Food web structure in riverine landscapes. Freshwater Biology. 47:777-798.

Yang, S. X. Gao, M. Li, B. Ma, and H. Liu. 2012. Interannual variations of the fish assemblage in the transitional zone of the Three Gorges Reservoir: persistence and stability. Environ Biol Fish 93:295-304. 
Table 1. Mean (standard error) of water chemistry parameters for study sites which received a factor loading $\geq|0.4|$ in PCA. Overall A-type, I-type, and R-type statistics are included at the bottom of the table.

\begin{tabular}{lccccc}
\hline Site & pH & Alk & Acid & SpC & TDS \\
\hline \hline JRR & $5.7(0.4)$ & $5.1(1.5)$ & $58.3(26.3)$ & $45.9(3.3)$ & $0.03(0)$ \\
UGR & $4.2(0.3)$ & $0.1(0.1)$ & $175.7(41.4)$ & $725.7(96.2)$ & $0.5(0.06)$ \\
CZZ & $7.2(0.2)$ & $18.8(1.9)$ & $18.2(14.9)$ & $68.4(2.7)$ & $0.04(0)$ \\
FRM & $3.2(0.3)$ & $0.1(0.1)$ & $426.2(69.6)$ & $1746.7(109.4)$ & $1.1(0.07)$ \\
MJR & $7.1(0.2)$ & $23.5(1.5)$ & $44.5(31.6)$ & $78.7(4.6)$ & $0.1(0.08)$ \\
MTS & $7.2(0.1)$ & $22.9(5.5)$ & $22.8(13.3)$ & $196.4(32.9)$ & $0.1(0.02)$ \\
MAM & $6.2(0.2)$ & $12.0(1.4)$ & $43.1(31.3)$ & $206.3(9.5)$ & $0.1(0.01)$ \\
MDB & $7.2(0.2)$ & $28.1(1.7)$ & $27.2(16.3)$ & $210.4(13.3)$ & $0.1(0.01)$ \\
UUG & $4.4(0.3)$ & $0.2(0.1)$ & $164.7(39.5)$ & $811.4(146.5)$ & $0.4(0.09)$ \\
LUG & $4.3(0.3)$ & $0.1(0.1)$ & $139.3(19.6)$ & $1168.4(131.7)$ & $0.8(0.09)$ \\
GRM & $3.8(0.3)$ & $0.1(0.1)$ & $185.9(31)$ & $1107.7(69.4)$ & $0.7(0.05)$ \\
MGR & $4.9(0.3)$ & $3.2(1.3)$ & $78.3(20.8)$ & $1029(68.9)$ & $0.7(0.04)$ \\
MCO & $4.2(0.3)$ & $0.8(0.7)$ & $94.1(24.6)$ & $589.9(61.9)$ & $0.4(0.04)$ \\
MFR & $3.9(0.2)$ & $0.1(0.1)$ & $151.1(26.3)$ & $1050.4(62.1)$ & $0.7(0.04)$
\end{tabular}




\begin{tabular}{lccccc} 
MCM & $3.4(0.2)$ & $0.1(0.1)$ & $222.5(36)$ & $1207.1(84.5)$ & $0.8(0.05)$ \\
SYP & $7.1(0.2)$ & $39.9(1.8)$ & $15.4(9.9)$ & $450.9(30.8)$ & $0.3(0.02)$ \\
MUM & $5.5(0.4)$ & $2.2(1.1)$ & $91.7(21.6)$ & $561.4(50.2)$ & $0.4(0.03)$ \\
MSR & $5.1(0.3)$ & $2.9(1.7)$ & $81.1(23.6)$ & $579.9(56.5)$ & $0.4(0.04)$ \\
RCM & $6.9(0.1)$ & $15.2(1.2)$ & $22.0(13.1)$ & $135(5.5)$ & $0.1(0)$ \\
SFG & $2.9(0.2)$ & $0.1(0.1)$ & $435.5(87.1)$ & $1307.6(133.1)$ & $0.9(0.09)$ \\
UMC & $7.6(0.3)$ & $29.4(3.6)$ & $1.3(1.2)$ & $104.8(6.1)$ & $0.1(0)$ \\
UUM & $7.4(0.3)$ & $23.1(1.3)$ & $94(94)$ & $106(0)$ & $0.1(0)$ \\
UDC & $7.2(0.2)$ & $15.3(3.7)$ & $36.3(31.0)$ & $73.3(3.2)$ & $0.1(0)$ \\
DRM & $7.4(0.2)$ & $17.3(3.4)$ & $62.1(62.1)$ & $125.5(22.5)$ & $0.1(0.01)$ \\
URC & $7.5(0.2)$ & $24.9(2.8)$ & $35.4(24.8)$ & $75.4(1.6)$ & $0.1(0)$ \\
A-type & $3.8(0.2)$ & $0.6(0.2)$ & $234.1(25.6)$ & $1231(53.5)$ & $0.8(0.03)$ \\
I-type & $5.1(0.2)$ & $7.7(2.3)$ & $103.8(13.9)$ & $619.9(39)$ & $0.4(0.02)$ \\
R-type & $6.9(0.1)$ & $19.6(1.2)$ & $34.1(6.9)$ & $121.2(8.3)$ & $0.1(0.01)$ \\
\hline
\end{tabular}


Table 2. Mean (standard error) of water chemistry parameters for study sites which received a factor loading $\geq|0.4|$ in PCA. Overall A-type, I-type, and R-type statistics are included at the bottom of the table.

\begin{tabular}{|c|c|c|c|c|c|c|c|c|c|c|c|c|}
\hline Site & Al & $\mathbf{B a}$ & $\mathbf{C a}$ & Cl- & Co & $\mathbf{F e}$ & Mg & Mn & $\mathrm{Na}$ & $\mathbf{N i}$ & $\mathbf{Z n}$ & $\mathrm{SO}_{4}{ }^{2}$ \\
\hline JRR & $2.2(1.9)$ & $0.07(0.01)$ & $17.3(14.9)$ & $1.1(0.1)$ & $0.03(0.02)$ & $0.3(0.2)$ & $7.5(6.9)$ & $0.7(0.6)$ & $2.5(1.6)$ & $0.04(0.03)$ & $0.09(0.07)$ & $21.2(8.4)$ \\
\hline UGR & $8.6(2.8)$ & $0.04(0.01)$ & $60.9(15.6)$ & $5.2(0.8)$ & $0.09(0.03)$ & $8.9(6.7)$ & $24.0(3.7)$ & $2.3(0.3)$ & $5.6(2.5)$ & $0.2(0.03)$ & $0.3(0.04)$ & $351.6(53.8)$ \\
\hline $\mathrm{CZZ}$ & $0.1(0.07)$ & $0.07(0.02)$ & $6.6(0.4)$ & $1.3(0.1)$ & $0.03(0.02)$ & $0.1(0.05)$ & $0.9(0.08)$ & $0.07(0.03)$ & $2.1(0.8)$ & $0.04(0.03)$ & $0.04(0.02)$ & $31.6(19.7)$ \\
\hline FRM & $11.5(4.2)$ & $0.06(0.02)$ & $97.4(22.4)$ & $7.0(0.7)$ & $0.08(0.03)$ & $39.7(14.1)$ & $23.9(6.0)$ & $3.7(0.9)$ & $11.6(0.9)$ & $0.2(0.04)$ & $0.4(0.09)$ & $836.4(69.1)$ \\
\hline MJR & $0.1(0.1)$ & $0.05(0.01)$ & $8.2(0.5)$ & $1.4(0.07)$ & $0.01(0)$ & $0.05(0.01)$ & $1.1(0.1)$ & $0.06(0.03)$ & $1.9(0.7)$ & $0.01(0)$ & $0.02(0.01)$ & $30.7(18.5)$ \\
\hline MTS & $0.07(0.02)$ & $0.06(0.01)$ & $19.1(3.9)$ & $1.6(0.1)$ & $0.01(0)$ & $0.1(0.08)$ & $6.8(1.6)$ & $0.1(0.03)$ & $2.5(0.9)$ & $0.01(0)$ & $0.02(0.01)$ & $53.6(13.3)$ \\
\hline MAM & $0.3(0.2)$ & $0.04(0.01)$ & $19.7(1.7)$ & $1.9(0.1)$ & $0.01(0)$ & $0.4(0.3)$ & $6.6(0.6)$ & $0.2(0.03)$ & $2.7(1.1)$ & $0.01(0)$ & $0.03(0.02)$ & $55.4(8.9)$ \\
\hline MDB & $0.07(0.02)$ & $0.06(0.01)$ & $20.0(1.9)$ & $1.9(0.2)$ & $0.01(0)$ & $0.05(0.01)$ & $6.9(0.6)$ & $0.1(0.02)$ & $2.3(0.8)$ & $0.02(0.01)$ & $0.02(0.01)$ & $51.2(7.5)$ \\
\hline UUG & $5.9(1.8)$ & $0.08(0.05)$ & $47.8(8.9)$ & $2.0(0.4)$ & $0.09(0.03)$ & $1.2(0.4)$ & $31.1(6.5)$ & $4.9(1.2)$ & $2.4(0.6)$ & $0.2(0.04)$ & $0.4(0.07)$ & $414.4(87.8)$ \\
\hline LUG & $6(1.5)$ & $0.02(0)$ & $118.8(16.0)$ & $1.1(0.1)$ & $0.1(0.05)$ & $0.8(0.2)$ & $63.5(8.9)$ & $6.4(1.2)$ & $2.9(1.7)$ & $0.2(0.04)$ & $0.4(0.07)$ & $701.4(44.9)$ \\
\hline GRM & $8.1(2.5)$ & $0.03(0.01)$ & $67.1(11.3)$ & $2.9(0.2)$ & $0.09(0.03)$ & $1.4(0.3)$ & $35.0(6.4)$ & $3.9(0.8)$ & $3.6(1.1)$ & $0.2(0.03)$ & $0.3(0.05)$ & $530.3(47.9)$ \\
\hline MGR & $1.3(0.7)$ & $0.06(0.03)$ & $104.1(19.3)$ & $1.1(0.1)$ & $0.08(0.04)$ & $0.3(0.1)$ & $44.3(8.2)$ & $2(0.4)$ & $3.7(1.5)$ & $0.1(0.05)$ & $0.2(0.04)$ & $539.1(33.4)$ \\
\hline $\mathrm{MCO}$ & $3.1(1.1)$ & $0.04(0.01)$ & $41.5(8.1)$ & $2.2(0.1)$ & $0.03(0.01)$ & $3.4(0.7)$ & $14.7(2.9)$ & $1.0(0.2)$ & $3.8(1.5)$ & $0.1(0.02)$ & $0.1(0.02)$ & $257.7(37.1)$ \\
\hline MFR & $6.1(2.0)$ & $0.03(0.01)$ & $78.7(15.3)$ & $2.3(0.1)$ & $0.08(0.02)$ & $0.8(0.2)$ & $37.7(7.7)$ & $3.5(0.8)$ & $3(0.6)$ & $0.1(0.02)$ & $0.3(0.04)$ & $516.6(35.7)$ \\
\hline $\mathrm{MCM}$ & $8.0(2.6)$ & $0.03(0.01)$ & $88.3(18.1)$ & $3.5(0.2)$ & $0.09(0.02)$ & $11.2(2.9)$ & $36.1(7.7)$ & $3.4(0.8)$ & $5.3(0.9)$ & $0.1(0.03)$ & $0.3(0.05)$ & $593.7(54.2)$ \\
\hline SYP & $3.4(3.2)$ & $0.04(0)$ & $47.3(3.8)$ & $1.3(0.1)$ & $0.03(0.02)$ & $17.3(15.7)$ & $15.4(1.4)$ & $0.3(0.2)$ & $3.5(1.4)$ & $0.03(0.02)$ & $0.07(0.05)$ & $165.9(21.8)$ \\
\hline
\end{tabular}




\begin{tabular}{|c|c|c|c|c|c|c|c|c|c|c|c|c|}
\hline MUM & $1.9(0.8)$ & $0.05(0.01)$ & $43.1(8.8)$ & $2.2(0.1)$ & $0.03(0.01)$ & $2.6(0.6)$ & $14.6(3.1)$ & $0.9(0.2)$ & $3.7(1.0)$ & $0.06(0.01)$ & $0.1(0.01)$ & $246.9(34.1)$ \\
\hline MSR & $3(0.9)$ & $0.04(0.01)$ & $49.5(5.1)$ & $2.3(0.2)$ & $0.02(0.01)$ & $3.4(0.7)$ & $17.7(1.8)$ & $1.0(0.1)$ & $3.3(0.6)$ & $0.06(0.01)$ & $0.1(0.02)$ & $240.9(42.3)$ \\
\hline $\mathrm{RCM}$ & $0.04(0.01)$ & $0.05(0.01)$ & $12.7(1.0)$ & $1.8(0.1)$ & $0.01(0)$ & $0.04(0.01)$ & $3.0(0.1)$ & $0.09(0.02)$ & $2.2(0.9)$ & $0.01(0)$ & $0.02(0.01)$ & $34.0(3.0)$ \\
\hline SFG & $7.6(3.2)$ & $0.04(0.01)$ & $24.1(6.7)$ & $12.7(0.6)$ & $0.04(0.01)$ & $31.9(12.9)$ & $7.0(2.1)$ & $1.1(0.3)$ & $6.1(0.5)$ & $0.1(0.02)$ & $0.2(0.04)$ & $474.7(83.7)$ \\
\hline UMC & $0.2(0.1)$ & $0.06(0.02)$ & $19.9(8.8)$ & $1.6(0.1)$ & $0.01(0.01)$ & $0.1(0.08)$ & $4.3(2.8)$ & $0.05(0.01)$ & $2.3(0.9)$ & $0.01(0)$ & $0.03(0.01)$ & $12.2(1.0)$ \\
\hline UUM & $0.2(0.1)$ & $0.16(0.11)$ & $13.3(0.9)$ & $2.3(0.08)$ & $0.1(0.1)$ & $0.1(0.1)$ & $1.1(0.2)$ & $0.1(0.1)$ & $5.3(3.2)$ & $0.1(0.1)$ & $0.1(0.1)$ & $10.5(2.0)$ \\
\hline UDC & $0.1(0.1)$ & $0.06(0.02)$ & $32.8(29.2)$ & $2.2(0.5)$ & $0.02(0)$ & $0.1(0.1)$ & $10.3(9.2)$ & $0.03(0.01)$ & $5.3(3.2)$ & $0.01(0)$ & $0.01(0)$ & 20.7 (6.9) \\
\hline DRM & $0.06(0.01)$ & $0.05(0.01)$ & $16.4(0.3)$ & $2.5(0.4)$ & $0.01(0)$ & $0.04(0.01)$ & $3.0(0.01)$ & $0.01(0)$ & $5.7(3.3)$ & $0.02(0.01)$ & $0.01(0)$ & $18.6(9.8)$ \\
\hline URC & $0.04(0.01)$ & $0.05(0.01)$ & $7.2(1.3)$ & $1.7(0.1)$ & $0.01(0)$ & $0.04(0.01)$ & $0.8(0.1)$ & $0.03(0.01)$ & $2.1(0.5)$ & $0.01(0)$ & $0.04(0.02)$ & $10.6(1.1)$ \\
\hline A-type & $6.9(1.0)$ & $0.04(0.01)$ & $82.7(7.2)$ & $4.3(0.5)$ & $0.08(0.01)$ & $12.3(3.3)$ & $35.3(3.4)$ & $3.4(0.4)$ & $5.2(0.5)$ & $0.1(0.01)$ & $0.3(0.02)$ & $598.9(28.3)$ \\
\hline I-type & $4.3(0.8)$ & $0.05(0.01)$ & $48.3(3.7)$ & $2.6(0.2)$ & $0.05(0.01)$ & $6.1(2.7)$ & $19.6(1.7)$ & $1.7(0.3)$ & $3.7(0.5)$ & $0.09(0.01)$ & $0.2(0.02)$ & $279.6(23.8)$ \\
\hline R-type & $0.3(0.2)$ & $0.06(0)$ & $15.1(2.1)$ & $1.6(0.07)$ & $0.02(0)$ & $0.1(0.04)$ & $4.3(0.8)$ & $0.2(0.06)$ & $2.6(0.3)$ & $0.02(0.01)$ & $0.04(0.01)$ & $31.9(3.8)$ \\
\hline
\end{tabular}


Table 3. Principal component analysis output for PC1-PC4 for $\log +1$ and $\log$ transformed water chemistry data at the 25 sample reaches.

\begin{tabular}{|c|c|c|c|c|}
\hline Variable & $\mathrm{PC} 1$ & $\mathrm{PC} 2$ & PC3 & PC4 \\
\hline Variance explained (\%) & 0.56 & 0.09 & 0.06 & 0.06 \\
\hline Cumulative variance explained (\%) & 0.56 & 0.65 & 0.72 & 0.78 \\
\hline Eigenvalues & 10.02 & 1.77 & 1.16 & 1.12 \\
\hline $\mathrm{pH}$ & 0.86 & 0.37 & -0.01 & 0.01 \\
\hline Alkalinity (Alk) & 0.85 & 0.23 & -0.05 & 0.00 \\
\hline Acidity (Acid) & -0.74 & -0.33 & 0.23 & 0.13 \\
\hline Specific Conductivity (SpC) & -0.89 & -0.21 & 0.09 & -0.15 \\
\hline Aluminum (Al) & -0.77 & 0.17 & -0.13 & 0.11 \\
\hline Barium $(\mathrm{Ba})$ & 0.36 & 0.45 & 0.01 & 0.60 \\
\hline Calcium $(\mathrm{Ca})$ & -0.70 & 0.50 & 0.06 & -0.12 \\
\hline Chlorine $(\mathrm{Cl})$ & -0.53 & -0.44 & -0.35 & 0.42 \\
\hline Cobalt (Co) & -0.54 & 0.46 & -0.85 & 0.49 \\
\hline
\end{tabular}




\begin{tabular}{lcccc} 
Iron (Fe) & -0.84 & 0.10 & -0.09 & 0.08 \\
Magnesium (Mg) & -0.79 & 0.42 & 0.15 & -0.21 \\
Manganese (Mn) & -0.90 & 0.29 & 0.16 & -0.03 \\
Sodium (Na) & -0.46 & -0.06 & -0.66 & 0.19 \\
Nickel (Ni) & -0.88 & 0.19 & -0.04 & 0.05 \\
Zinc (Zn) & -0.87 & 0.26 & -0.07 & 0.05 \\
Sulfates (SO ${ }^{2}$ ) & -0.88 & -0.17 & 0.15 & -0.19 \\
Total Suspended Solids (TSS) & -0.09 & -0.15 & 0.66 & 0.57 \\
Total Dissolved Solids (TDS) & -0.86 & -0.32 & 0.01 & -0.09 \\
\hline
\end{tabular}


Table 4. Mean Euclidean Distance values for water chemistry at each study site across the span of seven years. Sites are sorted from smallest distance (most stable) to largest distance (least stable). $\mathrm{CA}=$ Cluster Analysis.

\begin{tabular}{ccc}
\hline Site Name Abbreviated & CA Group & Mean Euclidean Distance \\
\hline \hline UMC & R & 40.33 \\
RCM & R & 50.98 \\
URC & R & 77.97 \\
CZZ & R & 84.23 \\
MDB & R & 83.48 \\
MAM & R & 110.97 \\
UDC & R & 110.14 \\
JRR & R & 112.95 \\
MJR & R & 133.86 \\
MTS & R & 142.98 \\
DRM & R & 133.96 \\
SYP & $\mathrm{I}$ & 152.22 \\
UUM & R & 188.35
\end{tabular}




\begin{tabular}{lll} 
MUM & I & 218.80 \\
MSR & I & 260.35 \\
MCO & I & 263.10 \\
MFR & A & 279.96 \\
MGR & A & 292.03 \\
GRM & A & 320.38 \\
MCM & A & 363.37 \\
UGR & I & 383.42 \\
LUG & A & 493.68 \\
FRM & A & 520.42 \\
UUG & I & 540.26 \\
SFG & A & 651.73 \\
\hline
\end{tabular}


Table 5. Mean Bray-Curtis Distance values associated with each study site along with its respective classified degree of AMD impairment. Sites are sorted from smallest distance (most stable) to largest distance (least stable). CA = Cluster Analysis.

\begin{tabular}{ccc}
\hline Site Name Abbreviated & CA Group & Mean Bray-Curtis Distance \\
\hline \hline MFR & A & 0.36 \\
DRM & R & 0.36 \\
UGR & I & 0.40 \\
GRM & A & 0.43 \\
MCM & A & 0.43 \\
UUG & I & 0.43 \\
UUM & R & 0.46 \\
LUG & A & 0.48 \\
JRR & R & 0.53 \\
URC & R & 0.54 \\
SFG & A & 0.57 \\
MJR & R & 0.59 \\
CZZ & A & 0.64
\end{tabular}




\begin{tabular}{lll} 
UDC & R & 0.65 \\
RCM & R & 0.66 \\
MAM & R & 0.68 \\
MTS & R & 0.68 \\
MGR & A & 0.68 \\
UMC & R & 0.69 \\
FRM & A & 0.70 \\
MDB & R & 0.71 \\
MCO & I & 0.76 \\
SYP & I & 0.80 \\
MSR & I & 0.80 \\
MUM & I & 0.89 \\
\hline
\end{tabular}


Table 6. Mean Euclidean (water chemistry) and Bray-Curtis (benthic invertebrate genera) distance values for each cluster analysis clustered water chemistry group, as well as within group, between group, and overall distances.

\begin{tabular}{lcc}
\hline & Water Chemistry & Benthic invertebrate genera \\
\hline \hline "A" Type Sites & 404.70 & 0.53 \\
"I" Type Sites & 303.03 & 0.68 \\
"R" Type Sites & 105.85 & 0.60 \\
Within Group & 280.81 & 0.75 \\
Between Groups & 926.12 & 0.84 \\
Overall & 705.11 & 0.81 \\
\hline
\end{tabular}


Table 7. ADONIS output table for tests of significant differences in water chemistry and benthic macroinvertebrate assemblages between water chemistry clustered groups.

\begin{tabular}{|c|c|c|c|c|c|c|}
\hline Terms & df & SS & MSS & F-Model & $\mathrm{R} 2$ & P-Value \\
\hline \multicolumn{7}{|l|}{$\log 1 \mathrm{p}($ Water Chemistry $) \sim$ Cluster } \\
\hline Groups & 2 & 13648.0 & 6824.0 & 138.75 & 0.68 & 0.001 \\
\hline Residuals & 133 & 6541.3 & 49.2 & & 0.32 & \\
\hline Total & 135 & 20189.4 & & & 1.00 & \\
\hline BMI Assemblages $\sim$ Cluster Groups & 2 & 6.46 & 3.23 & 10.86 & 0.14 & 0.001 \\
\hline Residuals & 133 & 39.57 & 0.30 & & 0.86 & \\
\hline Total & 135 & 46.01 & & & 1.00 & \\
\hline
\end{tabular}


Table 8. Post-hoc ADONIS output table for tests of significant differences in water chemistry between each water chemistry clustered group.

\begin{tabular}{|c|c|c|c|c|c|c|}
\hline Terms & df & SS & MSS & F-Model & $\mathrm{R} 2$ & P-Value \\
\hline Reference/Quality - AMD Impaired & 1 & 13087.1 & 13087.1 & 282.75 & 0.74 & 0.001 \\
\hline Residuals & 98 & 4535.9 & 46.3 & & 0.26 & \\
\hline Total & 99 & 17623.1 & & & 1.00 & \\
\hline Reference/Quality - Intermediate AMD & 1 & 4400.7 & 4400.7 & 99.15 & 0.52 & 0.001 \\
\hline Residuals & 92 & 4083.4 & 44.4 & & 0.48 & \\
\hline Total & 93 & 8484.1 & & & 1.00 & \\
\hline AMD Impaired - Intermediate AMD & 1 & 1714.76 & 1714.76 & 29.20 & 0.28 & 0.001 \\
\hline Residuals & 76 & 4463.3 & 58.73 & & 0.72 & \\
\hline Total & 77 & 6178.1 & & & 1.00 & \\
\hline
\end{tabular}


Table 9. Post-hoc ADONIS output table for tests of significant differences in raw benthic macroinvertebrate assemblages between each water chemistry clustered group.

\begin{tabular}{|c|c|c|c|c|c|c|}
\hline Terms & df & SS & MSS & F-Model & $\mathrm{R} 2$ & P-Value \\
\hline Reference/Quality - AMD Impaired & 1 & 5.39 & $\overline{5.39}$ & 19.31 & 0.16 & 0.001 \\
\hline Residuals & 98 & 27.36 & 0.28 & & 0.84 & \\
\hline Total & 99 & 32.75 & & & 1.00 & \\
\hline Reference/Quality - Intermediate AMD & 1 & 2.98 & 2.98 & 9.31 & 0.09 & 0.001 \\
\hline Residuals & 92 & 29.49 & 0.32 & & 0.91 & \\
\hline Total & 93 & 32.47 & & & 1.00 & \\
\hline AMD Impaired - Intermediate AMD & 1 & 0.75 & 0.75 & 2.57 & 0.03 & 0.019 \\
\hline Residuals & 76 & 22.26 & 0.29 & & 0.97 & \\
\hline Total & 77 & 23.01 & & & 1.00 & \\
\hline
\end{tabular}




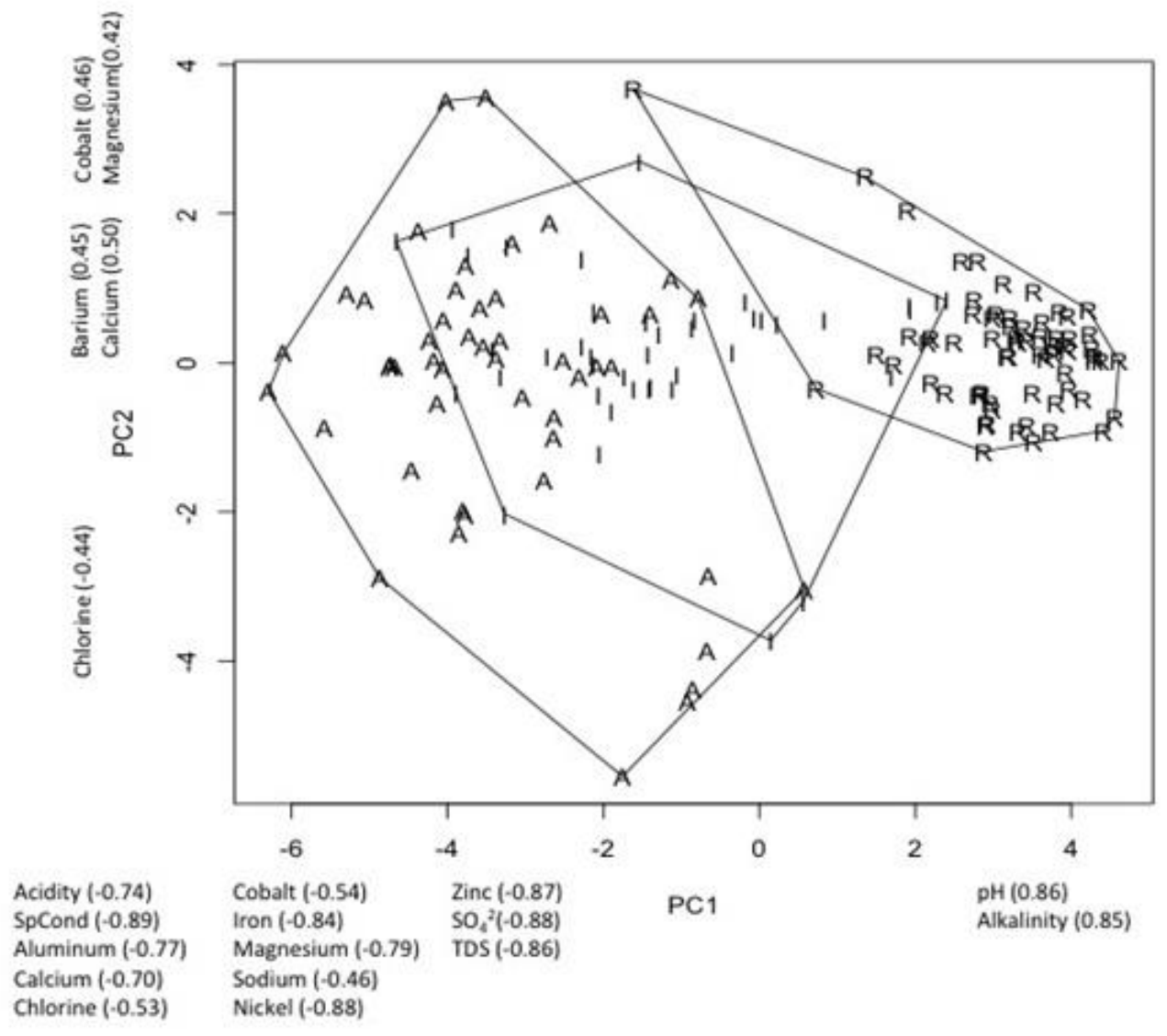

Figure 1. Principal component analysis of all water chemistry observations for all study reaches over the seven year time period. Water chemistry based cluster groupings are overlain and grouped together. Significant parameters (factor loading $\geq|0.4|$ ) driving PC1 and PC2 are displayed along the axes. 


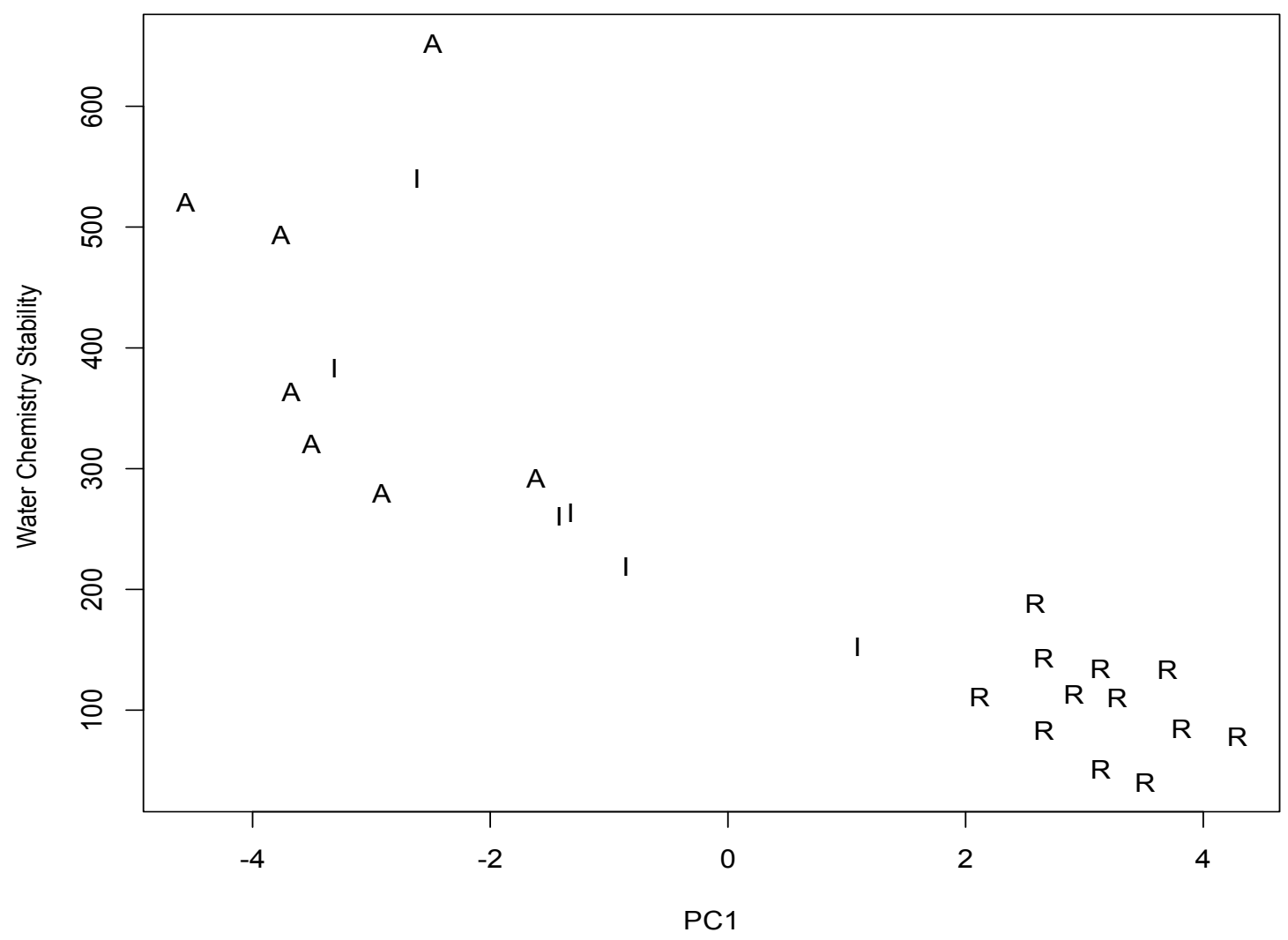

Figure 2. Principal component 1 (PC1) and mean Euclidean distance values (water chemistry stability) for each study reach are graphed against each other. PC1 is interpreted as a gradient of AMD impairment and mean Euclidean distance is interpreted as a gradient of water chemistry stability over the seven-year study. Water chemistry clustered groups are overlain. 


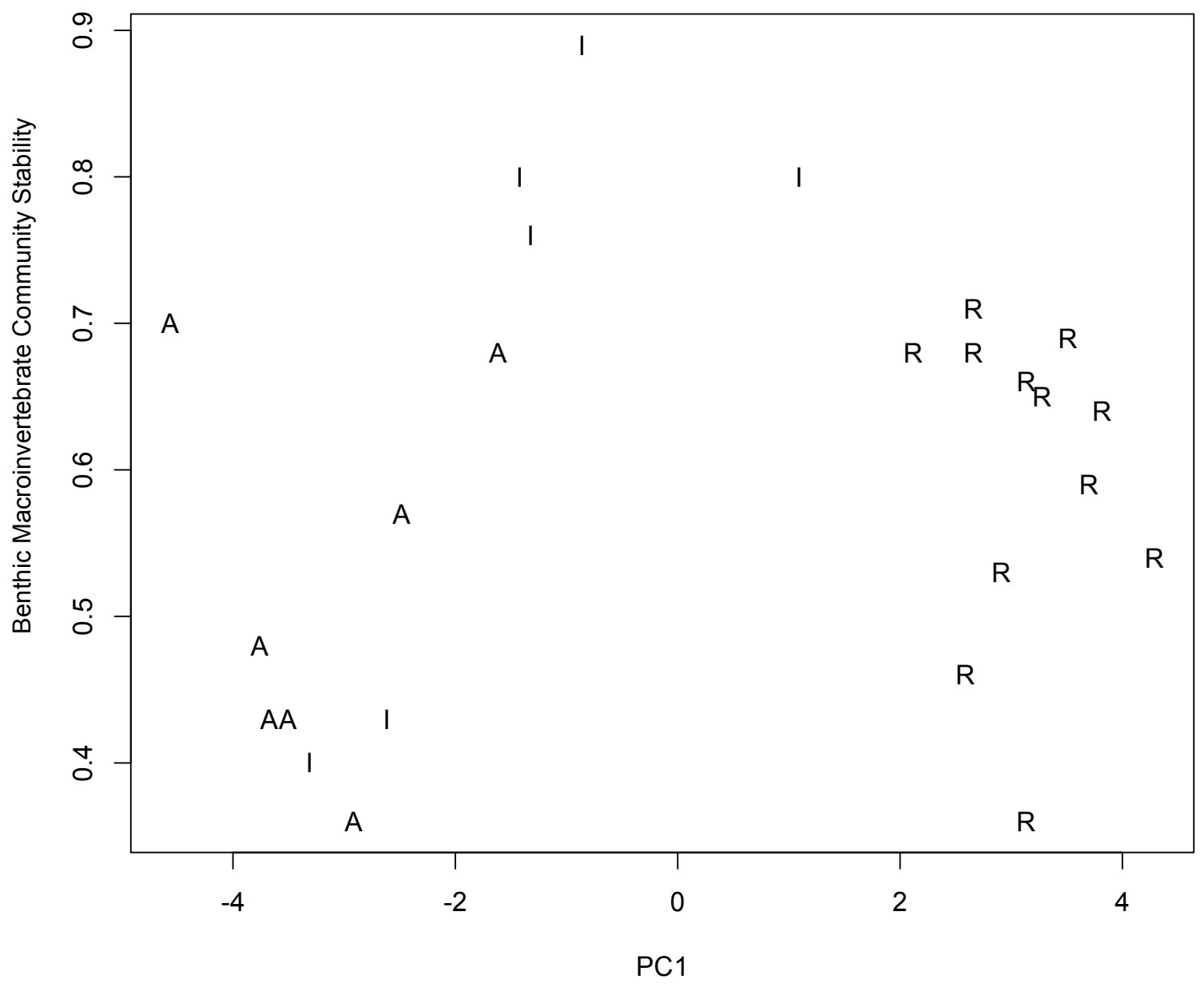

Figure 3. Principal component 1 (PC1) and mean Bray-Curtis distance values (Community Stability) for each study reach are graphed against each other. PC1 is interpreted as a gradient of AMD impairment and mean Bray-Curtis distance values are interpreted as a gradient of benthic macroinvertebrate community stability over the seven-year study. Water chemistry clustered groups are overlain. 


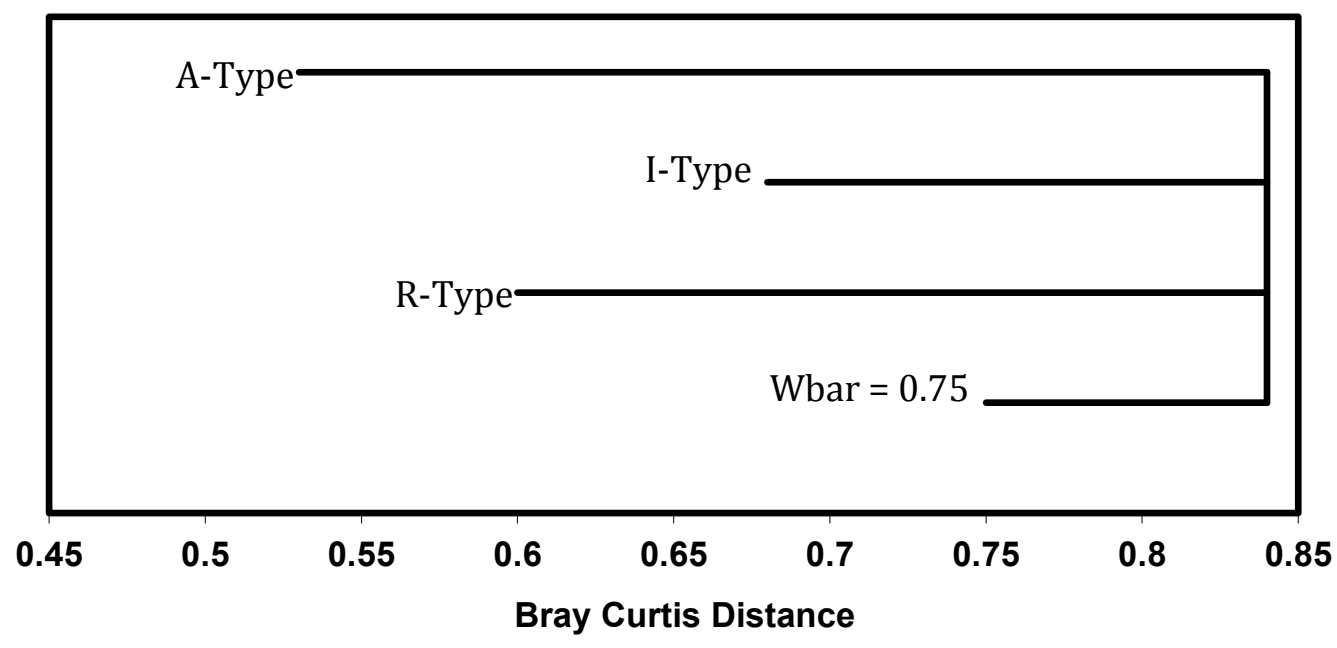

Figure 4. Dissimilarity dendrogram displaying mean Bray- Curtis distance values for benthic Macroinvertebrate assemblages for each water chemistry type in reference to other water chemistry types as well as within (Wbar) and between (Bbar) group dissimilarity values. 


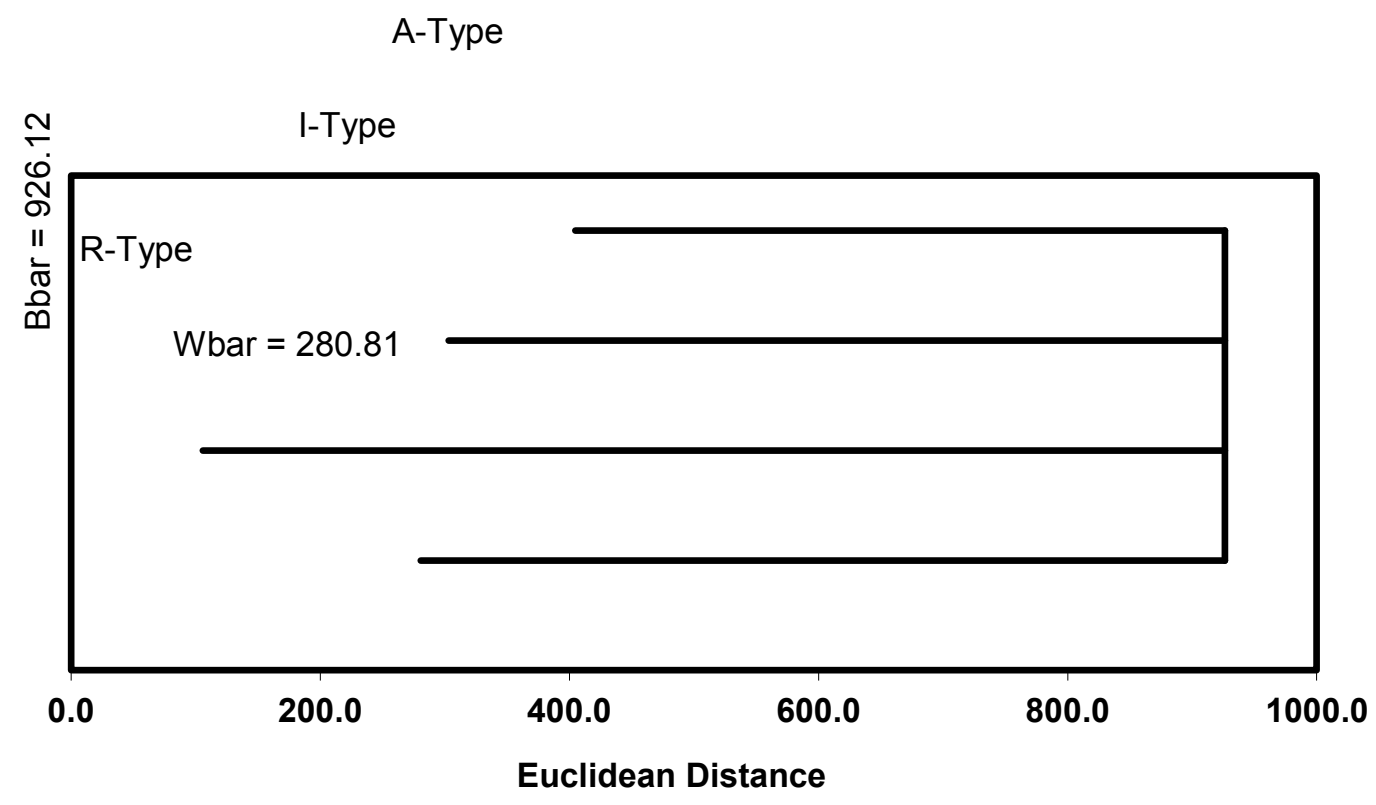

Figure 5. Dissimilarity dendrogram displaying mean Euclidean distance values for water water chemistry parameters for each water chemistry type in reference to other water chemistry types as well as within (Wbar) and between (Bbar) group dissimilarity values. 


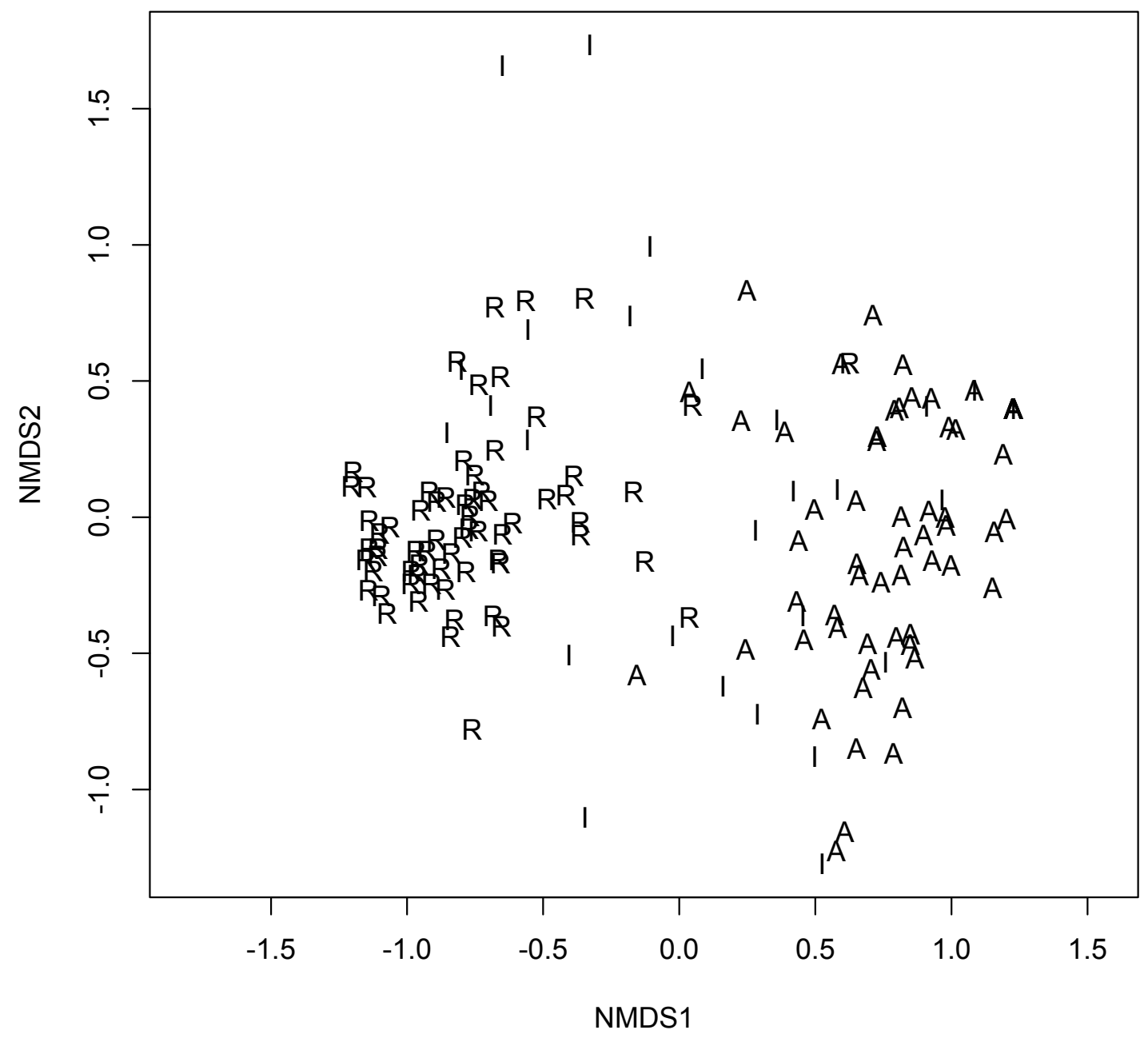

Figure 6. Non-metric multidimensional scaling (NMDS) of all observed benthic macroinvertebrate assemblages over the seven-year study. Water chemistry clustered grouping are overlain. 


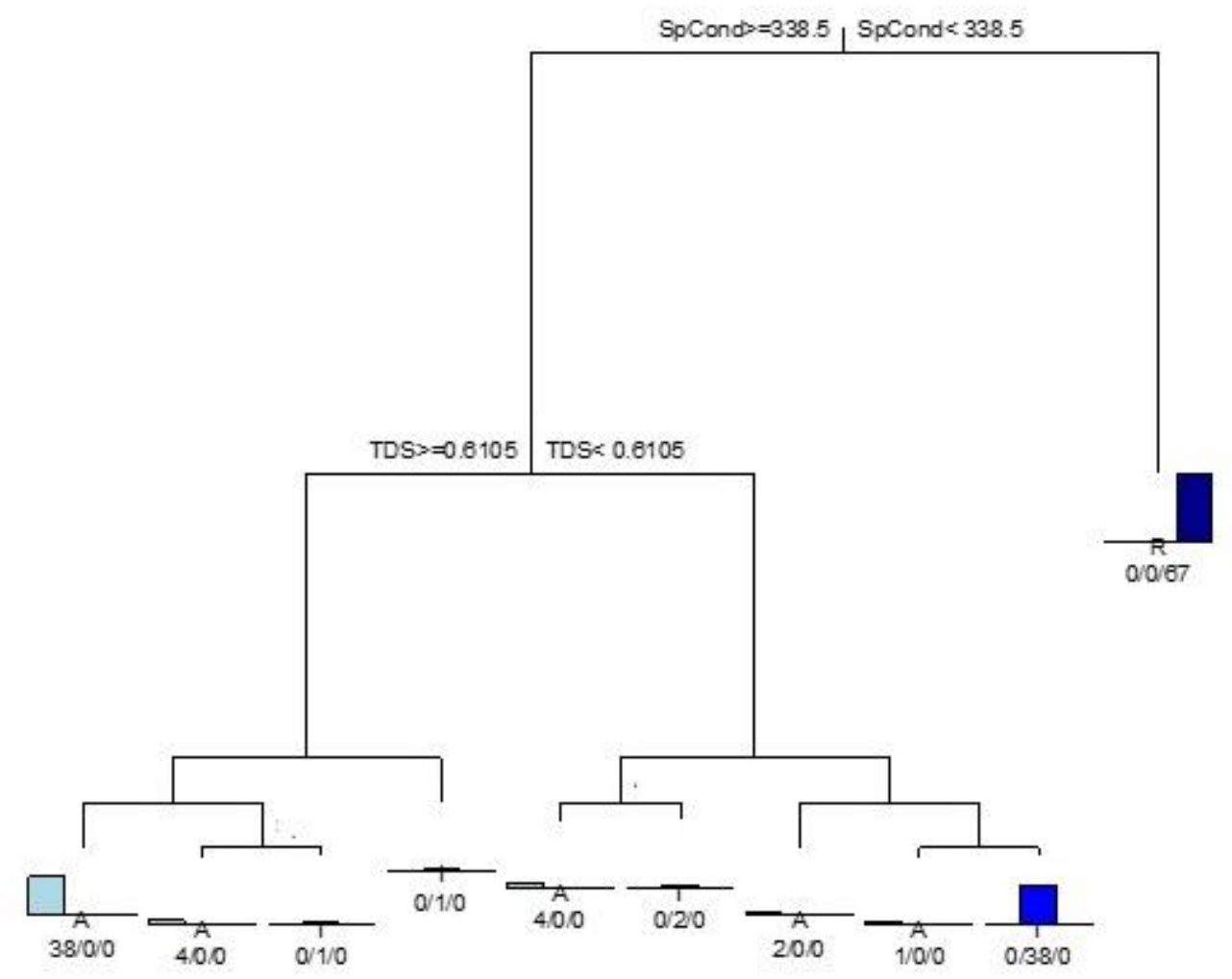

Figure 7. Classification and Regression Tree (CART) analysis of water chemistry clustered groupings. The first number at the end of each terminal branch is the number of A-type observations that end on that branch, the second number is the number of I-type observations that end on that branch, and the third number is the number of R-type observations that end on that branch. The letter at the end of each terminal branch indicates the dominant water chemistry type that comprises that branch. 